\title{
A Common Feature of Pesticides: Oxidative Stress-The Role of Oxidative Stress in Pesticide-Induced Toxicity
}

\author{
Rasheed O. Sule $\mathbb{D D}^{1}{ }^{1}$ Liam Condon, ${ }^{1}$ and Aldrin V. Gomes $\mathbb{D D}^{1,2}$ \\ ${ }^{1}$ Department of Neurobiology, Physiology and Behavior, University of California, Davis, Davis, CA 95616, USA \\ ${ }^{2}$ Department of Physiology and Membrane Biology, University of California, Davis, Davis, CA 95616, USA
}

Correspondence should be addressed to Aldrin V. Gomes; avgomes@ucdavis.edu

Received 28 February 2021; Accepted 17 December 2021; Published 19 January 2022

Academic Editor: Xiaoyuan Zhou

Copyright (c) 2022 Rasheed O. Sule et al. This is an open access article distributed under the Creative Commons Attribution License, which permits unrestricted use, distribution, and reproduction in any medium, provided the original work is properly cited.

\begin{abstract}
Pesticides are important chemicals or biological agents that deter or kill pests. The use of pesticides has continued to increase as it is still considered the most effective method to reduce pests and increase crop growth. However, pesticides have other consequences, including potential toxicity to humans and wildlife. Pesticides have been associated with increased risk of cardiovascular disease, cancer, and birth defects. Labels on pesticides also suggest limiting exposure to these hazardous chemicals. Based on experimental evidence, various types of pesticides all seem to have a common effect, the induction of oxidative stress in different cell types and animal models. Pesticide-induced oxidative stress is caused by both reactive oxygen species (ROS) and reactive nitrogen species (RNS), which are associated with several diseases including cancer, inflammation, and cardiovascular and neurodegenerative diseases. ROS and RNS can activate at least five independent signaling pathways including mitochondrial-induced apoptosis. Limited in vitro studies also suggest that exogenous antioxidants can reduce or prevent the deleterious effects of pesticides.
\end{abstract}

\section{Introduction}

The term pesticide is generally used to identify agrochemicals such as bactericides, fungicides, herbicides, insecticides, or rodenticides [1]. Pesticides are a group of chemicals, and sometimes microorganisms (e.g., viruses), that are used for the eradication of insects, weeds, fungi, and bacteria $[1,2]$. Pesticides can be grouped into different chemical families, such as organochlorines, organophosphates, organofluorines, carbamates, pyrethroids, bipyridyl herbicides, triazine herbicides, triazoles, and chloroacetanilide herbicides [2]. Globally, about 2 million tons of pesticides are being utilized each year [3]. China is the largest pesticide-producing nation, followed by the United States and Argentina [3]. Due to the continuous rise in the worldwide population, there has been an increase in demand for agricultural products such as pesticides [4].

The World Health Organization has estimated that about 3 million workers in developing countries experience severe poisoning from pesticides each year, of which approx- imately 18,000 of them eventually die [5]. The broad use of pesticides for agricultural and nonagricultural purposes (e.g., industrial, commercial, and individual households) around the world indicates how important these compounds are, but the adverse risks involved for the environment, wildlife, and human health are not well investigated [6]. Individuals who apply pesticides in agricultural, occupational, or residential settings are at a high risk of direct exposure. However, the general population can also be exposed to pesticides and their degradation products indirectly at low levels through water, air, dust, and food [7]. Pesticide contamination of surface waters has been well documented worldwide and constitutes a major issue that gives rise to concerns at local, regional, national, and global levels [8]. While these indirect exposure routes involve low levels of pesticide, long-term exposure to these routes could be harmful to human health [7]. At low doses of exposure, pesticides do not seem to produce any permanent harmful effects to adult humans [9]. However, individuals who reside close to fields where pesticides are applied and agricultural workers such as 
mixers, loaders, and applicators, who are in direct contact with pest control agents, exhibit pesticide poisoning [10, 11]. Other epidemiological studies have suggested that high levels of pesticide exposure are associated with increased risk of chronic diseases, including cancers, cardiotoxicity, Parkinson's disease, diabetes mellitus, neurological deficits, birth defects, and reproductive disorders [12, 13]. The increased risk of various diseases may be due to pesticides being absorbed into the body and accumulated in fat, liver, kidneys, and salivary glands [14].

Prometryn, a triazine herbicide, is relatively persistent in waters, soil, and even in air near its production or application sites and was detected at a concentration of $3-6.1 \mu \mathrm{g} / \mathrm{L}$ in different rivers and lakes in Europe [8]. Previous studies have shown that other triazine herbicide was found at levels as high as $21 \mathrm{ppb}$ in groundwater, $42 \mathrm{ppb}$ in surface waters, $102 \mathrm{ppb}$ in river basins in agricultural areas, and up to $224 \mathrm{ppb}$ in Midwestern U.S. streams during the summer of 1996. Triazine concentrations of up to $108 \mu \mathrm{g} / \mathrm{L}$ have been reported in North America rivers [15]. In addition, all triazine herbicides and their degradation products are persistent in the environment, especially in air and water, and these pesticides can damage human cardiac and immune systems and endanger the health of humans, animals, and plants [16].

A large number of hazardous organic chemicals are pesticides, and the Stockholm Convention on Persistent Organic Pollutants states that nine out of the twelve most dangerous and persistent organic chemicals in the environment belong to the organochlorine pesticide group [17]. There have been several calls and campaigns for "less pesticides, safer food" around the world especially in the European Union (EU) where over one million EU citizens from 22 member states supported an initiative to ban a broadspectrum systemic herbicide called glyphosate due to its possibly carcinogenic effects on humans. However, pest resistance, hygiene control, and the unending demand for agriproducts have resulted in an increase in the formulation of new, more potent pesticides [18]. Long-term exposures to pesticides, due to occupational or environmental exposures, are capable of disrupting the physiology of different organs in the body, including those of the nervous, endocrine, immune, reproductive, renal, cardiovascular, and respiratory systems [19]. Pesticides' effects could be physiological or biological, causing changes at the molecular, cellular, or tissue level. Although the underlying molecular mechanisms of how pesticides induce biochemical changes are not well understood, investigation of previous research on pesticides suggest that pesticides all induce oxidative stress. Oxidative stress is an imbalance between the production of ROS and the ability of the defense system to actively detoxify and neutralize the excess ROS [20]. The present review focuses on oxidative stress induced by dominant pesticide groups (e.g., organochlorines, organophosphates, carbamates, and triazines) with emphasis on oxidative stress biomarkers and ROS generation from genetic and biochemical studies. This review also includes 3 figures and 6 supplementary tables summarizing the signaling pathways and pesticide concentration levels involved in pesticide-induced oxidative stress.
1.1. Pesticides and Organ Toxicity. Most pesticides investigated seem to damage many animal organs and tissues (supplemental table 1). Investigation of the damaged tissues suggests a multitarget mechanism, with many different pathways being affected by the pesticides. However, our understanding of the targeting of multiple sites and signaling pathways in cells is limited. While there are very few studies published discussing the toxic effects of pesticides at the systematic level, one of the most widely investigated pesticides, paraquat, is known to cause damage to the kidneys, lungs, heart, gastrointestinal tract, nervous system, and the immune system [21-23]. Some studies have also suggested links between pesticides and cancers. 1,1,1-trichloro-2,2-bis(p-chlorophenyl)ethane (DDT), and its metabolites have been associated with liver, breast, and testicular cancers [24-26]. Due to the lack of specific studies with respect to the many effects of pesticide on various tissues, it is difficult to determine if specific tissue injuries caused by pesticides are unique. The current scientific studies suggest that irrespective of the target tissue, toxicity caused by pesticides is associated with oxidative stress. Some common characteristics of oxidative stress include increased protein oxidation (carbonylation), lipid peroxidation, nucleic acid oxidation (8-OHdG), and changes in the levels of antioxidants such as glutathione and the activities of antioxidant enzymes [27].

1.2. Reactive Oxygen Species (ROS) and Pesticides. Reactive oxygen species (ROS) is a term commonly mentioned in biology and medicine. This term can be defined as oxygencontaining reactive species. ROS is a collective term that includes superoxide $\left(\mathrm{O}_{2}{ }^{--}\right)$, hydrogen peroxide $\left(\mathrm{H}_{2} \mathrm{O}_{2}\right)$, hydroxyl radical $(\bullet \mathrm{OH})$, singlet oxygen $\left({ }^{1} \mathrm{O}_{2}\right)$, peroxyl radical $\left(\mathrm{ROO}^{\circ}\right)$, alkoxyl radical $\left(\mathrm{RO}^{\circ}\right)$, lipid hydroperoxide $(\mathrm{LOOH})$, peroxynitrite $\left(\mathrm{ONOO}^{-}\right)$, hypochlorous acid $(\mathrm{HOCl})$, and ozone $\left(\mathrm{O}_{3}\right)$ [28]. ROS are byproducts of normal cellular metabolic processes that are required to generate energy for life processes [29]. They are produced in the reactions catalyzed by the electron transport chain, $\mathrm{NAD}(\mathrm{P}) \mathrm{H}$ oxidase, and some other specialized oxidases and are an inevitable by-product of many redox reactions. However, the amount of ROS produced in a cell under normal conditions is relatively small. As such, ROS are able to serve as signaling molecules to regulate biological and physiological processes [30]. Recent evidence also suggests that ROS function as important physiological regulators of intracellular signaling pathways [31].

During normoxia, there is a steady-state balance between ROS and cellular antioxidant systems. However, overproduction of ROS in intra- or extracellular spaces can occur due to exposure to xenobiotics and other environmental factors which can result in the onset of cellular dysfunction and apoptosis [32]. ROS are capable of causing damage to biomolecules leading to cell and tissue injury [32]. Antioxidants act by reacting with ROS and RNS to neutralize or terminate the chain reaction before key molecules in the body are affected [20]. The major enzymatic antioxidant defense mechanisms consist of different forms of superoxide dismutases (SODs), catalase (CAT), and the glutathione 
peroxidases (GPXs). SODs are thought to provide a first line of defense against oxygen radicals, specifically the superoxide anion $\left(\mathrm{O}_{2}{ }^{--}\right)$, which is the major ROS produced by mitochondrial respiration and various metabolic reactions. The SODs remove the potentially dangerous superoxide anions from biological systems by converting them to $\mathrm{H}_{2} \mathrm{O}_{2}$, while $\mathrm{CAT}$ found in peroxisomes catalyzes the conversion of two molecules of $\mathrm{H}_{2} \mathrm{O}_{2}$ to $\mathrm{O}_{2}$ and two molecules of $\mathrm{H}_{2} \mathrm{O}$ [33]. The most abundant intracellular antioxidant, glutathione (GSH), is involved in the protection of cells against oxidative stress [34]. However, exposure to pesticides seem to be associated with significantly increased ROS and oxidative stress induction, beyond what the intrinsic cellular antioxidant system can reduce to normal physiological levels (Figure 1, Tables 1 and 2, and Supplemental Tables 1-6).

1.3. Reactive Nitrogen Species (RNS) and Pesticides. Reactive nitrogen species (RNS) belong to a family of nitrogen moieties that are closely associated with oxygen [35]. The interaction between exogenously and endogenously produced nitric oxide (NO) with oxidants such as hydrogen peroxide $\left(\mathrm{H}_{2} \mathrm{O}_{2}\right)$, superoxide anion $\left(\mathrm{O}_{2}^{-}\right)$, and reductants such as lithium aluminum hydride $\left(\mathrm{LiAlH}_{4}\right)$ typically gives rise to RNS [36]. RNS can be classified as nitric oxide-derived compounds, including nitroxyl anion $\left(\mathrm{NO}^{-}\right)$(derived from the reduction of $\cdot \mathrm{NO})$, nitrosonium cation $\left(\mathrm{NO}^{+}\right)$, higher oxides of nitrogen $\left(\mathrm{NO}_{2}, \mathrm{~N}_{2} \mathrm{O}_{4}\right.$, etc.), S-nitrosothiols (RSNO), and dinitrosyl iron complexes [37]. NO is a ubiquitous intracellular messenger that regulates physiological functions including neural and cardiovascular activities. However, under pathologic conditions, NO can become deleterious because of its high reactivity with other free radicals, such as $\mathrm{O}_{2}^{--}$[37]. $\mathrm{NO}^{+}$is created during the removal of one electron from $\cdot \mathrm{NO} . \mathrm{NO}^{+}$can react with nucleophilic centers, producing nitroso compounds. Nitrosyl halides are liberated when $\bullet N O$ reacts with fluorine, chlorine, or bromine [35].

Although RNS play vital roles in numerous biological processes such as the physiological regulation of smooth muscle cells, cardiomyocytes, platelets, and nervous and juxtaglomerular cells, they are harmful to the cells if produced and present in excessive amounts [37, 38]. RNS has pleiotropic properties on cellular targets, including effects even after both posttranslational modifications and interaction of targets with ROS [37]. These effects are likely due to increased levels of RNS reacting with different biomolecules such as lipids, DNA and RNA bases, metal cofactors, and proteins. The interplay of RNS with various cellular components leads to cellular abnormalities, cell injury, and cell death via the induction of nitrosative stress. Nitrosative stress can occur when NO or related species are induced during exposure to certain xenobiotic factors such as pesticides, leading to the nitrosylation of critical protein cysteine thiols (S-nitrosylation) and metallocofactors of proteins. Nitrosylation is the addition of a nitroso (-NO) group to an active metal ion center or thiol of a protein [28].

A comprehensive study of epidemiologic and toxicologic literature implicates oxidative stress, ROS, and RNS as culprits in the damage to lipids, DNA, and proteins induced by pesticides $[39,40]$. Figure 2 shows a schematic diagram summarizing some of the major effects of pesticides that lead to RNS and subsequent oxidative stress. Diquat ( $1,1^{\prime}$-ethylene-2,2' -bipyridinium ion) (DQ), a nonselective quick-acting herbicide, is used as a contact and preharvest desiccant to control terrestrial and aquatic vegetation. $\mathrm{Fu}$ et al. found that DQ-induced oxidative stress was caused by ROS. However, this oxidative stress was also partly caused by increased RNS generation by peroxynitrite (ONOO-) generation in hepatocytes [41]. Wang et al. found that permethrin (PER) may exhibit toxic effects on animals by $\mathrm{NO}$ generation [40]. A study by Jin et al. revealed that PER significantly increased the mRNA expression of induced nitric oxide synthase (iNOS) after exposure of zebrafish to PER [42]. Another study found increased NO levels in the plasma of rats treated with a low dose of PER (34.05 mg/kg b.w.) [43]. When Afolabi et al. exposed the insecticide cypermethrin (CYP) to rats, they found a significant increase in the plasma concentration of 8-nitroguanine (8-NO2Gua). CYP treatment resulted in over $200 \%$ increase in the level of 8 -NO2Gua when compared with the control [44]. The elevated plasma 8-NO2Gua level in CYP-exposed rats suggests that CYP plays a role in nitrosative stress and possesses genotoxic and mutagenic potential [44]. The presence of NO and NO metabolites in blood could be a possible source for RNS that causes damage to several organs and tissues.

It has been hypothesized that the damage to cellular macromolecules (nucleic acids, proteins, and lipids) by increased ROS and RNS caused by long-term pesticide exposure leads to cell death and overall tissue damage [45]. It is worth highlighting that RNS and ROS usually work together when they are present in a cell. Under conditions such as pesticide toxicity, $\mathrm{NO}$ is generated via the expression of iNOS which then reacts with the superoxide radical to form highly reactive peroxynitrite (ONOO-). ONOO- then causes cellular damage by interacting with biomolecules. One such reaction is that of ONOO- with guanine which results in nitrative and oxidative DNA lesions, such as 8NO2Gua and 8-oxodeoxyguanosine (8-OHdG), respectively [46]. Previous findings have suggested that 8 -NO2Gua formation occurred to a greater extent in cancerous tissues than noncancerous tissues [47]. This supports previous studies that have linked pesticide exposure with cancer [48, 49]. Although RNS is not as well studied as ROS, the experimental data for RNS suggests that RNS can cause tissue damage and should be investigated to a greater extent, especially to determine if all pesticides can cause RNS.

1.4. Pesticides and Oxidative Stress Generation. The low molecular weight and high liposolubility of pesticides increases their absorption and toxicity level [50]. Organophosphate (OP) and carbamate pesticides produce their effects through the inhibition of carboxyl ester hydrolases, in particular acetylcholinesterase, which leads to acetylcholine accumulation [50]. Moreover, some studies have suggested that acetylcholinesterase enzyme inhibition is associated with the increase in ROS in agricultural workers exposed to OP pesticides and bipyridyl herbicides (e.g., 


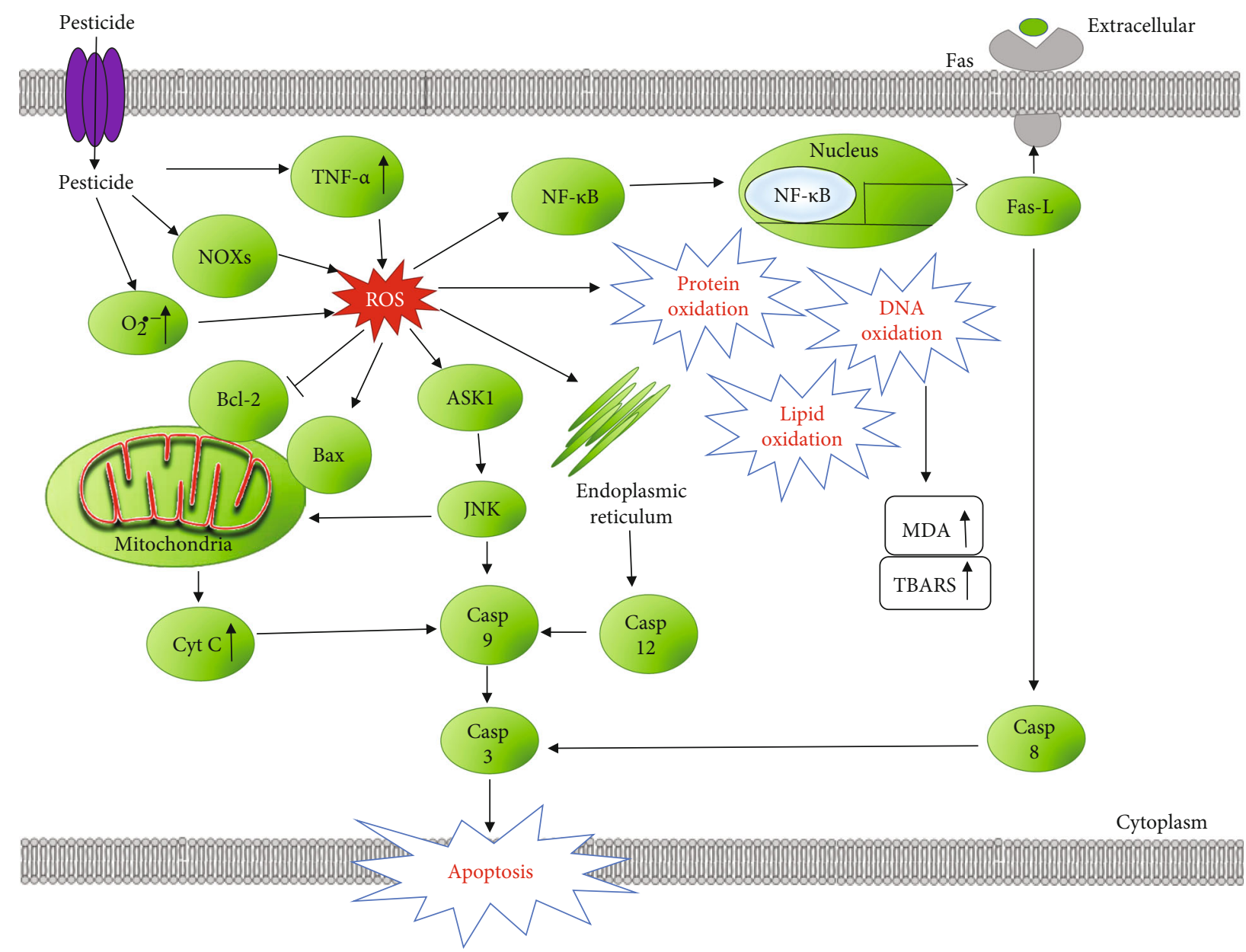

FIGURE 1: Schematic representation of signaling pathways involved in pesticide-induced reactive oxygen species (ROS) and oxidative stress. Pesticides increase NADPH oxidases (NOXs) and superoxide $\left(\mathrm{O}_{2}{ }^{--}\right)$levels, which leads to an increase in ROS signaling in the cell. Increased ROS may induce lipid, protein, and DNA oxidation, leading to various toxicities. These stressors lead to activation of TNFR1/TNF- $\alpha$, MAPKs, NF- $\kappa \mathrm{B}$, and the mitochondrial apoptosis pathways. Continued stress leads to cell apoptosis and inflammation.

paraquat (PQ)). Oxidative stress can be induced by an increase in lipid peroxidation and a decrease in antioxidant capacity $[51,52]$. Herein, some of the major classes of pesticides and the roles they play in oxidative stress generation are discussed.

1.5. Organophosphorus Pesticides. Quinalphos (QP), an organophosphorus (OP) pesticide, is used to control pests on various crops such as vegetables, fruits, cereals, rice, wheat, maize, coconut, tobacco, coffee, tea, sugarcane, jute, and cotton. Dwivedi et al. found that QP enhanced all the levels of adult rat hepatic antioxidant components, namely, SOD, CAT, GPx, and GSH-reductase, which take care of ROS generated in vivo. They also found a significant induction of hepatic P450 [53]. A list of OP pesticides and their effects on oxidative stress in different tissues is summarized in supplemental table 4.

Chlorpyrifos (CPF), a crystalline-kind OP insecticide, acaricide, and miticide, is mainly used to control foliage and soil-borne pests on a variety of food and feed crops [54]. Studies have implicated CPF and its derivatives in carcinogenesis [55]. Jung et al. demonstrated in their study that methyl parathion and CPF induced the production of inflammatory cytokines, such as tumor necrosis factor- $\alpha$ (TNF- $\alpha$ ), interleukin-6 (IL-6), and interleukin-1 $\beta$ (IL-1 $\beta$ ) in human hepatocellular carcinoma (HepG2) cells [56]. With regard to examining the deleterious effects of pesticides, Binukumar et al. found that rats chronically exposed to dichlorvos, another OP insecticide, displayed microglial activation with the induction of NADPH oxidase and proinflammatory cytokines (TNF- $\alpha$, IL-1 $\beta$, and IL-6) [57]. In vitro studies on human keratinocytes revealed the insecticide monocrotophos significantly increased NO, lactate dehydrogenase $(\mathrm{LDH})$, malondialdehyde (MDA), nuclear changes, proinflammatory cytokines (TNF- $\alpha$, IL-6, and IL-8), and ROS generation [58]. Several other studies conducted in rats exposed to OP pesticides have displayed similarly increased levels of proinflammatory cytokines [59-61].

Pesticides such as DQ do not bind covalently to macromolecules (i.e., lipids, proteins, and nucleic acids). However, they cause oxidative stress by generating ROS intracellularly via the reduction-oxidation (redox) cycling processes. DQ can easily cross the cell membrane and enter the cell through the dopamine transporter (DAT). While in the cell, DQ is 
TABLE 1: The effects of the most commonly used pesticides in the agricultural market sector in 2012 on oxidative stress in different tissues.

\begin{tabular}{|c|c|c|c|c|c|c|c|c|c|c|c|c|c|}
\hline Pesticide & Cell type/model system & ROS & SOD & GSH & CAT & GST & GPx & $\mathrm{DD}$ & LP & $\mathrm{PC}$ & $\mathrm{AOC}$ & MMP & Reference \\
\hline \multirow{6}{*}{ Glyphosate } & $\begin{array}{l}\text { Human skin keratinocyte } \mathrm{HaCaT} \\
\text { cells }\end{array}$ & $\uparrow$ & $\downarrow$ & & & & & & & & & & {$[178]$} \\
\hline & $\begin{array}{l}\text { Human liver carcinoma (HepG2) } \\
\text { cells }\end{array}$ & & & & & & $\downarrow$ & $\uparrow$ & & & $\downarrow$ & & {$[179]$} \\
\hline & Rat heart $\mathrm{H} 9 \mathrm{c} 2$ cells & & & & & & & & & & & $\downarrow$ & {$[180]$} \\
\hline & Adult albino male rats (liver) & & & $\downarrow$ & & & & & $\uparrow$ & & & & {$[181]$} \\
\hline & Caenorhabditis elegans & & & & & $\uparrow$ & & & & & & $\downarrow$ & {$[182]$} \\
\hline & Chlorella kessleri & & $\uparrow$ & $\uparrow$ & $\uparrow$ & & & & $\uparrow$ & & & & {$[183]$} \\
\hline \multirow{9}{*}{ Atrazine (ATR) } & Male and female Balb/c mice & $\uparrow$ & & $\downarrow$ & & & & & & & & & {$[184]$} \\
\hline & Male mice (liver and kidney) & & $\downarrow$ & & $\downarrow$ & $\downarrow$ & & & $\uparrow$ & & $\downarrow$ & & {$[185]$} \\
\hline & Male Wistar rats (erythrocytes) & & $\uparrow$ & $\downarrow$ & $\uparrow$ & $\uparrow$ & $\uparrow$ & & & & & & {$[155]$} \\
\hline & $\begin{array}{c}\text { Adult male Wistar rats (testes and } \\
\text { epididymis) }\end{array}$ & & $\downarrow$ & & $\downarrow$ & $\downarrow$ & & & $\uparrow$ & & & & [186] \\
\hline & Male Wistar rats & & $\downarrow$ & $\downarrow$ & $\downarrow$ & & & & $\uparrow$ & & & & {$[187]$} \\
\hline & Adult male albino rats & & $\downarrow$ & $\downarrow$ & $\downarrow$ & & $\downarrow$ & & $\uparrow$ & & & & {$[188]$} \\
\hline & Female Wistar rats & & & & $\downarrow$ & & $\downarrow$ & & $\uparrow$ & & & & [189] \\
\hline & Murine microglial cells (BV-2) & $\uparrow$ & & & & & & & & & & & {$[190]$} \\
\hline & Albino rats & & & $\downarrow$ & $\uparrow$ & & $\uparrow$ & $\uparrow$ & $\uparrow$ & & & & {$[191]$} \\
\hline \multirow{3}{*}{ Metolachlor-S } & $\begin{array}{c}\text { Scenedesmus obliquus (green } \\
\text { algae) }\end{array}$ & $\uparrow$ & $\uparrow$ & & $\uparrow$ & & & & & & & & {$[192]$} \\
\hline & Parachlorella kessleri (microalga) & $\uparrow$ & & & $\uparrow$ & & & & $\uparrow$ & & & & [193] \\
\hline & Wheat (Triticum aestivum L.) & $\uparrow$ & $\uparrow$ & & $\downarrow$ & & & & $\uparrow$ & & & & {$[194]$} \\
\hline \multirow{14}{*}{$\begin{array}{l}2,4- \\
\text { Dichlorophenoxyacetic } \\
\text { acid }(2,4-D)\end{array}$} & $\begin{array}{l}\text { Umbelopsis isabelline (Fungus) } \\
\text { pea (Pisum sativum L.) }\end{array}$ & $\uparrow$ & $\uparrow$ & & & & $\uparrow$ & & $\uparrow$ & & & & $\begin{array}{l}{[195} \\
196]\end{array}$ \\
\hline & Pea (Pisum sativum L.) & & $\uparrow$ & & $\uparrow$ & & $\uparrow$ & & $\uparrow$ & & & & {$[196]$} \\
\hline & Nongreen potato tuber callus & & $\uparrow$ & & $\uparrow$ & $\uparrow$ & & & & & & & [197] \\
\hline & Male 7-week-old Kunming mice & & $\downarrow$ & & $\downarrow$ & & & & $\uparrow$ & & & & [198] \\
\hline & Goldfish gills, Carassius auratus & & $\uparrow$ & & $\uparrow$ & & $\uparrow$ & & $\uparrow$ & $\uparrow$ & & & [199] \\
\hline & Cnesterodon decemmaculatus & & & $\uparrow$ & $\uparrow$ & $\uparrow$ & & $\uparrow$ & & & & & {$[200]$} \\
\hline & $\begin{array}{c}\text { Acanthospermum hispidum D.C., } \\
\text { Asteraceae weed }\end{array}$ & & & & & & & & $\uparrow$ & & & & {$[201]$} \\
\hline & Rat cerebellar granule cells & $\uparrow$ & & $\downarrow$ & $\downarrow$ & & $\uparrow$ & & & & & & {$[202]$} \\
\hline & Wistar rats & & $\downarrow$ & $\downarrow$ & $\downarrow$ & & $\downarrow$ & & $\uparrow$ & & & & [203] \\
\hline & Wistar Albino rats & & $\downarrow$ & $\downarrow$ & $\downarrow$ & $\downarrow$ & $\downarrow$ & & $\uparrow$ & $\uparrow$ & & & [204] \\
\hline & Male Wistar rats (liver) & & $\uparrow \downarrow$ & & $\downarrow$ & & $\downarrow$ & & $\uparrow$ & & & & {$[205]$} \\
\hline & $\begin{array}{l}\text { Male Wistar albino rats-plasma, } \\
\text { liver, kidney, erythrocytes }\end{array}$ & & $\downarrow$ & & $\downarrow$ & & $\downarrow$ & & $\uparrow$ & & & & [206] \\
\hline & Male Wistar rats (liver) & & & & $\downarrow$ & & & & & & & & {$[207]$} \\
\hline & $\begin{array}{c}\text { Female B6C3F1 mice peritoneal } \\
\text { macrophages }\end{array}$ & & & $\downarrow$ & & & & & & & & & {$[208]$} \\
\hline Metam & Soil bacteria & & & & $\uparrow \downarrow$ & & & & $\uparrow$ & & & & [209] \\
\hline \multirow{7}{*}{ Acetochlor } & Bufo raddei tadpole liver & & & & & & & $\uparrow$ & $\uparrow$ & & $\downarrow$ & & {$[210]$} \\
\hline & Female zebrafish & $\uparrow$ & $\uparrow$ & & $\uparrow$ & & $\uparrow$ & & & & & & {$[211]$} \\
\hline & Male C57BL/6 mice (testis) & & $\downarrow$ & $\downarrow$ & & & & & $\uparrow$ & & & & {$[212]$} \\
\hline & GC-1 spermatogonia cell & & $\downarrow$ & $\downarrow$ & & & & & $\uparrow$ & & & & {$[212]$} \\
\hline & $\begin{array}{l}\text { Human liver carcinoma cells } \\
\text { (HepG2) }\end{array}$ & $\uparrow$ & $\downarrow$ & & & & $\downarrow$ & & & & & $\downarrow$ & [213] \\
\hline & Zebrafish & & & & $\uparrow$ & & $\uparrow$ & & & & & & {$[214]$} \\
\hline & $\begin{array}{l}\text { Primary human corneal epithelial } \\
\text { (HCE) cells }\end{array}$ & & & & & & & $\uparrow$ & $\uparrow$ & $\uparrow$ & & & {$[215]$} \\
\hline
\end{tabular}


TABle 1: Continued.

\begin{tabular}{|c|c|c|c|c|c|c|c|c|c|c|c|c|c|}
\hline Pesticide & Cell type/model system & ROS & SOD & GSH & CAT & GST & GPx & DD & LP & $\mathrm{PC}$ & $\mathrm{AOC}$ & MMP & Reference \\
\hline \multirow{3}{*}{ Chloropicrin } & $\begin{array}{l}\text { Human retinal pigment epithelial } \\
\text { cells (ARPE-19) }\end{array}$ & $\uparrow$ & & & & & & & & & & & {$[216]$} \\
\hline & $\begin{array}{l}\text { Human lung epithelial cells } \\
\text { (A549) }\end{array}$ & $\uparrow$ & & & & & & & & & & & {$[217]$} \\
\hline & $\begin{array}{c}\text { Gill tissues of Pacific oyster } \\
\text { (Crassostrea gigas), blue mussels } \\
\text { (Mytilus edulis) }\end{array}$ & & $\uparrow$ & $\uparrow$ & $\uparrow$ & & $\uparrow$ & & $\uparrow$ & & & & {$[218]$} \\
\hline \multirow{7}{*}{ Chlorothalonil } & Polychaete Laeonereis acuta & & & & & & & & $\uparrow$ & & $\downarrow$ & & {$[219]$} \\
\hline & Fish Danio rerio (gills) & $\uparrow$ & & & & $\uparrow$ & & & & & $\uparrow$ & & {$[220]$} \\
\hline & Fish Danio rerio (liver) & & $\uparrow$ & & & & & & $\uparrow$ & & & & {$[220]$} \\
\hline & Isolated rat hepatocytes & & & $\downarrow$ & & & & & $\uparrow$ & & & & {$[221]$} \\
\hline & Botryllus schlosseri hemocytes & & & $\downarrow$ & & & & & & & & & {$[222]$} \\
\hline & Male Wistar rats (liver) & & & & & & & $\uparrow$ & & & & & [223] \\
\hline & $\begin{array}{c}\text { Fresh water fish, Channa } \\
\text { punctatus }\end{array}$ & & $\downarrow$ & $\downarrow$ & $\downarrow$ & & & & $\uparrow$ & & & & {$[224]$} \\
\hline \multirow{8}{*}{ Pendimethalin } & $\begin{array}{l}\text { Male Wistar rats (liver and } \\
\text { kidney) }\end{array}$ & & $\downarrow$ & $\downarrow$ & $\downarrow$ & $\downarrow$ & & $\uparrow$ & $\uparrow$ & $\uparrow$ & & & {$[225]$} \\
\hline & Human lymphocytes & $\uparrow$ & & & & & & $\uparrow$ & & & & & {$[226]$} \\
\hline & Rat bone marrow cells & $\uparrow$ & & $\downarrow$ & $\downarrow$ & & & $\uparrow$ & $\uparrow$ & & & & [226] \\
\hline & Clarias batrachus (liver) & & $\uparrow$ & & $\uparrow$ & & & & $\uparrow$ & & & & {$[227]$} \\
\hline & Fish Channa punctatus (brain) & & $\downarrow$ & $\downarrow$ & $\downarrow$ & $\downarrow$ & & & $\uparrow$ & $\uparrow$ & & & {$[228]$} \\
\hline & $\begin{array}{c}\text { Fish Channa punctatus (gills, } \\
\text { liver, kidney) }\end{array}$ & & & $\downarrow$ & $\downarrow$ & $\downarrow$ & $\downarrow$ & & $\uparrow$ & $\uparrow$ & & & {$[229]$} \\
\hline & $\begin{array}{l}\text { Chinese hamster lung fibroblast } \\
\text { (V79) cells }\end{array}$ & $\uparrow$ & & & & & & $\uparrow$ & & & & & {$[230]$} \\
\hline & Male mice (spleen and thymus) & & $\leftrightarrow$ & $\downarrow$ & $\downarrow$ & & $\downarrow$ & & $\uparrow$ & & & & {$[145]$} \\
\hline \multirow{4}{*}{ Ethephon } & $\begin{array}{l}\text { 3T3 murine embryonic fibroblast } \\
\text { (MEF) cells }\end{array}$ & $\uparrow$ & & & & & & $\uparrow$ & $\uparrow$ & & & & [231] \\
\hline & Spinach (Spinacia oleracea L.) & & & & $\uparrow$ & & & & & & & & {$[232]$} \\
\hline & Ipomoea cairica (Linn.) sweet & $\uparrow$ & & & & & & & & & & & {$[233]$} \\
\hline & $\begin{array}{c}\text { Carassius auratus goldfish blood } \\
\text { and gills }\end{array}$ & & $\uparrow$ & & $\uparrow$ & $\uparrow$ & & & $\uparrow$ & $\uparrow$ & & & {$[234]$} \\
\hline \multirow{11}{*}{ Mancozeb } & $\begin{array}{c}\text { Carassius auratus Goldfish-liver } \\
\text { and kidney }\end{array}$ & & $\uparrow$ & & $\uparrow$ & & $\uparrow$ & & $\uparrow$ & $\uparrow$ & & & [235] \\
\hline & Carassius auratus Goldfish-brain & & & & & & & & $\uparrow$ & $\uparrow$ & & & {$[235]$} \\
\hline & Cassia angustifolia & & $\uparrow$ & $\uparrow$ & $\uparrow$ & & & & $\uparrow$ & & & & {$[236]$} \\
\hline & Caenorhabditis elegans & $\uparrow$ & & & & $\uparrow$ & & & & & & $\downarrow$ & [237] \\
\hline & Caenorhabditis elegans & $\uparrow$ & & & & $\uparrow$ & & & & & & $\downarrow$ & [238] \\
\hline & Drosophila melanogaster & $\uparrow$ & $\downarrow$ & $\downarrow$ & $\uparrow$ & $\uparrow$ & & & $\uparrow$ & & & & [239] \\
\hline & $\begin{array}{l}\text { Rat-1 fibroblasts, peripheral blood } \\
\text { mononucleated cells (PBMC) }\end{array}$ & $\uparrow$ & & & & & & $\uparrow$ & & & & & {$[240]$} \\
\hline & Male NMRI mice & & $\downarrow$ & $\downarrow$ & $\downarrow$ & & $\downarrow$ & & $\uparrow$ & $\uparrow$ & $\downarrow$ & & {$[241]$} \\
\hline & Rat thymocytes & $\uparrow$ & & & & & & & & & & $\downarrow$ & {$[242]$} \\
\hline & $\begin{array}{l}\text { Human gastric adenocarcinoma } \\
\qquad(A G S) \text { cells }\end{array}$ & $\uparrow$ & & & & & & & & & & $\downarrow$ & {$[243]$} \\
\hline & $\begin{array}{c}\text { Immortalized murine } \\
\text { mesencephalic dopaminergic } \\
(\mathrm{N} 27) \text { cells }\end{array}$ & $\uparrow$ & & $\downarrow$ & & & & $\uparrow$ & & & & $\downarrow$ & {$[80]$} \\
\hline
\end{tabular}


TABle 1: Continued.

\begin{tabular}{|c|c|c|c|c|c|c|c|c|c|c|c|c|}
\hline Pesticide & Cell type/model system & ROS & SOD & GSH & $\mathrm{CAT}$ & GST & GPx & $\mathrm{DD}$ & $\mathrm{LP}$ & PC AOC & MMP & Reference \\
\hline \multirow{11}{*}{ Chlorpyrifos } & $\begin{array}{l}\text { Lund human mesencephalic } \\
\text { (LUHMES) cells }\end{array}$ & $\uparrow$ & & & & & & $\uparrow$ & & & $\downarrow$ & {$[80]$} \\
\hline & $\begin{array}{l}\text { Human neuroblastoma } \mathrm{SH}-\mathrm{SY} 5 \mathrm{Y} \\
\text { cells }\end{array}$ & $\uparrow$ & & & & & & & & & & {$[244]$} \\
\hline & $\begin{array}{l}\text { Rat adrenal pheochromocytoma } \\
\text { (PC12) cells }\end{array}$ & $\uparrow$ & & & & & & & $\uparrow$ & & & {$[245]$} \\
\hline & Rat erythrocytes & & $\downarrow$ & & $\downarrow$ & $\downarrow$ & & & $\uparrow$ & & & {$[156]$} \\
\hline & Male Wistar rats & & $\downarrow$ & & $\downarrow$ & & $\uparrow$ & & $\uparrow$ & & & {$[63]$} \\
\hline & $\begin{array}{l}\text { Male Wistar rats (aorta, liver, } \\
\text { plasma, and kidney) }\end{array}$ & & $\uparrow$ & & & & & & $\uparrow$ & & & {$[246]$} \\
\hline & Male Swiss albino adult rats & & $\downarrow$ & $\downarrow$ & $\downarrow$ & & $\downarrow$ & & $\uparrow$ & & & [247] \\
\hline & Adult male Wistar rats & $\uparrow$ & & & & & & & & & & {$[248]$} \\
\hline & Male Wistar rats & & $\uparrow$ & & $\uparrow$ & $\downarrow$ & $\downarrow$ & & $\uparrow$ & & & [249] \\
\hline & Male Kunming mice & $\uparrow$ & $\downarrow$ & $\downarrow$ & $\downarrow$ & & $\downarrow$ & & $\uparrow$ & & & {$[250]$} \\
\hline & Male Wistar rats (liver) & & & & & & & & & & $\downarrow$ & [251] \\
\hline \multirow{3}{*}{ Metolachlor } & Soil bacteria & & & & $\downarrow \uparrow$ & & & & $\uparrow$ & & & [209] \\
\hline & $\begin{array}{c}\text { Lettuce, bean, and pea seeds and } \\
\text { leaves }\end{array}$ & & $\downarrow$ & & $\downarrow$ & & $\downarrow$ & & & & & {$[252]$} \\
\hline & 8-week-old male rats & & $\downarrow$ & $\downarrow$ & & $\downarrow$ & $\downarrow$ & & $\uparrow$ & & & [253] \\
\hline \multirow{4}{*}{ Propanil } & Wistar rats, liver & & $\downarrow$ & $\downarrow$ & $\downarrow$ & $\downarrow$ & & & $\uparrow$ & & & {$[151]$} \\
\hline & Albino rats, liver & & & $\downarrow$ & $\downarrow$ & & & & $\uparrow$ & & & {$[254]$} \\
\hline & $\begin{array}{c}\text { Common carp (Cyprinus carpio) } \\
\text { brain }\end{array}$ & & $\downarrow$ & $\downarrow$ & $\downarrow$ & & & & $\uparrow$ & $\uparrow$ & & {$[255]$} \\
\hline & $\begin{array}{c}\text { Isolated mitochondria from } \\
\text { potato tubers (Solanum } \\
\text { tuberosum) }\end{array}$ & & & & & & & & & & $\downarrow$ & {$[256]$} \\
\hline \multirow{4}{*}{ Dicamba } & Nongreen potato tuber callus & & $\uparrow$ & & $\uparrow$ & $\uparrow$ & & & & & & {$[197]$} \\
\hline & Cnesterodon decemmaculatus & & & $\uparrow$ & $\uparrow$ & $\uparrow$ & & $\uparrow$ & & & & {$[200]$} \\
\hline & $\begin{array}{c}\text { Isolated mitochondria } \\
\text { Arabidopsis }\end{array}$ & $\uparrow$ & & & & & & & & & & [257] \\
\hline & $\begin{array}{l}\text { Chinese hamster lung fibroblast } \\
\text { (V79) cells }\end{array}$ & $\uparrow$ & & & & & & $\uparrow$ & & & & {$[230]$} \\
\hline \multirow[t]{2}{*}{ Trifluralin } & $\begin{array}{l}\text { Male Wistar albino rats-kidney, } \\
\text { ureter, urinary bladder }\end{array}$ & & $\downarrow$ & & & & $\downarrow$ & $\uparrow$ & $\uparrow$ & & & {$[258]$} \\
\hline & Chlamydomonas mexicana & & $\uparrow$ & & $\uparrow$ & & & & & & & {$[259]$} \\
\hline \multirow{8}{*}{ Acephate } & Drosophila melanogaster & & $\bar{\uparrow}$ & & $\uparrow$ & $\uparrow$ & & $\uparrow$ & $\uparrow$ & $\bar{\uparrow}$ & & {$[260]$} \\
\hline & $\begin{array}{c}\text { Male albino rats (plasma and } \\
\text { liver) }\end{array}$ & & $\downarrow$ & $\downarrow$ & $\downarrow$ & & $\uparrow$ & & $\uparrow$ & & & {$[261]$} \\
\hline & Male rats (erythrocytes) & & & $\downarrow$ & & $\uparrow$ & & & $\uparrow$ & & & {$[262]$} \\
\hline & Albino rats & & $\downarrow$ & $\downarrow$ & $\downarrow$ & & & & $\uparrow$ & & & {$[263]$} \\
\hline & Human sperm & & & & & & & $\uparrow$ & & & & {$[264]$} \\
\hline & $\begin{array}{l}\text { Chinese hamster ovary (CHO-K1) } \\
\text { cells }\end{array}$ & & & $\uparrow$ & & $\uparrow$ & $\uparrow$ & & & & & [265] \\
\hline & $\begin{array}{l}\text { Porcine kidney proximal tubule } \\
\text { cell line }(L L C-P K)\end{array}$ & $\uparrow$ & & & & & & & $\uparrow$ & & & {$[266]$} \\
\hline & $\begin{array}{c}\text { Human dopaminergic } \\
\text { neuroblastoma cells (SK-N-SH) }\end{array}$ & $\uparrow$ & & & & & & & $\uparrow$ & & $\downarrow$ & {$[267]$} \\
\hline
\end{tabular}


TABLE 1: Continued.

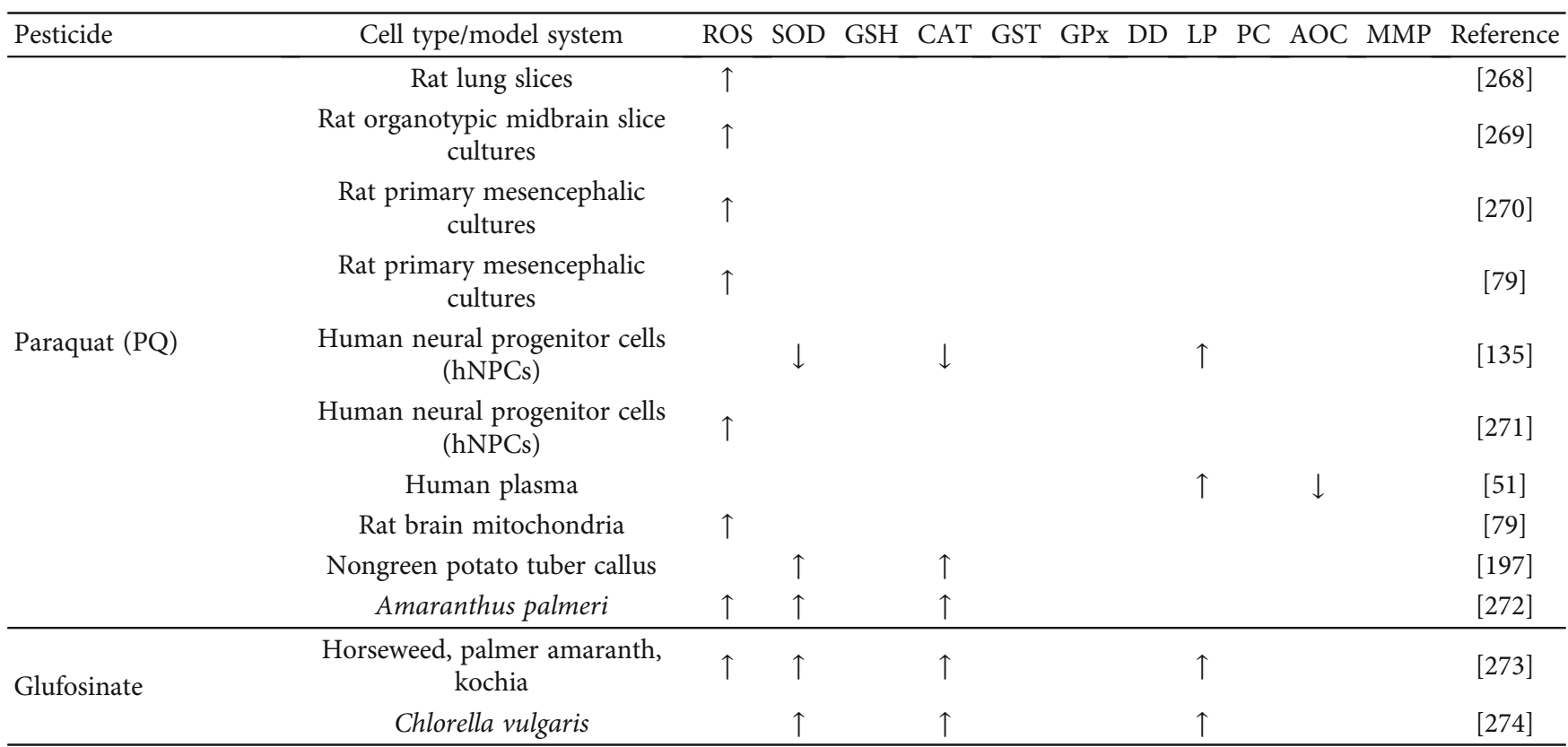

ROS: reactive oxygen species; SOD: superoxide dismutase; GSH: glutathione; CAT: catalase; GST: glutathione-S-transferase; GPx: glutathione peroxidase; DD: DNA damage; LP: lipid peroxidation; PC: protein carbonylation; AOC: antioxidant capacity; MMP: mitochondrial membrane potential; $\uparrow:$ increased; $\downarrow$ : decreased.

reduced by receiving a single electron from $\mathrm{NADPH}$, which serves as the main source of reducing equivalents in cells. This reaction forms $\mathrm{NADP}^{+}$and a highly unstable $\mathrm{DQ}^{+\bullet}$, which, in turn, transfers an electron to molecular oxygen $\left(\mathrm{O}_{2}\right)$ to generate $\mathrm{O}_{2}{ }^{\bullet-}$. This process goes on continuously, even in small amounts, to generate large quantities of $\mathrm{O}_{2}{ }^{--}$ and these oxygen radicals are neutralized spontaneously or enzymatically via SOD to produce $\mathrm{H}_{2} \mathrm{O}_{2}$. However, with the large increase in ROS production, the cellular protective mechanisms, either nonenzymatic components (e.g. GSH, thioredoxin, selenium, and vitamins $\mathrm{C}$ and $\mathrm{E}$ ) or antioxidant enzymes (e.g., SOD, GPx, glutathione peroxidase (GR), and CAT), become overwhelmed, resulting in oxidative stress and, consequently, apoptosis [62].

Uchendu et al. indicated that CPF and deltamethrin ((S) a-cyano-3-phenoxybenzyl-(1R)-cis-3-(2.2-dibromovinyl)2,2-dimethylcyclopropane carboxylate (DM)), which belong to the OP and pyrethroid pesticide groups, respectively, induced oxidative stress due to the generation of free radicals and alteration in antioxidant defense mechanisms. They used a mixture of OP and pyrethroid insecticides, which are common insecticides used by farmers and stored near grains in some countries such as Nigeria [63]. The Uchendu et al. study showed that rats exposed to CPF and deltamethrin, either individually or in combination, had significantly lower levels of CAT, SOD, and GPx and significantly increased levels of MDA compared to the control group [63]. It was suggested that the elevated MDA concentration was due to increased lipid peroxidation, which was induced by excessive production of ROS. The decreased activities of the antioxidant enzymes in the rats exposed to OP and pyrethroid pesticides may be due to the direct deleterious effects of ROS [63].
Another study conducted by Ojha and Gupta indicated that commonly used OP pesticides such as CPF, methyl parathion (MPT), and malathion (MLT) induced apoptosis and DNA interstrand crosslink formation [64]. Ojha and Gupta showed that all OP pesticides significantly increased caspase-3 and caspase-9 activities in rat lymphocytes [64]. Their findings support the suggestion that elevated programmed cell death or apoptosis arises in the presence of oxidative stress and activated caspase- 3 and caspase- 9 play a role in the breakdown of several cellular components related to DNA repair and regulation during apoptosis [64].

Multiple studies have explored the tendency of OPs to cause cytotoxicity, DNA damage, and disturb oxidative balance, which leads to oxidative stress. In one study, Lu and $\mathrm{Yu}$ evaluated the effects of profenofos (PFF) on rat adrenal pheochromocytoma (PC12) cells. They found that PFF and its enantiomers significantly increased intracellular ROS and MDA levels in treated PC12 cells when compared to the control [65]. Their results showed that PFF treatment resulted in a significant increase in the expression of copper/zinc superoxide dismutase ( $\mathrm{Cu}-\mathrm{ZnSOD})$, glutathione-stransferase (GST), and CAT. They also found a significant upregulation in heat shock protein (HSP 70 and HSP 90) mRNAs in PC12 cells exposed to PFF. This suggests that the increased HSPs were playing a protective role against oxidative damage [65].

A common feature of all of these publications is that organophosphorus pesticides activates ROS cellular defenses (such as increased SOD, CAT, and GST) in many cell types and tissues. However, the antioxidant protective pathways do not seem to be enough to prevent cell and tissue damage as apoptosis is a common outcome of treatment with these pesticides (supplemental table 2). 
TABLE 2: Effects of commonly used conventional pesticide active ingredients in the home and garden market sector in 2012 on oxidative stress in different tissues.

\begin{tabular}{|c|c|c|c|c|}
\hline Pesticide & Cell type/model system & Concentration/dose & Oxidative stress markers & Reference \\
\hline \multirow{6}{*}{ Carbaryl } & $\begin{array}{l}\text { Cantareus apertus } \\
\text { (digestive gland) }\end{array}$ & $1 \mu \mathrm{M}$ & $\begin{array}{c}\text { Increased lipid peroxidation, increased activities of } \\
\text { CAT, SOD, GPx, and GR, and decreased total } \\
\text { oxyradical scavenging capacity }\end{array}$ & {$[275]$} \\
\hline & Calothrix brevissima & $\begin{array}{l}10,20,30 \text {, and } 40 \mathrm{mg} / \\
\mathrm{L}\end{array}$ & $\begin{array}{c}\text { Increased lipid peroxidation and increased SOD, } \\
\text { CAT, and APX activities }\end{array}$ & {$[276]$} \\
\hline & Caenorhabditis elegans & $0.5,1$, and $1.5 \mathrm{mM}$ & $\begin{array}{l}\text { Decreased SOD activity and increased CAT and GPx } \\
\text { activities }\end{array}$ & [277] \\
\hline & $\begin{array}{l}\text { Mouse neuroblastoma } \\
\text { cells (neuro 2A) }\end{array}$ & $10 \mu \mathrm{M}$ & $\begin{array}{c}\text { Increased ROS level, loss of mitochondrial membrane } \\
\text { potential, increased proapoptotic gene Bax and } \\
\text { caspase- } 3 \text { expression, and decreased antiapoptotic } \\
\text { gene Bcl-2 expression }\end{array}$ & {$[278]$} \\
\hline & $\begin{array}{l}\text { Rat adrenal } \\
\text { pheochromocytoma } \\
\text { (PC12) cells }\end{array}$ & $100 \mu \mathrm{g} / \mathrm{mL}$ & $\begin{array}{l}\text { Increased lipid peroxidation, increased SOD activity, } \\
\text { decreased GSH content, and decreased mitochondrial } \\
\text { membrane potential }\end{array}$ & {$[279]$} \\
\hline & $\begin{array}{l}\text { Water buffalo (Bubalus } \\
\text { bubalis) }\end{array}$ & $1 \mathrm{mg} / \mathrm{kg}$ & $\begin{array}{c}\text { Increased lipid peroxidation, increased activities of } \\
\text { GPx, GR, GST, SOD, and CAT, and decreased GSH } \\
\text { level }\end{array}$ & {$[280]$} \\
\hline \multirow{10}{*}{ Permethrin (PER) } & \multirow{2}{*}{$\begin{array}{l}\text { Rat polymorphonuclear } \\
\text { neutrophils (PMNs) }\end{array}$} & $\operatorname{PER}(10 \mu \mathrm{M})$ & $\begin{array}{l}\text { Increased apoptosis, protein carbonyl, and conjugated } \\
\text { diene formation in lipids }\end{array}$ & [69] \\
\hline & & $\begin{array}{l}\text { PER metabolites }(3- \\
\text { PBAlc, PBAld, and 3- } \\
\text { PBA) }(10 \mu \mathrm{M})\end{array}$ & $\begin{array}{l}\text { Increased apoptosis, protein carbonyl, and conjugated } \\
\text { diene formation in lipids }\end{array}$ & [69] \\
\hline & \multirow{3}{*}{$\begin{array}{l}\text { Rat adrenal } \\
\text { pheochromocytoma } \\
\text { (PC12) cells }\end{array}$} & $\begin{array}{l}\text { PER }(10,20, \text { and } \\
30 \mathrm{mg} / \mathrm{L})\end{array}$ & $\begin{array}{l}\text { PER induced enantioselective oxidative stress and } \\
\text { cytotoxicity }\end{array}$ & {$[281]$} \\
\hline & & $\begin{array}{l}1 R \text {-trans-PER }(10,20, \\
\quad \text { and } 30 \mathrm{mg} / \mathrm{L})\end{array}$ & $\begin{array}{l}\text { Increased ROS generation and MDA level and } \\
\text { decreased the activity of SOD, CAT, and GSH }\end{array}$ & {$[281]$} \\
\hline & & $\begin{array}{l}\text { 1S-trans-PER }(10,20 \\
\quad \text { and } 30 \mathrm{mg} / \mathrm{L})\end{array}$ & $\begin{array}{l}\text { The toxic effect on PC12 cells induced by } 1 R \text {-trans- } \\
\text { PER was approximately } 1.6 \text { times higher than by } 1 S \text { - } \\
\text { cis-PER }\end{array}$ & {$[281]$} \\
\hline & \multirow{2}{*}{$\begin{array}{l}\text { Thymic cells from } \\
\text { C57BL/6 mice }\end{array}$} & $\begin{array}{l}\text { PER }(150,300,600 \\
\quad \text { and } 1000 \mu \mathrm{M}\end{array}$ & Induced $\mathrm{O}_{2}^{\bullet-}$ and $\mathrm{H}_{2} \mathrm{O}_{2}$ & {$[282]$} \\
\hline & & $\begin{array}{l}\text { Lindane }(37.5,50,75 \\
150, \text { and } 200 \mu \mathrm{M})\end{array}$ & $\begin{array}{l}\text { PER and lindane mixtures increased SOD activity, had } \\
\text { no effect on CAT levels, and inhibited GPx and GSH- } \\
\text { R-specific activities }\end{array}$ & [282] \\
\hline & Wistar rats & $34.05 \mathrm{mg} / \mathrm{kg}$ & $\begin{array}{c}\text { Increased Nurr-1, Nrf2, and NF- } \kappa \mathrm{B} \text { p } 65 \text { mRNA levels } \\
\text { in the cerebellum }\end{array}$ & {$[91]$} \\
\hline & Wistar rats & $34.05 \mathrm{mg} / \mathrm{kg}$ & Increased plasma lipid peroxidation & {$[92]$} \\
\hline & $\begin{array}{l}\text { Male and female 500- } \\
\text { day-old rats }\end{array}$ & $4 \mathrm{~mL} / \mathrm{kg}$ & $\begin{array}{c}\text { Increased calcium and } \mathrm{Nrf} 2 \text { gene expression levels in } \\
\text { old age }\end{array}$ & {$[134]$} \\
\hline \multirow[t]{2}{*}{ Cypermethrin } & Wistar rats & $25 \mathrm{mg} / \mathrm{kg}$ & $\begin{array}{c}\text { Increased lipid peroxidation and protein oxidation, } \\
\text { increased plasma IL- } 6 \text { and TNF- } \alpha \text { levels, and } \\
\text { increased } 8-\mathrm{NO}_{2} \text { Gua levels }\end{array}$ & {$[44]$} \\
\hline & Wistar rats & $1.5-15 \mathrm{mg} / \mathrm{kg}$ & Increased lipid peroxidation & {$[283]$} \\
\hline \multirow{3}{*}{ Deltamethrin } & $\begin{array}{l}\text { Sprague-Dawley rats } \\
\text { (hippocampi) }\end{array}$ & $\begin{array}{l}3.125 \mathrm{mg} / \mathrm{kg} \text { and } \\
12.50 \mathrm{mg} / \mathrm{kg}\end{array}$ & $\begin{array}{l}\text { Increased reactive free radical formation in the brain, } \\
\text { increased nuclear Nrf2 expression, and increased HO- } \\
\qquad 1 \mathrm{mRNA} \text { levels }\end{array}$ & {$[136]$} \\
\hline & $\begin{array}{l}\text { Rat adrenal } \\
\text { pheochromocytoma } \\
\text { (PC12) cells }\end{array}$ & $10,100 \mu \mathrm{M}$ & Increased intracellular ROS production & {$[136]$} \\
\hline & Male Wistar rats & $6.25 \mathrm{mg} / \mathrm{kg}$ & $\begin{array}{l}\text { Decreased CAT activity, SOD activity, and GPx } \\
\text { activity. Increased lipid peroxidation }\end{array}$ & {$[63]$} \\
\hline
\end{tabular}


TABle 2: Continued.

\begin{tabular}{|c|c|c|c|c|}
\hline Pesticide & Cell type/model system & Concentration/dose & Oxidative stress markers & Reference \\
\hline \multirow{4}{*}{ Bifenthrin } & $\begin{array}{c}\text { Human colon } \\
\text { carcinoma (HCT116) } \\
\text { cell }\end{array}$ & $\begin{array}{l}1 / 4 \mathrm{IC} 50,1 / 2 \mathrm{IC} 50,3 / \\
4 \mathrm{IC} 50, \text { and IC50 }\end{array}$ & $\begin{array}{l}\text { Increased ROS production levels, increased lipid } \\
\text { peroxidation, increased DNA damage, decreased } \\
\text { mitochondrial membrane potential, and increased } \\
\text { caspase- } 3 \text { activity and MAPK activation }\end{array}$ & {$[284]$} \\
\hline & Male ICR mice & $1 \mathrm{~S}-c i s-\mathrm{BF}(5 \mathrm{mg} / \mathrm{kg})$ & $\begin{array}{l}\text { Increased hepatic ROS level, increased serum and } \\
\text { hepatic lipid peroxidation, decreased GSH activity, } \\
\text { increased CAT activity, increased SOD activity, and } \\
\text { increased Cat and Ho-1 mRNA levels }\end{array}$ & [285] \\
\hline & $\begin{array}{l}\text { Human umbilical vein } \\
\text { endothelial cells } \\
\text { (HUVECs) }\end{array}$ & $15,30 \mu \mathrm{M}$ & Increased apoptosis & {$[286]$} \\
\hline & Zebrafish & $15,30 \mu \mathrm{M}$ & Increased intestinal ROS level & [286] \\
\hline \multirow{3}{*}{$\begin{array}{l}\text { 2-Methyl-4- } \\
\text { chlorophenoxyacetic } \\
\text { acid (MCPA) }\end{array}$} & Human erythrocytes & $250,500 \mathrm{ppm}$ & Decreased GSH level & [287] \\
\hline & Human erythrocytes & $2.0 \mathrm{mM}, 4.0 \mathrm{mM}$ & Increased lipid peroxidation & [288] \\
\hline & Ramalina fraxinea & $20,50,100 \mathrm{mg} / \mathrm{L}$ & Increased lipid peroxidation & {$[289]$} \\
\hline \multirow{12}{*}{ Malathion } & $\begin{array}{l}\text { Thymic cells from } \\
\text { C57BL/6 mice }\end{array}$ & $37.5,75,150,300 \mu \mathrm{M}$ & Induced $\mathrm{O}_{2}^{\bullet-}$ and $\mathrm{H}_{2} \mathrm{O}_{2}$ & {$[282]$} \\
\hline & Rat erythrocytes & $0.13 \mathrm{mg} / \mathrm{kg}$ & $\begin{array}{l}\text { Increased lipid peroxidation, increased SOD and CAT } \\
\text { activities, and increased total-SH content }\end{array}$ & {$[146]$} \\
\hline & $\begin{array}{l}\text { Male Wistar rats } \\
\text { (cortex, striatum, } \\
\text { cerebellum, } \\
\text { hippocampus) }\end{array}$ & $\begin{array}{l}25,50,100, \text { and } \\
150 \mathrm{mg} / \mathrm{kg}\end{array}$ & $\begin{array}{c}\text { Increased lipid peroxidation, increased protein } \\
\text { carbonylation, increased/decreased CAT activity, and } \\
\text { increased/decreased SOD activity }\end{array}$ & [290] \\
\hline & Prepubertal male mice & $200 \mathrm{mg} / \mathrm{kg}$ & $\begin{array}{l}\text { Increased lipid peroxidation, increased ROS level, } \\
\text { decreased SH group, reduced CAT and GPx activities } \\
\text { in the liver and kidney, decreased total SOD, Cu/Zn- } \\
\text { SOD, and Mn-SOD activities in the liver, and } \\
\text { decreased total SOD and Mn-SOD activities in the } \\
\text { kidney }\end{array}$ & [291] \\
\hline & Male Swiss mice & $500 \mathrm{mg} / \mathrm{kg}$ & $\begin{array}{c}\text { Increased lipid peroxidation, increased ROS level, } \\
\text { increased SH group content, and increased testicular } \\
\text { activities of SOD, Cu/Zn-SOD, Mn-SOD, Fe-SOD, } \\
\text { and CAT }\end{array}$ & [292] \\
\hline & Male Wistar rats & $250 \mathrm{mg} / \mathrm{kg}$ & $\begin{array}{l}\text { Increased lipid peroxidation and decreased testicular } \\
\text { total antioxidant capacity }\end{array}$ & [293] \\
\hline & Male Swiss albino mice & $27 \mathrm{mg} / \mathrm{kg}$ & $\begin{array}{c}\text { Increased lipid peroxidation, decreased testicular } \\
\text { activities of SOD, CAT, and GPx, and decreased GSH } \\
\text { level }\end{array}$ & [294] \\
\hline & Wistar male rats & $250 \mathrm{mg} / \mathrm{kg}$ & $\begin{array}{c}\text { Increased 8-hydroxy-2' } \text {-deoxyguanosine (8-OHdG) } \\
\text { level, increased NO level, decreased total antioxidant } \\
\text { capacity (TAC), increased total oxidant status (TOS), } \\
\text { decreased CAT and SOD activities, and increased } \\
\text { DNA damage }\end{array}$ & [295] \\
\hline & Sprague Dawley rats & $200 \mathrm{mg} / \mathrm{kg}$ & $\begin{array}{l}\text { Increased lipid peroxidation, increased NO level, and } \\
\text { decreased GSH level }\end{array}$ & {$[296]$} \\
\hline & $\begin{array}{l}\text { Human liver carcinoma } \\
\text { cell (HepG2) }\end{array}$ & $6-24 \mathrm{mM}$ & $\begin{array}{l}\text { Increased lipid peroxidation and increased oxidative } \\
\text { DNA damage }\end{array}$ & {$[297]$} \\
\hline & $\begin{array}{l}\text { Porcine cumulus-oocyte } \\
\text { complexes }\end{array}$ & 750 and $1000 \mu \mathrm{M}$ & $\begin{array}{l}\text { Increased ROS level, increased lipid peroxidation, } \\
\text { increased protein carbonylation, increased Cu/Zn- } \\
\text { SOD, GST, and G6PD expression levels, and } \\
\text { decreased CAT and GPx expression levels }\end{array}$ & {$[298]$} \\
\hline & Male Wistar rats & $\begin{array}{l}25,50,100, \text { and } \\
150 \mathrm{mg} / \mathrm{kg}\end{array}$ & $\begin{array}{l}\text { Increased mitochondrial superoxide production in the } \\
\text { hippocampus, increased lipid peroxidation in the } \\
\text { hippocampus and striatum, and decreased complex } \\
\text { IV activity in the hippocampus }\end{array}$ & {$[299]$} \\
\hline
\end{tabular}


TABLE 2: Continued.

\begin{tabular}{|c|c|c|c|c|}
\hline Pesticide & Cell type/model system & Concentration/dose & Oxidative stress markers & Reference \\
\hline & $\begin{array}{l}\text { Rohu (Labeo rohita) } \\
\text { liver }\end{array}$ & $5 \mu \mathrm{g} / \mathrm{L}$ & $\begin{array}{l}\text { Increased intracellular ROS level, increased lipid } \\
\text { peroxidation, increased activities of CAT, SOD, POD, } \\
\text { GSH, GR, GST, and GPx, and increased DNA damage }\end{array}$ & {$[300]$} \\
\hline & Human erythrocytes & $25,75,200 \mu \mathrm{M}$ & $\begin{array}{l}\text { Increased lipid peroxidation, decreased SOD, CAT, } \\
\text { and GPx activities }\end{array}$ & [301] \\
\hline & $\begin{array}{l}\text { Female Wistar rats } \\
\text { (ovary) }\end{array}$ & $50 \mathrm{mg} / \mathrm{kg}$ & $\begin{array}{c}\text { Increased lipid peroxidation and decreased GSH } \\
\text { content }\end{array}$ & {$[302]$} \\
\hline & Allium cepa & $\begin{array}{l}0.05,0.13,0.26,0.39 \\
\quad \text { and } 0.52 \mathrm{~g} / \mathrm{L}\end{array}$ & $\begin{array}{l}\text { Increased lipid peroxidation, increased CAT, GST, } \\
\text { and SOD activities, decreased APX and GR activities, } \\
\text { and increased DNA damage }\end{array}$ & {$[303]$} \\
\hline & Male Kunming mice & $10^{-5} \mathrm{M}$ & $\begin{array}{c}\text { Increased lipid peroxidation, increased } \bullet \mathrm{OH} \text { level, } \\
\text { decreased SOD, GPx, and CAT activities, decreased } \\
\text { GSH content, and increased levels of Bax, Bcl-2, and } \\
\text { p53 in splenic T cells }\end{array}$ & {$[250]$} \\
\hline
\end{tabular}

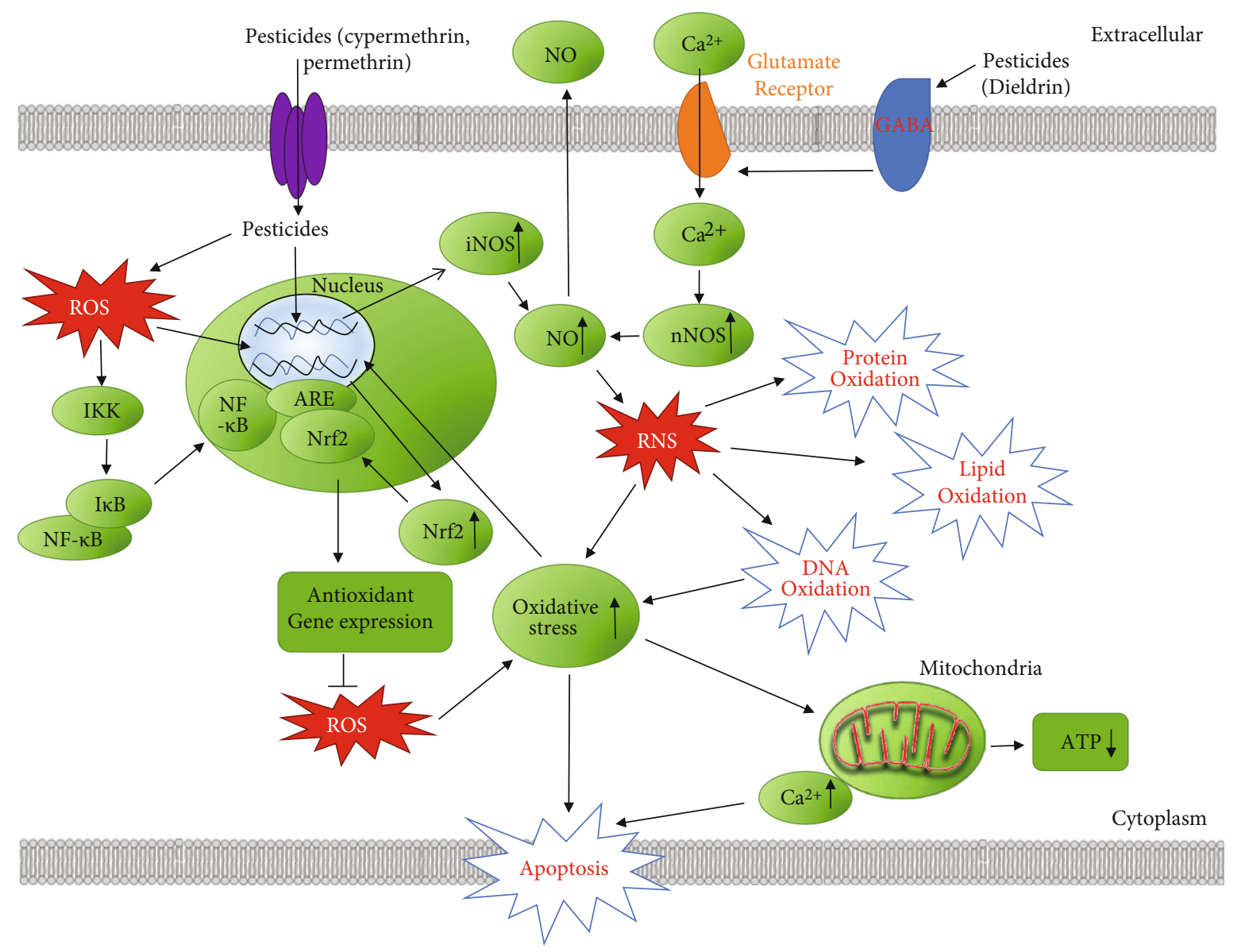

FIGURE 2: Schematic representation of signaling pathways involved in pesticide-induced reactive nitrogen species (RNS) signaling and oxidative stress. Pesticides including cypermethrin and permethrin increase nitric oxide (NO) and $\mathrm{Ca}^{2+}$ levels which increases reactive RNS signaling, thereby increasing oxidative stress in the cell. Pesticides can also lead to Keap1/Nrf2/ARE activation as well as the NF- $\kappa \mathrm{B}$ pathway. Increased RNS may induce lipid, protein, and DNA oxidation, resulting in mitochondrial dysfunction and apoptosis.

1.6. Pyrethroid Insecticides. Permethrin (PER) is a type 1 pyrethroid insecticide. It is the most commonly used pyrethroid in the US and many other countries because of its high activity as an insecticide and its low mammalian toxic- ity [66]. PER can be used as a fungicide or insecticide for wood preservation purposes and can be found in lice shampoos or scabies treatment which increases their potential to cause harm to human health due to their widespread use 
around humans [67]. Due to the worldwide use of permethrin, humans and animals may have had exposure to this compound [67]. Studies have shown that pesticides in the pyrethroid family have a role in weakening the immune system because they can induce leukocytosis, decrease natural killer (NK) cell counts, and increase the cluster of differentiation antigen 4/cluster of differentiation antigen 8 (CD4 +/CD8+) ratio [68]. A study by Gabbianelli et al. showed that $10 \mu \mathrm{M}$ of PER and its metabolites, 3-phenoxybenzyl alcohol (3-PBAlc), 3-phenoxybenzaldehyde (PBAld), and 3-phenoxybenzoic acid (3-PBA), significantly increased apoptosis in rat polymorphonuclear neutrophils (PMNs) [69]. Moreover, pyrethroids could alter the metabolism of catechol estrogens through the action of peroxidases, leading to the production of semiquinones and quinones, which are capable of forming DNA adducts [70]. In addition, quinones potentially affect DNA topoisomerase II, an enzyme that participates in DNA repair and recombination, which could lead to breaks in certain susceptible sites of the genome (breakpoint cluster regions of certain genes), modifying DNA topology through the induction of double-strand breaks (DSB) that need to be rejoined [70]. Furthermore, there are genes, such as mixed lineage leukemia (MLL), with particular susceptibility to the breakage by DNA topoisomerase II; the inhibition of this enzyme produces ruptures in this gene which participates in diverse oncogenic fusions driving the leukemogenic process [70] (Figure 3).

Like organophosphorus pesticides, pyrethroid insecticides also increase the levels of antioxidant enzymes and induces apoptosis (supplemental table 2). The lack of detailed studies with respect to the effects of many pesticides on the immune system limits what can be concluded from pyrethroid pesticide studies. However, the current data suggests that pyrethroid pesticides may have a greater effect on weakening the immune system than other pesticides.

1.7. Organochlorine (OC) Pesticides. Organochlorine (OC) pesticides are synthetic pesticides that belong to a group of chlorinated hydrocarbon derivatives, which are widely used in the chemical industry and in agriculture [1]. The chemicals identified as OC pesticides have been classified as persistent organic pollutants (POPs) because they have high persistence in the environment [1]. Despite their effective control of malaria and typhus fever, the majority of OC pesticides have been banned in most highly developed countries due to their high toxicity, slow degradation, and bioaccumulation [71]. OC insecticides such as dichloro-diphenyltrichloroethane (DDT), hexachlorocyclohexane $(\mathrm{HCH})$, aldrin, and dieldrin are among the most widely used pesticides in developing countries of Asia and Africa [1]. Dieldrin is a highly persistent $\mathrm{OC}$ insecticide that was widely used to control soil pests such as grasshoppers, locusts, termites, beetles, and textile pests in the agriculture field [72]. It was also effective in controlling tsetse flies, which are the vector that caused African sleeping sickness (African trypanosomiasis) and other tropical diseases including malaria, yellow fever, Chagas disease, Oroya fever, river blindness, and filariasis. The United States Environmental Protection Agency
(USEPA) banned and restricted the use of dieldrin in 1974 due to its possible carcinogenicity to human and animal health after many years of widespread use. Since some developing countries are still using this pesticide, humans are still exposed to dieldrin mainly through contaminated foods [72]. Several postmortem studies have suggested that exposure to dieldrin has the likelihood of increasing the incidence of Parkinson's disease because significant levels of dieldrin were detected in the brains from Parkinson's patients, while no dieldrin was detected in age-matched control brains [72]. A list of other pesticides, including some not discussed in the text, and their effects on cell types or model systems are shown in supplemental table 5 .

Like with organophosphorus and pyrethroid pesticides, organochlorine pesticides that are currently used can be found at low levels in the environment. The organochlorine pesticides show cellular effects that are similar to other classes of pesticides further suggesting that most pesticides may be causing some or most of their deleterious effects via excessive ROS production.

1.7.1. Paraquat. One pesticide that has been well investigated relative to others is paraquat. Exposure to paraquat is associated with the increased risk of pulmonary fibrosis, as well as lung, brain, and heat injuries [73, 74]. Paraquat can generate several types of ROS intracellularly, including $\mathrm{O}_{2}{ }^{--}, \mathrm{H}_{2} \mathrm{O}_{2}$, and $\bullet \mathrm{HO}$ [75]. Paraquat can interact with nicotinamide adenine dinucleotide phosphate (NADPH) oxidase (NOX) and inducible nitric oxide synthase (iNOS) generating ROS and RNS in the cytosol [76]. Paraquat induced NOX type 1(NOX1-) mediated ROS generation in dopaminergic cells [77], while it activates NOX type 2 (NOX2) in microglia [78]. High levels of $\mathrm{NO}$ can react with superoxide ions to form highly toxic peroxynitrite anions (ONOO-). Paraquat can also disrupt the oxidation of $\mathrm{NAD}(\mathrm{P}) \mathrm{H}$ to $\mathrm{NAD}(\mathrm{P})^{+}$that occurs by the mitochondrial electron transport chain (ETC) complex I, by accepting electrons to form a charged version of paraquat $(\mathrm{PQ}+) . \mathrm{PQ}+$ can generate superoxide radicals $\left(\mathrm{O}_{2}{ }^{--}\right)$which can lead to other ROS products such as $\mathrm{HO}$. Brain mitochondria ETC complex III was also shown to affect the $\mathrm{H}_{2} \mathrm{O}_{2}$ levels induced by paraquat [79].

1.8. Signaling Mechanisms through Which Pesticides Induce ROS. Although the precise molecular mechanism by which acute or chronic exposure to pesticides induces oxidative stress and damage remains currently unknown, several events involving different cell signaling pathways such as changes in gene expression, activation, and/or inhibition occur. Understanding the cellular and molecular level changes is needed to elucidate the major pathways involved in pesticide-induced oxidative stress and develop potential protective agents or therapies.

1.9. Signal Transducers and Activators of Transcription (STAT). OP pesticides are amongst the most commonly used pesticides in the US. Several studies have reported that CPF increases the production of free radicals and superoxide by disrupting mitochondrial electron transport chain (ETC) complex I activity depleting the antioxidant defenses [80]. 


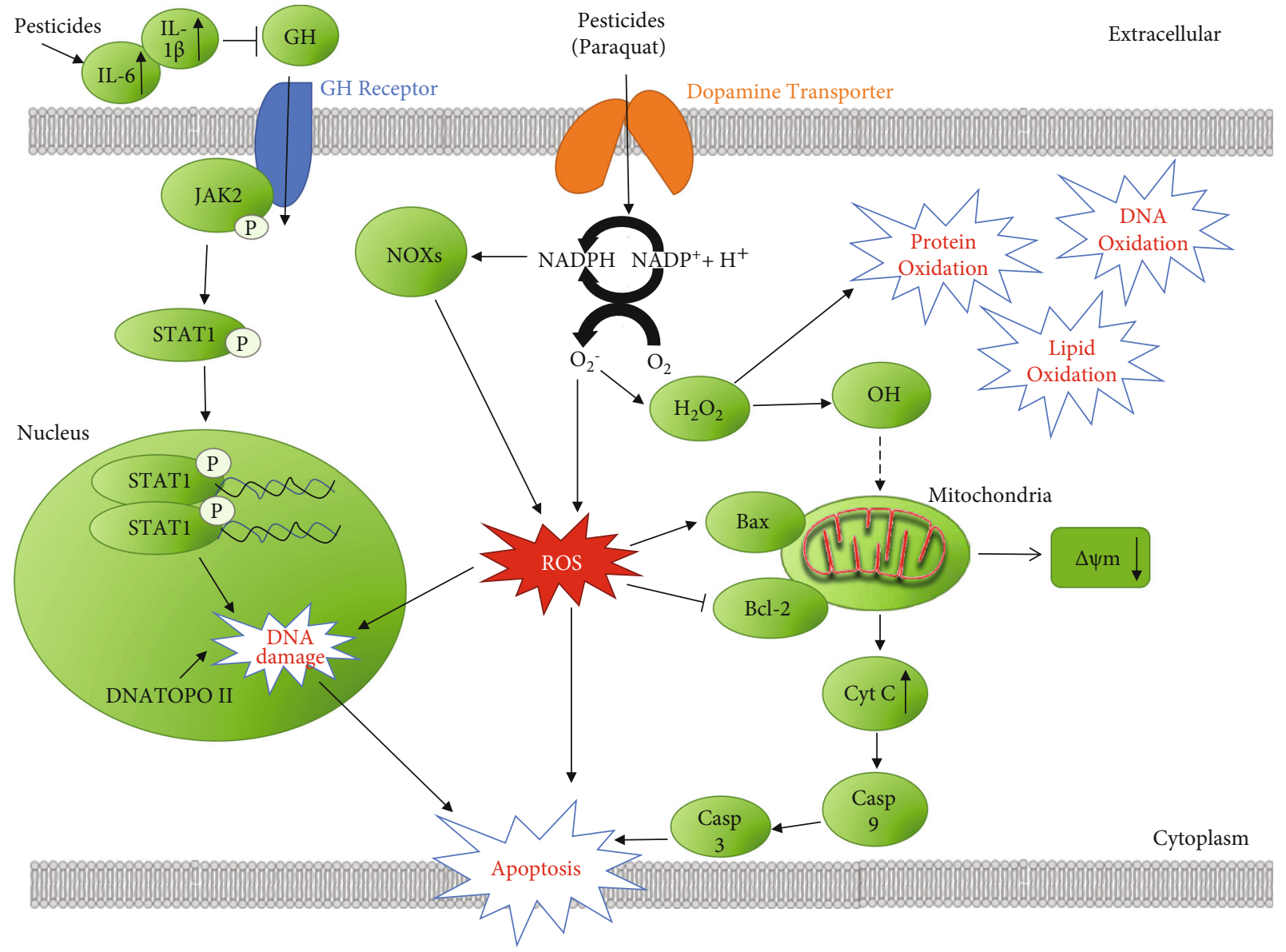

Figure 3: Schematic diagram of the mechanism by which pesticides affect DNA damage and mitochondrial function. Pesticides induce inflammatory cytokines (IL-6, IL-11, and IL-1 $\beta$ ) and caspases that inhibit growth hormone (GH) thereby causing reproductive and birth defects in humans. Phosphorylation of the $\mathrm{C}$ terminal of STAT1 at residue 727 enhances the activity of other factors such as p53 that leads to DNA damage. Together with the action of DNA topoisomerase II, these molecules can cause DNA damage and eventually apoptosis. Pesticides can also induce NOXs and $\mathrm{O}_{2}{ }^{--}$and result in an increase in ROS that leads to mitochondrial dysfunction and activates the mitochondrial apoptosis pathway.. $\mathrm{OH}$ may also be causing mitochondrial stress. $\Delta \psi m$ : mitochondrial membrane potential.

Singh et al. reported that $\mathrm{CPF}$ induced a dose-dependent increase in cell death and contributed to oxidative stress by upregulating ROS generation and decreasing GSH levels in dopaminergic neuronal and human mesencephalic cells [80]. Based on the results of CPF-induced dopaminergic cell death, the group hypothesized that signal transducers and activators of transcription 1 (STAT1) regulate CPFinduced ROS production and that elevated ROS eventually leads to apoptotic cell death [80]. STAT proteins belong to a family of latent cytoplasmic transcription factors that play a major role in proliferation, growth, apoptosis, and differentiation within different cell types [81]. Janus kinase(JAK-) STAT signaling is critical for both neuronal survival and cell death [80]. Upon the binding of ligands to their receptors, activation of JAK takes place and, in turn, phosphorylates STAT1 on tyrosine 701 and serine 727 residues. The phosphorylated STAT1 dimerizes and translocates into the nucleus, where STAT1 binds to the gamma interferonactivated site/interferon-stimulated response element (GAS/ISRE) present on the promoter region of specific target genes that regulate proinflammatory cytokines, NADPH oxidase (NOX), apoptosis, and cell cycle arrest regulators, such as caspases, Fas, and Bax [80]. STAT1 regulates cell death through both transcriptional-dependent expressions of proapoptotic genes and nontranscriptional signaling pathways [81]. In another study, OP pesticides induced a $66 \%$ decrease in intracellular ROS levels in STAT1 knockdown (KD) dopaminergic cells in comparison with scrambled small interfering RNA- (siRNA-) transfected cells exposed to the same pesticides [80]. NOX-1, a superoxidegenerating NADPH-oxidase isoform, has been shown to regulate ROS generation in some cell types, including, but not limited to, monocytes, macrophages, vascular endothelial cells, and smooth muscle cells [82]. NOX-1 is the main ROS-producing enzyme during inflammation [83]. OP pesticides increased the recruitment of STAT1 to the endogenous NOX-1 promoter suggesting that NOX-1 is transcriptionally regulated by STAT1 [80]. STAT1 plays an important role in regulating ROS generation and antioxidant GSH levels in a NOX-1-dependent manner in neuronal cells treated with $\mathrm{CPF}$, an OP pesticide. Mangum et al. found that OC insecticides induced NOX-dependent ROS generation in 
human monocytic cells [84]. Together, these data suggest that STAT1 activation of NOX is important for ROS generation in OP pesticide-induced oxidative stress.

1.10. TNFR1/TNF- $\alpha$ Pathway. Some reports suggest that the death receptor pathway is one of the possible mechanisms that induce oxidative stress. The ligation of cell surface death receptors, such as the tumor necrosis factor receptor (TNFR), enables communication signals of tumor necrosis factor-alpha (TNF- $\alpha$ ), which leads to the activation of caspase- 8 that cleaves effector caspase-3, either directly or indirectly via the mitochondrial route [40]. TNF- $\alpha$ is a powerful and potent proinflammatory cytokine produced by macrophages/monocytes during acute inflammation and is responsible for different signaling events within cells, leading to necrosis or apoptosis [85]. The inflammatory responses induced by TNF- $\alpha$ are mediated by its interaction with two cell surface receptors, TNFR1 and TNFR [86]. TNF- $\alpha$ is also involved in the induction of cytokine production, the activation and expression of adhesion molecules, and growth stimulation [87]. Pacheco et al. showed that increased TNF- $\alpha$ levels by itself could induce ROS generation and oxidative stress in the L929 mouse fibrosarcoma cell line [86]. A study in rats exposed to permethrin showed that an increase in the TNF- $\alpha$ levels increases ROS generation and decreases the antioxidant defense system, which leads to oxidative stress [40]. Additionally, Jin et al. found that permethrin increased TNF- $\alpha$ mRNA expression in a concentration-dependent manner when exposed to zebrafish for 72 hours of postfertilization [42]. Zebrafish is considered a good model for investigating cytokine genes such as TNF- $\alpha$ [88]. A study conducted by Tyagi et al. that focused on idiopathic preterm birth documented that significantly higher levels of $\beta-\mathrm{HCH}$ (beta-hexachlorocyclohexane) and p,p'-DDE (para, paradichlorodiphenyldichloroethylene) were observed in maternal blood of preterm birth cases $(n=30)$ as compared to term delivery $(n=30)$ from July 2012 to June 2013 in Delhi, India [89]. Tyagi et al. found that TNF- $\alpha$ mRNA expression was 2.31-fold higher in preterm birth cases in comparison to term delivery [89]. This suggests that pesticides might be involved in the induction of proinflammatory pathway genes such as TNF- $\alpha$.

1.11. Nurr1 and the NF- $\kappa B$ pathway. Orphan nuclear receptor-related 1 (Nurr1) is a transcription factor that belongs to the nuclear receptor subfamily 4 group A member 2 (NR4A2) family of proteins and plays an important role in the metabolism of dopaminergic neurons [40]. Emerging evidence indicates that impaired Nurr1 function might contribute to the pathogenesis of Parkinson's disease [90]. Nurr1 exhibits anti-inflammatory actions due to its inhibitory activity towards the transcription factor NF- $\kappa \mathrm{B}$ in brain tissue [40]. Carloni et al. reported in their study that permethrin induced an increase in the expression of the proinflammatory NF- $\kappa \mathrm{B}$ transcription factor and a decrease in Nurr1 gene expression [91]. Another study conducted by Fedeli et al. showed that permethrin increased proinflammatory cytokine TNF- $\alpha$ expression and decreased IL- $1 \beta$, IL-2, and IL-13 expression in the oldest treated rats [92]. These results suggest that TNF- $\alpha$, Nurr1, and NF- $\kappa$ B pathways may be partly responsible for some of the mechanisms related to oxidative stress caused by pesticides.

1.12. Protein Kinase C Signaling Pathway. Kitazawa et al. reported that caspase-3-mediated proteolytic cleavage of protein kinase $\mathrm{C}$ (PKC) $\delta$ contributed to apoptosis of dopaminergic PC12 cells following exposure to dieldrin [72]. PKC can be grouped into a family of serine/threonine kinase enzymes that belong to the AGC (cAMP-dependent, cGMPdependent, and protein kinase $C$ ) superfamily of protein kinases [93]. They are protein kinase enzymes that are able to change enzyme activity, cellular location, or association with other proteins via phosphorylation of hydroxyl groups on serine and threonine residues, resulting in a functional change of the target protein [94]. Kitazawa et al. found that exposure of PC12 cells to dieldrin triggered both a dosedependent release and a time-dependent release of cytosolic cytochrome $\mathrm{C}$ which is consistent with previous literature that suggests that increased ROS production induces or triggers mitochondrial cytochrome $\mathrm{C}$ release into cytosol [72]. Additionally, one of the most studied caspases that plays a critical role in execution of apoptosis, caspase-3, was found to be significantly activated following dieldrin exposure. Furthermore, exposure to dieldrin resulted in the proteolytic cleavage of native $\mathrm{PKC} \delta$ over a period of 5 hours [72]. Kitazawa et al. suggest that the proposed mechanism for dieldrin-induced apoptosis in dopaminergic cells was that ROS production triggers cytochrome $\mathrm{C}$ release, which activates caspase- 9 and caspase- 3 and in turn cleaves PKC $\delta$, resulting in apoptotic cell death. These results implicate $\mathrm{PKC}$ as a signaling pathway involved in pesticide-induced oxidative stress. Further studies on PKC involvement in pesticide-induced cellular changes are needed.

1.13. NF- $\kappa B$ Signaling Pathway. Another OP that was extensively used before it was banned and globally phased out due to high toxicity is endosulfan. Endosulfan is primarily used to control a number of insects on food crops like tea, fruits, and vegetables and on grains and can be used as a wood preservative. Endosulfan can be released into the air, water, and soil in areas where it is applied as a pesticide [95]. A mortality study reported an increased incidence of Parkinson's mortality in rural California counties with high use of agricultural pesticides [96]. Jia et al. examined endosulfan and zineb individually and in combination for their potential to stimulate oxidative stress in human neuroblastoma cells (SH-SY5Y) in vitro [97]. They found that exposure to endosulfan and zineb significantly increased intracellular $\mathrm{H}_{2} \mathrm{O}_{2}$ and $\mathrm{O}_{2}^{--}$and production in neuroblastoma cells in a doseand time-dependent manner which indicates that both pesticides induce oxidative stress [97]. Jia et al. also showed that the caspase-3 activity was significantly elevated in cells treated with endosulfan and zineb when compared with that of the control cells. The activity and expression of NF- $\kappa \mathrm{B}$, a ubiquitous transcription factor, which serves as an indicator of oxidative stress, had significantly higher levels in neuroblastoma cells treated with endosulfan and zineb individually or in combination [97]. These results suggest that the 
oxidative stress induced by pesticide exposure to cells contributes, at least in part, to the activation of the NF- $\kappa \mathrm{B}$ signaling pathway. It can be partly extrapolated from this study that combination or exposure to two or more pesticides causes great harm to the health of farmers, workers, and other individuals who are at a higher disposition to pesticide exposure.

1.14. Endoplasmic Reticulum (ER) Stress. The ER serves many functions including the assembly, folding, posttranslational modification, and transport of proteins. In addition, the ER stores calcium which is essential for muscle contraction. ER stress occurs when the protein folding capacity of the ER is overwhelmed, and cells with ER stress are characterized by an accumulation of misfolded proteins inside the lumen of the ER. ER stress could be induced by several conditions including hypoxia, nutrient deprivation, and pesticides. If the ER stress is severe or extended, apoptosis could be induced [18]. Several pesticides such as chlorpyrifos, 2,4-dichlorophenol, deltamethrin, and paraquat have been shown to induce ER stress. Many of these pesticides also induce apoptosis but research suggests that pesticides induce ER stress and apoptotic cell death via different pathways.

1.15. Nonmitochondrial Apoptosis Pathway. Apoptosis is a form of programmed cell death that is used to remove unwanted cells. This process is generally characterized by morphology changes including DNA fragmentation, cell shrinkage, and mRNA decay. Pesticides have been documented to induce apoptosis by triggering several different signaling pathways including intrinsic pathways involving the mitochondria and DNA damage as well as extrinsic pathways such as modulation of death receptors [98, 99]. Organophosphorus pesticides like monocrotophos, profenofos, chlorpyrifos, and acephate induce apoptosis in cultured human peripheral blood lymphocytes [100]. Chlorpyrifos and cypermethrin induce apoptosis in human SH-SY5Y neuroblastoma cells [101], while malathion induces apoptotic cell death in N2 neuroblastoma cells [102]. Chlorpyrifos action may be via FAS/TNF signaling pathways [101]. Although pesticides are typically in low concentrations in rivers, lakes, and surface water, these low concentrations have been documented to induce DNA damage and apoptosis in fish. Pyrethroid pesticides are known to be up to 1000 times more toxic in fish than in mammals and birds because of its high absorption into the gills [103].

1.16. Mitochondrial Apoptosis Pathway. A common dysfunction associated with oxidative stress is mitochondrial dysfunction [104]. In some cases, mitochondrial dysfunction causes ROS, while in some cases, ROS could cause mitochondrial dysfunction. The complexes in mitochondria are the main site for ROS production, and many pesticides have been shown to inhibit mitochondrial complexes [105, 106]. As such, it is likely that a major contributor to oxidative stress is the ROS produced by dysfunctional mitochondria. In mammals and fish, mitochondrial dysfunction is often associated with ER stress and apoptosis [103, 107].
Pentachlorophenol (PCP) and its metabolite, tetrachlorohydroquinone (TCHQ), decreased the antioxidant GSH level in the mouse liver and drastically increased lipid peroxidation via the abundant production of urinary 8-iso-prostaglandin F2 $\alpha$ (8-iso-PGF2 $\alpha$ ) [108]. Taking into consideration existing and emerging evidence, the mitochondrial apoptosis pathway is another possible mechanism that is involved in pesticide-induced oxidative stress. B cell lymphoma 2 (Bcl-2) and BCL2-associated X (Bax) are the main mitochondrial integrity regulators in this pathway. They also influence cytochrome $c$ release and caspase activation. Bcl-2 and Bax are two wellknown proteins associated with cell death but possess opposite function. The $\mathrm{Bcl}-2$ protein functions as a suppressor where it prevents apoptosis by its antioxidative activity, while the Bax protein functions as a promoter of apoptosis [40]. After mitochondrial damage, Bax is translocated from the cytosol to the mitochondria and a significant decrease in Bcl-2 expression also occurs. Due to high levels of ROS from pesticide exposure, mitochondrial cytochrome $\mathrm{c}$ is released into the cytoplasm, which is a critical apoptotic event [40]. Chen et al. found that TCHQ increased the expression of Hsp 70 but decreased the expression of the $\mathrm{Bcl}-2 / \mathrm{Bax}$ ratio and cellular apoptosis susceptibility (CAS), the genes that play a role in apoptotic and necrotic processes, in liver cells. The ratio of $\mathrm{Bcl}-2$ / Bax protein may account for the survival or death of intoxicated cells [108]. Their results corroborate the involvement of the mitochondrial apoptotic pathway in pesticide-induced oxidative stress.

1.17. Autophagy. Autophagy is a normal process that irreversibly degrades damaged or unwanted eukaryotic cell components. Like apoptosis, it is a form of programmed cell death but autophagy involves different pathways from apoptosis [109]. In mammals, the autophagy process involves the formation of autophagosomes (vesicles) that fuse with the lysosome. Autophagy is important in reducing the effects of oxidative stress on cells [110].

Several pesticides have been shown to increase autophagy. CPF, which was described earlier to increase apoptosis, induces autophagy in neuronal cells [111]. In one study, pretreatment of SH-SY5Y neuronal cells with rapamycin (autophagy inducer) resulted in reduced CPF toxicity (less cell death) while inhibition of autophagy resulted in increased CPF toxicity [111]. In another study in SY5Y neuronal cells, Dai et al. found that CPF induced PTEN-induced putative kinase 1 (PINK1)/parkin-regulated mitophagy (a selective form of autophagy) [112]. Experiments using the pesticide fipronil suggest that autophagy is important in reducing the effects of pesticides. In one study, autophagy was found to increase the viability of cells treated with fipronil [113]. The mechanism of action for improved cell viability may be decreased caspase 3 levels resulting in low levels of fipronil-induced apoptosis [113]. Several investigations also suggest that paraquat induces autophagy. In an interesting study, knockout of the innate proinflammatory mediator Toll-like receptor 4 (TLR4) lessened paraquat-induced cardiac dysfunction [114]. A potential mechanism for the 
reduced paraquat-induced cardiac dysfunction may be via the regulation of AMPK-mediated cardiac autophagy [114]. In rat adrenal pheochromocytoma PC12 cells, rapamycin significantly decreased paraquat-induced cellular toxicity suggesting that basal autophagy has a protective role in cytotoxicity caused by paraquat [115].

1.18. Mitogen-Activated Protein Kinases (MAPKs). The mitogen-activated protein kinases (MAPKs) are serine/threonine-specific protein kinases that phosphorylate their own dual-serine and threonine residues (autophosphorylation) or those found on their substrates, to activate or deactivate their target [116]. They are involved in regulating cellular processes such as proliferation, stress response, energy metabolism, gene expression, differentiation, proinflammation, mitosis, cell survival, apoptosis, and immune defense [117]. Chen et al. showed that exposure of TCHQ activated c-Jun NH2-terminal kinase (JNK) and p38 in NIH3T3 fibroblast cells [108]. Herein, this further demonstrates that the cascades of the MAPK (JNK, p38 MAPK, and extracellular signal-regulated protein kinase (ERK)) signaling pathway is involved in TCHQ-induced oxidative stress. Pentachlorophenol (PCP) is a restricted use OC pesticide, used industrially as a wood preservative for railroad ties, utility poles, and wharf pilings and used extensively as a biocide in the leather and textile industries [118]. It is highly effective against decay from fungus and damage from wood-boring insects in timbers [119]. Its molecular structure is that of a phenol group (aromatic ring) with five chlorine atoms which makes it a persistent organic pollutant. PCP has been detected in food and several consumable products. PCP has also been found in groundwater in micromolar concentrations. Even higher levels of PCP $(0.7 \mathrm{mM})$ have been reported in the vicinity of industrial point sources of chlorophenols [120]. Due to the difficulty in the degradation of PCP in the environment, its use has been banned by countries which signed the Stockholm Convention with exception to the US. The IARC (International Agency for Research on Cancer) categorized PCP as carcinogenic to humans (group 1) based on epidemiological studies that showed that exposure to PCP causes non-Hodgkin lymphoma in humans [108]. Several studies have reported that exposure to PCP increases the risk of nasal carcinoma and soft tissue sarcoma and induces hepatocellular carcinomas/adenomas, hemangiosarcomas, and pheochromocytomas in a chronic tumorigenesis mouse animal model $[121,122]$. Wispriyono et al. found that $20 \mu \mathrm{M}$ of PCP and its metabolite, TCHQ, markedly increased the number of apoptotic cells and induced DNA fragmentation in Jurkat human T cells after 10 hours of incubation. Notably, they discovered that after $1 \mathrm{hr}$ of incubation, $20 \mu \mathrm{M}$ of TCHQ phosphorylated all the MAPKs examined (i.e., extracellular signal-regulated protein kinase (ERK), p38, and cJun NH2-terminal kinase (JNK)). They went on to show that TCHQ-induced apoptosis disappeared almost completely when treated with both the p38 inhibitor (SB203580) and MAPK/ERK kinase inhibitor (U0126) at the same time. Wispriyono et al. came to the conclusion that p38 and ERK are likely important signal transduction pathways involved in apoptosis in the human $\mathrm{T}$ cell line exposed to
PCP metabolite [123]. CPF $(50 \mu \mathrm{M})$ induced redox imbalance altering the antioxidant defense system in breast cancer cells as well as increased formation of intracellular ROS and RNS. Finally, it was demonstrated by Ventura et al. that the main mechanism involved in the inhibition of CPFinduced cell proliferation is an increment of p-ERK1/2 levels mediated by $\mathrm{H}_{2} \mathrm{O}_{2}$ in breast cancer cells [124]. Apoptosis signal-regulating kinase 1 (ASK1) is a member of the mitogen-activated protein kinase (MAPK) family. ASK1 activates c-jun N-terminal kinase (JNK) and p38 in response to various stimuli including oxidative stress, endoplasmic reticulum stress, proinflammatory cytokines, infection, and calcium influx. ASK1 activates JNK and p38 by directly phosphorylating, and thereby activating, their respective MAP2Ks (also called mitogen-activated kinase kinase (MKK)), MKK4(SEK1)/MKK7, and MKK3/ MKK6 [125]. Meijles et al. found that activation of cardiac ASK1 is ROS dependent in neonatal rat cardiomyocytes from perfused hearts where $\mathrm{H}_{2} \mathrm{O}_{2}$ activated ASK1 which suggests that ASK1 is selectively activated by ROS [126]. When Niso-Santano et al. exposed human neuroblastoma SH-SY5Y cells to $100 \mu \mathrm{M}$ PQ for $24 \mathrm{~h}$, they found that paraquat increased ASK1 expression and nuclear apoptosis was significantly increased in PQ-treated cells [127].

1.19. Keap1/Nrf2/ARE Pathway and $\mathrm{Ca}^{2+}$ Signaling. The Keap1/Nrf2/ARE pathway plays a major role in the regulation of cytoprotective responses to endogenous and exogenous stresses caused by ROS [128]. There are four components involved in the Nrf2/Keap1 pathway; they are (a) the nuclear factor erythroid2-related factor 2 (Nrf2), (b) the actin-binding Kelch-like ECH-associated protein 1 (Keap1), (c) a group of small musculoaponeurotic fibrosarcoma (Maf) proteins, (d) and antioxidant response element (ARE) which are important for the antioxidant response in this pathway [116]. Nrf2 is a transcription factor that binds to the antioxidant responsive element (ARE) in DNA that induces the expression of a group of detoxing enzymes and antioxidant proteins/enzymes. Gene expression of heme oxygenase-1 (HO-1) and $\mathrm{NAD}(\mathrm{P}) \mathrm{H}$ dehydrogenase and others are regulated by Nrf2 [74-77]. Animal models that have increased Nrf2 levels show increased protection against oxidative stress $[129,130]$, while Nrf2 gene knockout mice have a higher susceptibility to oxidative damage [131, 132]. Keap1, a cysteine-rich protein, acts as an adaptor protein for a Cul3-dependent E3 ubiquitin ligase complex and supports ubiquitination of $\mathrm{Nrf} 2$ which then gets degraded by the ubiquitin proteasome system [116]. Consequently, the gene knockout of Keap1 results in constitutively hyperactive Nrf2 signaling.

The generation of excessive ROS from exposure to pesticides leads to the progression of oxidative stress in cells resulting in an increase in the oxidation or conjugation of key cysteine residues in Keap1. These modifications typically weaken its ability to act as an E3 ligase adaptor. As a result, Keap1 loses its ability to promote ubiquitination and degradation of Nrf2. Ultimately, Nrf2 dissociates from Keap1, leading to decreased proteasomal degradation of Nrf2, accumulation of free Nrf2 in the cytosol, and translocation of 
Nrf2 into the nucleus. Following Nrf2 translocation into the nucleus, it heterodimerizes with small Maf-binding proteins and binds to ARE. This binding ultimately activates AREdependent gene expression and initiates the transcription of antioxidant genes $[116,128]$. These genes include $\mathrm{NAD}(\mathrm{P}) \mathrm{H}$ : quinine oxidoreductase 1 (Nqo1), heme oxygenase-1 (HO-1), $\gamma$-glutamylcysteine ligase (Gcl), microsomal epoxide hydrolase (Eh-1), GSTs, sulfiredoxin 1 (Srxn1), multidrug resistance-associated proteins (Mrps), bile salt efflux pump (Bsep), and carboxylesterases (Ces) $[128,133]$. In a study conducted by Carloni et al., PER increased Nrf2 gene expression in the cerebellum of rats [91]. Another study found increased mRNA expression of Nrf2 (1.62-fold) and the intracellular $\mathrm{Ca}^{2+}$ influx in rat heart cells from 500-day-old rats exposed to PER during their early life (6th to 21st day of life) [134]. This suggests that the Keap1/Nrf2/ARE and $\mathrm{Ca}^{2+}$ signaling pathways might be involved in the toxic effect induced by PER. The overexpression of $\mathrm{Nrf} 2$ and the increased $\mathrm{Ca}^{2+}$ level might be due to epigenetic mechanisms that sustain the memory of pesticide contact, despite the fact that the exposure has ended [134]. Dou et al. found that the Nrf2/ARE pathway is involved in oxidative stress when induced by PQ in human neural progenitor cells (hNPCs) [135]. They detected significant upregulation in cytoplasmic and nuclear Nrf2 expression in hNPCs when exposed to $10 \mu \mathrm{M}$ of PQ. As a result of Nrf2 increase, they examined Nrf2-ARE-dependent genes and found that HO-1 and Nqol mRNA expression was significantly increased at 10 and $100 \mu \mathrm{M}$ after PQ treatment for 24 hours [135].

Deltamethrin ((S) a-cyano-3-phenoxybenzyl-(1R)-cis-3(2.2-dibromovinyl)-2,2-dimethylcyclopropane carboxylate $(\mathrm{DM})$ ), one of the most potent pyrethroid insecticides with a cyano substituent [136], is used to control apple and pear suckers, plum fruit moth, caterpillars on brassicas, pea moth, aphids (apples, plums, and hops), winter moth (apples and plums), codling and tortrix moths (apples), and numerous insect pests of field crops [137]. DM plays a key role in controlling malaria vectors and is used in the manufacturing of long-lasting insecticidal mosquito nets [138]. It acts as a neurotoxin causing a prototypical type II neurological syndrome characterized by jerking leg movements and progressive writhing convulsions [136]. Treatment with DM increased free radicals in the hippocampus of rats and increased ROS in PC12 cells suggesting that DM exposure resulted in oxidative damage. The authors showed that DM caused a significant increase in cytoplasmic and nuclear Nrf2 protein expression in the cerebral cortex and hippocampus tissue. HO-1 mRNA levels were significantly elevated in tissue from both cerebral cortex and hippocampus tissues when exposed to DM [136]. Hence, they detected a marked increase in Nrf2 protein, HO-1 mRNA, and free radicals in vivo in response to DM. Their findings show that Nrf2 translocation from the cytoplasm to nucleus is initiated in vivo and is most likely a response to the DM-dependent induction of free radicals (Figure 2). Although the role of $\mathrm{Ca}^{2+}$ signaling in pesticide-induced cellular changes needs to be more thoroughly investigated, the Keap1/Nrf2/ARE pathway involvement in cytoprotec- tive responses to pesticides is well supported by the current experimental data.

1.20. Possible Signaling Mechanisms through Which Pesticides Induce RNS. Kanthasamy et al. reported that dieldrin can cross the blood-brain barrier and can also be stored in adipose tissue with a half-life in humans of approximately 300 days, due to its lipophilicity [139]. Dieldrin targets neuronal ion channels in the brain through inhibition of the $\mathrm{GABA}(\mathrm{A})$ receptor, which results in hyperexcitation and a massive influx of $\mathrm{Ca}^{2+}$ via glutamate receptor channels. This $\mathrm{Ca}^{2+}$ influx can induce neuronal NOS, further increasing the production of ROS/RNS in the brain. $\mathrm{Ca}^{2+}$ plays an important role in numerous cellular processes including mediating cellular proliferation, apoptotic processes, the induction of oxidative stress, and physiological functions (Figure 2) $[140,141]$. The detection of 3-nitrotyrosine residues on intracellular proteins exposed to different pesticides such as maneb, rotenone, and dieldrin suggests a role of RNS in diseases such as Parkinson's disease [45].

1.21. Possible Mechanisms to Reduce Oxidative Stress Induced by Pesticides. One of the major mechanisms that the body implements in fighting external toxic and harmful agents involves the immune system. The immune response consists of the antigen-non-specific response (innate) and the antigen-specific response (adaptive) [9]. Several experimental studies have reported that exposure to pesticides can exert damaging effects on the immune system [19, 42, $68,85]$. Immunocompetent cells secrete inflammatory mediators, such as cytokines, chemokines, ROS, and RNS. In particular, cytokines can regulate innate or adaptive immunity, hematopoiesis, inflammatory processes, and many other cellular activities through specific binding to their respective receptors [9].

Sometimes, the endogenous antioxidant system becomes incompetent and cannot scavenge the induced oxidative stress [142]. Several studies have reported the potential protective effect of exogenous antioxidant vitamins and minerals against pesticide-induced toxicity in animal models that exhibit alterations in their enzymatic antioxidant system [4, 143-147]. It is important to study the potentially harmful effects of pesticide exposure and various significant methods to mitigate these adverse effects. This section briefly documents the protective role of antioxidant vitamins like vitamins $\mathrm{C}$ and $\mathrm{E}$, minerals like zinc, and other naturally occurring antioxidants like $\mathrm{N}$-acetyl cysteine and epicatechin, against pesticide-induced oxidative stress in animal models.

1.22. Vitamin C. Vitamin C (ascorbic acid) is a water-soluble antioxidant. It has been shown to react directly with superoxide and hydroxyl radicals to neutralize ROS and reduce oxidative stress [4]. It has been suggested that vitamin $\mathrm{C}$ acts as a chain-breaking antioxidant that stops the propagation of peroxidative processes, thereby reducing lipid peroxidation caused by pesticides. Vitamin $\mathrm{C}$ can also do a oneelectron reduction of lipid hydroperoxyl radicals via the vitamin E redox cycle [4]. A study conducted with male 
albino Wistar rats by Rai et al. found that vitamin $\mathrm{C}$ treatment prevented oxidative stress induced by carbofuran in the erythrocytes of rats [148]. Jaiswal et al. showed that pretreatment of vitamin $\mathrm{C}$ with carbofuran provided significant recovery in ameliorating the altered levels of oxidative stress biomarkers. They observed that the levels of MDA, total thiols, and GSH as well as the activities of SOD, CAT, and GST were close to those of the untreated control which suggest that vitamin $\mathrm{C}$ is able to provide significant protection from the pesticide's intoxication in the rat heart [149].

El-Gendy et al. studied the protective effect of vitamin C (200 mg/kg b.w.) before and after administration of imidacloprid (a neonicotinoid) in male Swiss albino mice. Their study showed that oral administration of $14.976 \mathrm{mg} / \mathrm{kg}$ imidacloprid caused significant elevation of lipid peroxidation levels and the activities of antioxidant enzymes including CAT, SOD, GPx, and GST [147]. However, they reported that vitamin $\mathrm{C}$ might ameliorate imidacloprid-induced oxidative damage by decreasing lipid peroxidation levels (measured by thiobarbituric acid-reactive substances (TBARS)) and altering antioxidant defense systems in the liver [147].

Vitamin C treatment of CPF-intoxicated mice decreased the lipid peroxidation level and GST activity, normalized CAT, SOD, and glucose-6-phosphate dehydrogenase activities, and increased the GSH level [150]. In addition, coadministration of propanil with vitamin $\mathrm{C}$ ameliorated the harmful effects of propanil in most of the tested oxidative stress parameters in mice liver tissues. Their study suggested that vitamin $\mathrm{C}$ could be an important dietary component based on its ability to attenuate propanil-induced hepatotoxicity [151]. All of these studies suggest a clear protective role of vitamin $\mathrm{C}$ against pesticide-induced toxicity. Hence, it is likely that other compounds with antioxidant properties can also have significant beneficial effects against pesticideinduced toxicity.

1.23. Vitamin E. Vitamin E, present in a biologically active form as $\alpha$-tocopherol, performs as an antioxidant. It is a major lipid-soluble antioxidant present in all cellular membranes and protects against lipid peroxidation [152]. It can act directly with a variety of oxygen radicals, including the peroxyl radical $(\mathrm{ROO} \bullet)$, trichloromethyl radial $(\mathrm{CCl} 3)$, and peroxide $(\mathrm{HO} \bullet$ ) production. Vitamin $\mathrm{E}$ acts by rapidly transferring its phenolic hydrogen atom to lipid peroxyl radicals resulting in the formation of two molecules that are unreactive toward polyunsaturated lipids [4].

Yousef et al. showed that when rats intoxicated with deltamethrin were exposed to vitamin E, the levels of GST and SOD were elevated and the levels of lipid peroxidation were decreased. Thus, vitamin E alleviated the harmful effects of deltamethrin that were observed, exhibiting its beneficial effects in male Sprague Dawley rats [153]. In male Wistar rats, vitamin $\mathrm{E}$ has shown its ameliorating effects by restoring the levels of endogenous antioxidant enzymes such as SOD, CAT, GPx, and GST, suggesting its potential antioxidant role against atrazine-induced oxidative stress [154, 155]. A study conducted by John et al. found that treatment of rats with dimethoate and malathion increased the levels of lipid peroxidation in erythrocytes; however, pretreatment of rats with vitamin $\mathrm{E}$ before administering dimethoate and malathion showed decreased levels of lipid peroxidation in erythrocytes. Their results display that vitamin E may ameliorate dimethoate- and malathion-induced oxidative stress by decreasing lipid peroxidation and altering antioxidant defense systems in erythrocytes [146]. Ben Amara et al. showed that exposure of rats to dimethoate for 30 days showed pronounced oxidative stress due to an increased lipid peroxidation level and decreased GSH and nonprotein thiol levels [144]. A decrease in GPx, SOD, and CAT activities was also observed, but coadministration of selenium and/or vitamin $\mathrm{E}$ through diet in rats improved the altered oxidative stress biomarkers [144]. These results suggest that the use of the antioxidant vitamin $\mathrm{E}$ may prevent or reduce many of the damaging effects of some pesticides.

1.24. Zinc. Zinc ( $\mathrm{Zn})$ is one of the most abundant trace elements in the body and can upregulate various transcription factors and detoxifying molecules (glutathione, SOD, glutathione S-transferase, and hemeoxygenase-1) [4]. Zn also induces the nuclear factor erythroid 2-related factor 2 (Nrf2) to act as an antioxidant and is required for enzymes involved in lipid synthesis and lipoprotein excretion [4]. Saad-Hussein et al. conducted a cross-section comparison study, comparing 80 pesticide sprayers from a small village located within an agricultural area in Upper Egypt with 80 control subjects not occupationally exposed to pesticides [142]. Their subjects had no medical history of chronic diseases, and the pesticide sprayer group had been exposed to pesticides for more than 15 years (15-30 years), without wearing any personal protective equipment. Interestingly, they found that $\mathrm{Zn}(110 \mathrm{mg})$ supplementation for 1 month significantly decreased MDA levels and increased SOD, GPx, and Zn levels in pesticide sprayers [142]. Goel et al. showed that zinc treatment to CPF-intoxicated male Sprague-Dawley rats normalized the raised levels of lipid peroxidation to within normal limits [158]. Moreover, they found that $\mathrm{Zn}$ treatment in these animals resulted in an elevation in GSH, CAT, and GST levels. Additionally, they found a significant decrease in the levels of SOD. However, results of studies from male and female rats revealed that $\mathrm{Zn}$ had greater ameliorating effects in female CPFintoxicated rats, when compared to males, in reducing oxidative stress parameters $[156,157]$. Overall, these results demonstrate the potential protective role of $\mathrm{Zn}$ in alleviating the hepatic toxicity, as well as emphasize a role for antioxidants in reducing pesticide toxicity [158]. Differences between females and males are now beginning to be investigated, but the current data suggests that female and male animals show unique differences with regard to pesticide and antioxidant treatments. As such, more targeted research is needed to help determine the differences between males and females.

1.25. N-Acetylcysteine. N-Acetylcysteine (NAC) is a nutritional supplement derived from L-cysteine amino acid. NAC is a well-tolerated mucolytic drug that moderates clinging mucous secretions and supports glutathione Stransferase (GST) activity. When administered orally, 
deacetylation of NAC occurs while passing along the small intestine as well as the liver. Thus, its bioavailability is decreased to $4-10 \%$. NAC stimulates glutathione biosynthesis, promotes detoxification, and acts directly as a scavenger of free radicals, especially oxygen radicals. It is a powerful antioxidant and a potential treatment option for diseases characterized by the generation of free oxygen radicals [159]. Tebuconazole (TEB), a triazole fungicide, is widely used to control fungal growth in vegetables, fruits, and seeds. It can also be used as a biocide preservative for industrial and construction material [160]. Ben Othmène et al. found that TEB increased lipid peroxidation, DNA damage, and p53 and p21 protein levels after $24 \mathrm{~h}$ in H9c2 cardiomyoblasts. They also suggested that TEB might induce oxidative stress in cardiac cells via the mitochondrial apoptotic pathway due to the loss of mitochondrial transmembrane potential $(\Delta \Psi \mathrm{m})$, an increase in the $\mathrm{Bax} / \mathrm{Bcl}-2$ ratio, an activation of caspase- 9 and caspase-3, a cleavage of poly (ADP-ribose) polymerase (PARP), and an increase in mitochondrial superoxide (measured by MitoSOX). However, when they treated cardiomyocytes with the ROS scavenger NAC, there was a decrease in TEB-induced DNA damage and activation of the mitochondrial pathway of apoptosis [161].

Dorval and Hontela showed that rainbow trout (Oncorhynchus mykiss) pretreated with NAC following exposure to endosulfan had significantly higher levels of GSH and decreased levels of lipid hydroperoxides (LOOH) [162]. Another study conducted by Cankayali et al. using male Wistar rats cotreated with dichlorvos and NAC found that NAC might prevent lipid peroxidation and decrease the risk of oxidative stress [163]. Finally, Yurumez et al. found that male NMRI mice treated with $250-500 \mathrm{mg} / \mathrm{kg}$ Mancozeb (MZB) for 40 days exhibited significantly increased lipid peroxidation, increased protein carbonyl concentration in the testes, and decreased activities of antioxidant enzymes (SOD and CAT). The total antioxidant capacity and GSH content were found to be significantly less in the testes of MZB-exposed mice [60]. However, cotreatment of MZBexposed mice with NAC reversed the changes in oxidative stress indices found earlier with MZB. They found significantly decreased levels of lipid peroxidation, and the activities of antioxidant enzymes SOD and CAT were maintained near control levels following NAC $+\mathrm{MZB}$ cotreatment [60]. As with other antioxidants discussed earlier, NAC seems to also have strong antioxidative stress properties.

1.26. Epicatechin. Flavonoids are a large group of natural phenolic compounds with different subclasses that have been described as powerful antioxidants from previous in vitro studies [164]. The antioxidant properties of flavonoids are largely dependent on their structure, and the major contributing factor is the presence of $3^{\prime}, 4^{\prime}$-dihydroxycatechol, which has reducing capabilities and influence on the intracellular redox status [165]. Epicatechin is a flavan-3ol, a subclass of the flavonoids found in green tea, grape, apples, and cocoa [166]. Tea extracts and/or its constituents have been reported to possess pharmacological effects such as anti-inflammatory, antibacterial, antiviral, antioxidant, antitumor, antihyperlipidemic, anticarcinogenic, and cyto- protective effects. Also, it was shown that green tea extract can scavenge nitric oxide (NO) and $\mathrm{O}_{2}{ }^{--}$very effectively [167]. Moreover, Afolabi et al. found that cotreatment of CYP-exposed rats with epicatechin significantly reduced the formation of nitrosative nucleic acids by 51\% [44]. Another study conducted to investigate the effects of catechin against PCP-induced cytotoxicity in human erythrocytes found that PCP significantly decreased GSH levels, total sulfhydryl (SH) content, and cellular antioxidant power. PCP treatment also lowered the activity of antioxidant enzymes and inhibited enzymes of glucose metabolism. However, prior treatment with catechin before incubation with PCP increased the GSH level and total SH content in erythrocytes [120]. Maheshwari and Mahmood reported that prior treatment of catechin prevented the oxidative damage of membrane lipids and lowered malondialdehyde and lipid hydroxyperoxide levels to 1.6- and 1.56-fold relative to control values. Finally, they found that catechin decreased intracellular ROS and RNS levels in PCP-treated erythrocytes [120]. In addition, Spencer et al. showed that epicatechin and its in vivo metabolite, $3^{\prime}$-O-methyl epicatechin, protected human fibroblasts from hydrogen peroxideinduced oxidative stress by inhibiting caspase- 3 activation [165]. These studies suggest that epicatechin significantly mitigates pesticide-induced oxidative modifications in a concentration-dependent manner while not exhibiting any deleterious effect on its own. Catechin may be a potential chemoprotectant against pesticide toxicity, and other structurally related compounds to catechin may also be beneficial, but further experimentation is needed.

\section{Conclusions}

The current experimental evidence from research studies suggests that all classes of pesticides induce oxidative stress, RNS, and ROS in different cell types and animal models and that oxidative stress is one of the most important mechanisms of pesticide toxicity. Albeit not exhaustive due to the large number of pesticides available, this review covers the major classes of commonly used pesticides in the United States and the rest of the world. Pesticide exposure could come from occupational routes as well as from food, water, air, and dust. What is typically lacking in previous reviews and research publications are the molecular mechanisms involved in pesticide toxicity because of the complexity of mechanisms that may be involved with different classes of pesticides. A search of the Internet for publications that attempted to explain the mechanisms involved in pesticide toxicity revealed only two publications with one figure each.

The higher levels of oxidative stress eventually cause cell apoptosis through several pathways: the mitochondrial apoptosis pathway, Keap1/Nrf2/ARE, $\mathrm{Ca}^{2+}$, TNFR1/TNF- $\alpha$, Nurr1, STAT1, ASK1, MAPKs, and NF- $\kappa$ B pathways amongst others. Increased levels of ROS and RNS may also affect the ubiquitin proteasome system (UPS) that degrades altered and misfolded proteins [168]. Numerous reports suggest that Kelch-like ECH-associated protein-1 (Keap1), a substrate adaptor protein for a cullin-3 E3-ubiquitin ligase (Cul3)/Ring-Box- (Rbx1-) dependent complex, plays a 
critical role in the ubiquitination and degradation of Nrf2, $\mathrm{IKK} \beta$, and $\mathrm{Bcl}-2 / \mathrm{Bcl}-\mathrm{xL}$. ROS disrupts Keap1 via modifying reactive cysteines (Cys273, Cys288, and Cys151) and then inducing a conformational change that leads to the release of $\mathrm{Nrf2}$, IKK $\beta$, and $\mathrm{Bcl}-2 / \mathrm{Bcl}-\mathrm{xL}$ from Keap1 and the suspending of their ubiquitination and degradation [169-172]. UPS dysfunction could lead to various cellular malfunctions including proteotoxicity, mitochondrial dysfunction, and apoptosis.

Even though we are starting to understand the mechanisms involved in pesticide toxicity, more research is needed as it is crucial to better understand the molecular mechanisms by which pesticides induce oxidative stress. Interestingly, the T-2 toxin, which is not a pesticide, shows molecular mechanisms for toxicity similar to pesticides. The T-2 toxin induces oxidative stress in numerous cell lines causing oxidative damage to lipids, proteins, and DNA [173]. The T-2 toxin increases MDA content (lipid peroxidation representative) and CAT and SOD activities as well as decreases GSH-Px activity in rat anterior pituitary GH3 cells. Caspase- $3,-8$ and -9 are significantly induced by the $\mathrm{T}-2$ toxin in a dose-dependent manner. While these T2 toxin-induced mechanisms are similar to pesticides, the T2 toxin also increases the mRNA levels of IL-6, IL-11, and IL- $1 \beta$ and inhibits the synthesis and secretion of GH. It is possible that pesticides could be working in a similar manner to T-2 toxin in regard to the induction of interleukins and growth hormone deficiency [174]. Both PCP and DDT increase IL-6 production [175]. Also, previous research found that people regularly exposed to pesticides, such as women and children raised in agricultural areas, had low levels of insulin-like growth factor-1 (IGF-1), which plays an important role in childhood growth. This makes the children at higher risk of developing growth disorders [176]. While studies suggest that antioxidants may be beneficial for reducing pesticide toxicity, further studies should focus on the possible ways to ameliorate the side effects of pesticide exposure not just via exogenous antioxidants but by influencing the signaling pathways involved in pesticideinduced oxidative stress. More studies are urgently needed to determine how sex differences may be involved in pesticide-induced toxicity, as well as if any other cellular pathways are involved in pesticide-related toxicity.

2.1. Limitations of Previous Studies. Many of the clinical studies on humans have relatively low sample sizes complicating the interpretation of the data as well as the reliability of that data to make generalized conclusions for different populations. Experimental data on gender-specific effects has not been well investigated, but experimental data suggest that xenobiotics affect males and females differently, so pesticides are likely to have gender-specific effects $[156,157]$. It would be of great interest to the public to understand the variations in the response of male and female animals to pesticide exposure. It would also be important to determine if there are gender-specific differences in the possible effects of exogenous antioxidants in the mitigation of pesticideinduced oxidative stress biomarkers (lipid peroxidation, lipid oxidation, and protein oxidation), DNA fragmentation, and apoptosis.

Oxidative modification of proteins and proteolytic pathways compromise the protein quality and cell viability due to oxidative stress that arose from the increased ROS level when exposed to pesticides. These events may be among the most relevant in driving protein toxicity in several pathologies such as neurodegenerative diseases, cardiovascular diseases, cancer, reproductive diseases, and birth defects. However, the experimental data on the role of protein toxicity and the UPS in pesticide toxicity is very limited [177]. Finding novel ways to prevent pesticide toxicity may require understanding the role of the UPS pathway in this process to increase the capacity of proteolytic systems to remove intracellular oxidized proteins.

\section{Abbreviations}

CAT: Catalase

CPF: Chlorpyrifos

CYP: Cypermethrin

DDT: Dichloro-diphenyl-trichloroethane

ER: $\quad$ Endoplasmic reticulum

Fas-L: $\quad$ Fas ligand

Flt: $\quad$ Fms-related receptor tyrosine kinase 1

GPX: Glutathione peroxidase

GR: $\quad$ Glutathione reductase

GSH: $\quad$ Glutathione

$\mathrm{HCH}: \quad H e x a c h l o r o c y c l o h e x a n e$

$\mathrm{H}_{2} \mathrm{O}_{2}$ : Hydrogen peroxide

HMOX1: Heme oxygenase 1

iNOS: Inducible nitric oxide synthase

JAK: Janus kinases

JNK: c-Jun N-terminal kinases

KD: $\quad$ Knockdown

MAPK: Mitogen-activated protein kinase

MDA: Malondialdehyde

NF- $\kappa$ B: $\quad$ Nuclear factor $\kappa$ B

NO: $\quad$ Nitric oxide

NOX: NADPH oxidase

Nrf2: $\quad$ Nuclear factor-erythroid 2-related factor 2

PER: Permethrin

PKC $\delta$ : Protein kinase $C \delta$

PQ: $\quad$ Paraquat

RNS: $\quad$ Reactive nitrogen species

ROS: Reactive oxygen species

STAT: Signal transducers and activators of transcription

SOD: $\quad$ Superoxide dismutase

TCHQ: Tetrachlorohydroquinone

TBARS: Thiobarbituric acid-reactive substances

TLR: Toll-like receptor

TNF $\alpha$ : Tumor necrosis factor $\alpha$

UPS: Ubiquitin proteasome system.

\section{Data Availability}

All information is from published papers and is summarized in supplemental tables. 


\section{Conflicts of Interest}

All the authors have no competing conflicts of interest.

\section{Acknowledgments}

We would like to thank members of the Gomes Lab for reading and providing suggestions. Partial support was provided by the American Heart Association (AHA) award and the NIEHS/Superfund Research Program (P42 ES004699).

\section{Supplementary Materials}

Supplemental Table 1: tissue toxicity of pesticides. Supplemental Table 2: signaling pathways altered by pesticides. Supplemental Table 3: effects of commonly used conventional pesticide active ingredients in the agricultural market sector in 2012 on oxidative stress in different tissues. Supplemental Table 4: effects of most commonly used organophosphate insecticide active ingredients in the home and in 2012 on oxidative stress in different tissues. Supplemental Table 5: table showing additional pesticides that have been documented to cause oxidative stress in different tissues. Supplemental Table 6: table showing pesticide tolerable and nontoxic concentrations. (Supplementary Materials)

\section{References}

[1] R. Jayaraj, P. Megha, and P. Sreedev, "Review Article. Organochlorine pesticides, their toxic effects on living organisms and their fate in the environment," Interdisciplinary Toxicology, vol. 9, no. 3-4, pp. 90-100, 2016.

[2] N. Georgiadis, K. Tsarouhas, C. Tsitsimpikou et al., "Pesticides and cardiotoxicity. Where do we stand?," Toxicology and Applied Pharmacology, vol. 353, pp. 1-14, 2018.

[3] A. Sharma, V. Kumar, B. Shahzad et al., "Worldwide pesticide usage and its impacts on ecosystem," SN Applied Sciences, vol. 1, no. 11, p. 1446, 2019.

[4] S. Medithi, Y. D. Kasa, B. Jee, V. Kodali, and P. R. Jonnalagadda, "Organophosphate pesticide exposure among farm women and children: Status of micronutrients, acetylcholinesterase activity, and oxidative stress," Archives of Environmental \& Occupational Health, vol. 75, pp. 1-16, 2020.

[5] J. Min, J. Han, K. Kim et al., "Human cholestatic hepatitis owing to polyoxyethylene nonylphenol ingestion," Medicine, vol. 96, no. 32, article e7737, 2017.

[6] C. A. Damalas and I. G. Eleftherohorinos, "Pesticide exposure, safety issues, and risk assessment indicators," International Journal of Environmental Research and Public Health, vol. 8, no. 5, pp. 1402-1419, 2011.

[7] A. L. Wani, A. Ara, and J. A. Usmani, "Lead toxicity: a review," Interdisciplinary Toxicology, vol. 8, no. 2, pp. 5564, 2015.

[8] I. K. Konstantinou, D. G. Hela, and T. A. Albanis, "The status of pesticide pollution in surface waters (rivers and lakes) of Greece. Part I. Review on occurrence and levels," Environmental Pollution, vol. 141, no. 3, pp. 555-570, 2006.

[9] S. Gangemi, E. Gofita, C. Costa et al., "Occupational and environmental exposure to pesticides and cytokine pathways in chronic diseases (Review)," International Journal of Molecular Medicine, vol. 38, no. 4, pp. 1012-1020, 2016.

[10] Reregistration eligibility decision for prometryn, U.S. Environmental Protection Agency, Prevention, Pesticides and Toxic Substances, U.S. Environmental Protection Agency, Washington, D.C., 1996.

[11] G. D. Coronado, S. Holte, E. Vigoren et al., "Organophosphate pesticide exposure and residential proximity to nearby Fields," Journal of Occupational and Environmental Medicine, vol. 53, no. 8, pp. 884-891, 2011.

[12] R. K. Kori, M. K. Singh, A. K. Jain, and R. S. Yadav, "Neurochemical and behavioral dysfunctions in pesticide exposed farm workers: a clinical outcome," Indian Journal of Clinical Biochemistry, vol. 33, no. 4, pp. 372-381, 2018.

[13] A. Sabarwal, K. Kumar, and R. P. Singh, "Hazardous effects of chemical pesticides on human health-Cancer and other associated disorders," Environmental Toxicology and Pharmacology, vol. 63, pp. 103-114, 2018.

[14] I. A. Hundekari, A. N. Suryakar, and D. B. Rathi, "Acute organo-phosphorus pesticide poisoning in North Karnataka, India: oxidative damage, haemoglobin level and total leukocyte," African Health Sciences, vol. 13, no. 1, pp. 129-136, 2013.

[15] H. Xing, Z. Wang, X. Gao et al., "Atrazine and chlorpyrifos exposure induces liver autophagic response in common carp," Ecotoxicology and Environmental Safety, vol. 113, pp. 52-58, 2015.

[16] Q. Liu, L. Wang, H. Chen et al., "Prometryn induces apoptotic cell death through cell cycle arrest and oxidative DNA damage," Toxicology Research, vol. 8, no. 6, pp. 833-841, 2019.

[17] R. C. Gilden, K. Huffling, and B. Sattler, "Pesticides and health risks," Journal of Obstetric, Gynecologic, and Neonatal Nursing, vol. 39, no. 1, pp. 103-110, 2010.

[18] S. Mostafalou and M. Abdollahi, "Pesticides and human chronic diseases: evidences, mechanisms, and perspectives," Toxicology and Applied Pharmacology, vol. 268, no. 2, pp. 157-177, 2013.

[19] A. D. Souza, A. . R. Medeiros, A. C. . Souza et al., "Avaliação do impacto da exposição a agrotóxicos sobre a saúde de população rural: Vale do Taquari (RS Brasil)," Ciência \& Saúde Coletiva, vol. 16, no. 8, pp. 3519-3528, 2011.

[20] V. Hajhashemi, G. Vaseghi, M. Pourfarzam, and A. Abdollahi, "Are antioxidants helpful for disease prevention?," Research in Pharmaceutical Sciences, vol. 5, no. 1, pp. 1-8, 2010.

[21] J. Chen, Y. Su, F. Lin et al., "Effect of paraquat on cytotoxicity involved in oxidative stress and inflammatory reaction: a review of mechanisms and ecological implications," Ecotoxicology and Environmental Safety, vol. 224, article 112711, 2021.

[22] Q. Li, X. Yang, N. Sreejayan, and J. Ren, "Insulin-like growth factor I deficiency prolongs survival and antagonizes paraquat-induced cardiomyocyte dysfunction: role of oxidative stress," Rejuvenation Research, vol. 10, no. 4, pp. 501512, 2007.

[23] W. Ge, Y. Zhang, X. Han, and J. Ren, "Cardiac-specific overexpression of catalase attenuates paraquat-induced myocardial geometric and contractile alteration: role of ER stress," Free Radical Biology \& Medicine, vol. 49, no. 12, pp. 20682077, 2010. 
[24] B. A. Cohn, M. S. Wolff, P. M. Cirillo, and R. I. Sholtz, "DDT and breast cancer in young women: new data on the significance of age at exposure," Environmental Health Perspectives, vol. 115, no. 10, pp. 1406-1414, 2007.

[25] K. A. McGlynn, C. C. Abnet, M. Zhang et al., "Serum concentrations of 1,1,1-trichloro-2,2-bis(p-chlorophenyl)ethane (DDT) and 1,1-dichloro-2,2-bis(p-chlorophenyl)ethylene (DDE) and risk of primary liver cancer," Journal of the National Cancer Institute, vol. 98, no. 14, pp. 1005-1010, 2006.

[26] K. A. McGlynn, S. M. Quraishi, B. I. Graubard, J. P. Weber, M. V. Rubertone, and R. L. Erickson, "Persistent organochlorine pesticides and risk of testicular germ cell tumors," Journal of the National Cancer Institute, vol. 100, no. 9, pp. 663-671, 2008.

[27] A. R. Ravula and S. Yenugu, "Pyrethroid based pesticides chemical and biological aspects," Critical Reviews in Toxicology, vol. 51, no. 2, pp. 117-140, 2021.

[28] R. Li, Z. Jia, and M. A. Trush, "Defining ROS in biology and medicine," Reactive oxygen species, vol. 1, no. 1, pp. 9-21, 2016.

[29] A. V. Snezhkina, A. V. Kudryavtseva, O. L. Kardymon et al., "ROS generation and antioxidant defense systems in normal and malignant cells," Oxidative Medicine and Cellular Longevity, vol. 2019, Article ID 6175804, 17 pages, 2019.

[30] M. Schieber and N. S. Chandel, "ROS function in redox signaling and oxidative stress," Current Biology: CB, vol. 24, no. 10, pp. R453-R462, 2014.

[31] T. Finkel, "Signal transduction by reactive oxygen species," The Journal of Cell Biology, vol. 194, no. 1, pp. 7-15, 2011.

[32] J. Mele, H. V. Remmen, J. Vijg, and A. Richardson, "Characterization of transgenic mice that overexpress both copper zinc superoxide dismutase and catalase," Antioxidants \& Redox Signaling, vol. 8, no. 3-4, pp. 628-638, 2006.

[33] B. Halliwell and J. M. Gutteridge, "Role of free radicals and catalytic metal ions in human disease: an overview," Methods in Enzymology, vol. 186, pp. 1-85, 1990.

[34] J. Shi, B. Sun, W. Shi et al., "Decreasing GSH and increasing ROS in chemosensitivity gliomas with IDH1 mutation," Tumour Biology, vol. 36, no. 2, pp. 655-662, 2015.

[35] A. Alhasawi, F. Legendre, S. Jagadeesan, V. Appanna, and V. Appanna, "Chapter 10 - biochemical strategies to counter nitrosative stress: nanofactories for value-added products," in Microbial Diversity in the Genomic Era, S. Das and H. R. Dash, Eds., pp. 153-169, Academic Press, 2019.

[36] C. Auger, J. Lemire, D. Cecchini, A. Bignucolo, and V. D. Appanna, "The metabolic reprogramming evoked by nitrosative stress triggers the anaerobic utilization of citrate in Pseudomonas fluorescens," PLoS One, vol. 6, no. 12, article e28469, 2011.

[37] M. C. Martínez and R. Andriantsitohaina, "Reactive nitrogen species: molecular mechanisms and potential significance in health and disease," Antioxidants \& Redox Signaling, vol. 11, no. 3, pp. 669-702, 2009.

[38] C. Vittorio, R. Sultana, G. Scapagnini et al., "Nitrosative stress, cellular stress response, and thiol homeostasis in patients with Alzheimer's disease," Antioxidants \& Redox Signaling, vol. 8, no. 11-12, pp. 1975-1986, 2006.

[39] T. P. Brown, P. C. Rumsby, A. C. Capleton, L. Rushton, and L. S. Levy, "Pesticides and Parkinson's disease-is there a link?," Environmental Health Perspectives, vol. 114, no. 2, pp. 156-164, 2006.

[40] X. Wang, M. A. Martínez, M. Dai et al., "Permethrin-induced oxidative stress and toxicity and metabolism. A review," Environmental Research, vol. 149, pp. 86-104, 2016.

[41] Y. Fu, H. Sies, and X. G. Lei, "Opposite roles of seleniumdependent glutathione peroxidase-1 in superoxide generator diquat- and peroxynitrite-induced apoptosis and signaling," The Journal of Biological Chemistry, vol. 276, no. 46, pp. 43004-43009, 2001.

[42] Y. Jin, R. Chen, W. Liu, and Z. Fu, "Effect of endocrine disrupting chemicals on the transcription of genes related to the innate immune system in the early developmental stage of zebrafish (Danio rerio)," Fish \& Shellfish Immunology, vol. 28, no. 5-6, pp. 854-861, 2010.

[43] D. Fedeli, M. Carloni, C. Nasuti, A. Gambini, V. Scocco, and R. Gabbianelli, "Early life permethrin exposure leads to hypervitaminosis D, nitric oxide and catecholamines impairment," Pesticide Biochemistry and Physiology, vol. 107, no. 1, pp. 93-97, 2013.

[44] O. K. Afolabi, F. A. Aderibigbe, D. T. Folarin, A. Arinola, and A. D. Wusu, "Oxidative stress and inflammation following sub-lethal oral exposure of cypermethrin in rats: mitigating potential of epicatechin," Heliyon, vol. 5, no. 8, article e02274, 2019.

[45] D. A. Drechsel and M. Patel, "Role of reactive oxygen species in the neurotoxicity of environmental agents implicated in Parkinson's disease," Free Radical Biology \& Medicine, vol. 44, no. 11, pp. 1873-1886, 2008.

[46] Y. Hiraku, "Formation of 8-nitroguanine, a nitrative DNA lesion, in inflammation-related carcinogenesis and its significance," Environmental Health and Preventive Medicine, vol. 15, no. 2, pp. 63-72, 2010.

[47] S. Pinlaor, B. Sripa, N. Ma et al., "Nitrative and oxidative DNA damage in intrahepatic cholangiocarcinoma patients in relation to tumor invasion," World Journal of Gastroenterology, vol. 11, no. 30, pp. 4644-4649, 2005.

[48] M. Amizadeh, M. Safari-Kamalabadi, G. Askari-Saryazdi, M. Amizadeh, and H. Reihani-Kermani, "Pesticide exposure and head and neck cancers: a case-control study in an agricultural region," Iranian Journal of Otorhinolaryngology, vol. 29, no. 94, pp. 275-285, 2017.

[49] M. C. Alavanja, M. K. Ross, and M. R. Bonner, "Increased cancer burden among pesticide applicators and others due to pesticide exposure," CA: a Cancer Journal for Clinicians, vol. 63, no. 2, pp. 120-142, 2013.

[50] S. C. Cortés-Iza and A. I. Rodríguez, "Oxidative stress and pesticide disease: a challenge for toxicology," Revista de la Facultad de Medicina, vol. 66, pp. 261-267, 2018.

[51] A. Ranjbar, P. Pasalar, A. Sedighi, and M. Abdollahi, "Induction of oxidative stress in paraquat formulating workers," Toxicology Letters, vol. 131, no. 3, pp. 191-194, 2002.

[52] A. Prakasam, S. Sethupathy, and S. Lalitha, "Plasma and RBCs antioxidant status in occupational male pesticide sprayers," Clinica Chimica Acta, vol. 310, no. 2, pp. 107112, 2001.

[53] P. D. Dwivedi, M. Das, and S. K. Khanna, "Role of cytochrome P-450 in quinalphos toxicity: effect on hepatic and brain antioxidant enzymes in ratsITRC communication no," Food and Chemical Toxicology, vol. 36, no. 5, pp. 437444, 1998. 
[54] Chlorpyrifos Facts 2002, Environmental Protection Agency, 2002, EPA 738-F-01-006.

[55] J. Noworyta-Glowacka, M. Beresinska, R. Bankowski, B. Wiadrowska, J. Siennicka, and J. K. Ludwicki, "Effect of chlorpyrifos on the profile of subpopulations immunocompetent cells B, T and NK in in vivo model," Roczniki Panstwowego Zakladu Higieny, vol. 65, no. 4, pp. 311-316, 2014.

[56] I. H. Jung, J. H. K. Choi, Y. Y. Chung, G. L. Lim, Y. N. Park, and S. W. Park, "Predominant Activation of JAK/STAT3 Pathway by Interleukin-6 Is Implicated in Hepatocarcinogenesis," Neoplasia, vol. 17, no. 7, pp. 586-597, 2015.

[57] B. K. Binukumar, A. Bal, and K. D. Gill, "Chronic dichlorvos exposure: microglial activation, proinflammatory cytokines and damage to nigrostriatal dopaminergic system," Neuromolecular Medicine, vol. 13, no. 4, pp. 251-265, 2011.

[58] N. Soundararajan, D. Mohan, R. Abbu, and T. Devasena, "Evaluation of cytotoxicity, oxidative stress, nuclear changes and pro-inflammatory cytokines induced by monocrotophos in human keratinocyte cells in vitro," International Journal of Pharmacy and Pharmaceutical Sciences, vol. 7, no. 1, 2014.

[59] S. Ayub, J. Verma, and N. Das, "Effect of endosulfan and malathion on lipid peroxidation, nitrite and TNF-alpha release by rat peritoneal macrophages," International Immunopharmacology, vol. 3, no. 13-14, pp. 1819-1828, 2003.

[60] Y. Yurumez, M. Cemek, Y. Yavuz, Y. O. Birdane, and M. E. Buyukokuroglu, "Beneficial effect of $\mathrm{N}$-acetylcysteine against organophosphate toxicity in mice," Biological \& Pharmaceutical Bulletin, vol. 30, no. 3, pp. 490-494, 2007.

[61] A. T. Hariri, S. A. Moallem, M. Mahmoudi, B. Memar, and H. Hosseinzadeh, "Sub-acute effects of diazinon on biochemical indices and specific biomarkers in rats: protective effects of crocin and safranal," Food and Chemical Toxicology, vol. 48, no. 10, pp. 2803-2808, 2010.

[62] N. Magalhães, F. Carvalho, and R. J. Dinis-Oliveira, "Human and experimental toxicology of diquat poisoning: Toxicokinetics, mechanisms of toxicity, clinical features, and treatment," Human \& Experimental Toxicology, vol. 37, no. 11, pp. 1131-1160, 2018.

[63] C. Uchendu, S. F. Ambali, J. O. Ayo, and K. A. N. Esievo, "Chronic co-exposure to chlorpyrifos and deltamethrin pesticides induces alterations in serum lipids and oxidative stress in Wistar rats: mitigating role of alpha-lipoic acid," Environmental Science and Pollution Research, vol. 25, no. 20, pp. 19605-19611, 2018.

[64] A. Ojha and Y. K. Gupta, "Evaluation of genotoxic potential of commonly used organophosphate pesticides in peripheral blood lymphocytes of rats," Human \& Experimental Toxicology, vol. 34, no. 4, pp. 390-400, 2015.

[65] X. Lu and C. Yu, "Enantiomer-specific profenofos-induced cytotoxicity and DNA damage mediated by oxidative stress in rat adrenal pheochromocytoma (PC12) cells," Journal of Applied Toxicology, vol. 34, no. 2, pp. 166-175, 2014.

[66] M. E. M. Nunes, L. E. Schimith, D. G. da Costa-Silva et al., "Acute exposure to permethrin modulates behavioral functions, redox, and bioenergetics parameters and induces DNA damage and cell death in larval zebrafish," Oxidative Medicine and Cellular Longevity, vol. 2019, Article ID 9149203, 19 pages, 2019.

[67] L. P. Naeher, D. B. Barr, N. Rithmire et al., "Pesticide exposure resulting from treatment of lice infestation in schoolaged children in Georgia," Environment International, vol. 35, no. 2, pp. 358-362, 2009.
[68] A. Mokarizadeh, M. R. Faryabi, M. A. Rezvanfar, and M. Abdollahi, "A comprehensive review of pesticides and the immune dysregulation: mechanisms, evidence and consequences," Toxicology Mechanisms and Methods, vol. 25, no. 4, pp. 258-278, 2015.

[69] R. Gabbianelli, M. L. Falcioni, C. Nasuti, F. Cantalamessa, I. Imada, and M. Inoue, "Effect of permethrin insecticide on rat polymorphonuclear neutrophils," Chemico-Biological Interactions, vol. 182, no. 2-3, pp. 245-252, 2009.

[70] M. D. P. Navarrete-Meneses and P. Pérez-Vera, "Pyrethroid pesticide exposure and hematological cancer: epidemiological, biological and molecular evidence," Reviews on Environmental Health, vol. 34, no. 2, pp. 197-210, 2019.

[71] M. W. Aktar, D. Sengupta, and A. Chowdhury, "Impact of pesticides use in agriculture: their benefits and hazards," Interdisciplinary Toxicology, vol. 2, no. 1, pp. 1-12, 2009.

[72] M. Kitazawa, V. Anantharam, and A. G. Kanthasamy, "Dieldrin induces apoptosis by promoting caspase-3-dependent proteolytic cleavage of protein kinase Cdelta in dopaminergic cells: relevance to oxidative stress and dopaminergic degeneration," Neuroscience, vol. 119, no. 4, pp. 945-964, 2003.

[73] R. Subbiah and R. R. Tiwari, "The herbicide paraquatinduced molecular mechanisms in the development of acute lung injury and lung fibrosis," Critical Reviews in Toxicology, vol. 51, no. 1, pp. 36-64, 2021.

[74] S. Wang, R. Guo, and J. Ren, "Stress signaling in paraquatinduced target organ toxicity," Reactive Oxygen Species, vol. 1, no. 2, pp. 131-140, 2016.

[75] E. L. Robb, J. M. Gawel, D. Aksentijević et al., "Selective superoxide generation within mitochondria by the targeted redox cycler mitoparaquat," Free Radical Biology \& Medicine, vol. 89, pp. 883-894, 2015.

[76] B. J. Day, M. Patel, L. Calavetta, L. Y. Chang, and J. S. Stamler, "A mechanism of paraquat toxicity involving nitric oxide synthase," Proceedings of the National Academy of Sciences of the United States of America, vol. 96, no. 22, pp. 12760$12765,1999$.

[77] A. C. Cristóvão, D. H. Choi, G. Baltazar, M. F. Beal, and Y. S. Kim, "The role of NADPH oxidase 1-derived reactive oxygen species in paraquat-mediated dopaminergic cell death," Antioxidants \& Redox Signaling, vol. 11, no. 9, pp. 2105-2118, 2009.

[78] T. Taetzsch and M. L. Block, "Pesticides, microglial NOX2, and Parkinson's disease," Journal of Biochemical and Molecular Toxicology, vol. 27, no. 2, pp. 137-149, 2013.

[79] P. R. Castello, D. A. Drechsel, and M. Patel, "Mitochondria are a major source of paraquat-induced reactive oxygen species production in the brain," The Journal of Biological Chemistry, vol. 282, no. 19, pp. 14186-14193, 2007.

[80] N. Singh, V. Lawana, J. Luo et al., "Organophosphate pesticide chlorpyrifos impairs STAT1 signaling to induce dopaminergic neurotoxicity: Implications for mitochondria mediated oxidative stress signaling events," Neurobiology of Disease, vol. 117, pp. 82-113, 2018.

[81] H. S. Kim and M. S. Lee, "STAT1 as a key modulator of cell death," Cellular Signalling, vol. 19, no. 3, pp. 454-465, 2007.

[82] M. Skonieczna, T. Hejmo, A. Poterala-Hejmo, A. CieslarPobuda, and R. J. Buldak, "NADPH oxidases: insights into selected functions and mechanisms of action in cancer and stem cells," Oxidative Medicine and Cellular Longevity, vol. 2017, Article ID 9420539, 15 pages, 2017. 
[83] X.-J. Fu, Y. B. Peng, Y. P. Hu, Y. Z. Shi, M. Yao, and X. Zhang, "NADPH oxidase 1 and its derived reactive oxygen species mediated tissue injury and repair," Oxidative Medicine and Cellular Longevity, vol. 2014, Article ID 282854, 10 pages, 2014.

[84] L. C. Mangum, A. Borazjani, J. V. Stokes et al., "Organochlorine insecticides induce NADPH oxidase-dependent reactive oxygen species in human monocytic cells via phospholipase A2/arachidonic acid," Chemical Research in Toxicology, vol. 28, no. 4, pp. 570-584, 2015.

[85] J. L. Munoz-Carrillo, J. F. Contreras-Cordero, O. GutiérrezCoronado, P. T. Villalobos-Gutiérrez, L. G. Ramos-Gracia, and V. E. Hernández-Reyes, Cytokine Profiling Plays a Crucial Role in Activating Immune System to Clear Infectious Pathogens, 2019.

[86] F. J. Pacheco, F. G. Almaguel, W. Evans et al., "Docosahexanoic acid antagonizes TNF- $\alpha$-induced necroptosis by attenuating oxidative stress, ceramide production, lysosomal dysfunction, and autophagic features," Inflammation Research : Official Journal of the European Histamine Research Society, vol. 63, no. 10, pp. 859-871, 2014.

[87] D. C. de Oliveira, A. A. Hastreiter, A. S. Mello et al., "The effects of protein malnutrition on the TNF-RI and NF- $\kappa \mathrm{B}$ expression via the TNF- $\alpha$ signaling pathway," Cytokine, vol. 69, no. 2, pp. 218-225, 2014.

[88] C. Sullivan and C. H. Kim, "Zebrafish as a model for infectious disease and immune function," Fish \& Shellfish Immunology, vol. 25, no. 4, pp. 341-350, 2008.

[89] V. Tyagi, M. D. Mustafa, T. Sharma et al., "Association of organochlorine pesticides with the mRNA expression of tumour necrosis factor-alpha (TNF- $\alpha$ ) \& cyclooxygenase-2 (COX-2) genes in idiopathic preterm birth," The Indian Journal of Medical Research, vol. 143, no. 6, pp. 731-738, 2016.

[90] M. Decressac, N. Volakakis, A. Björklund, and T. Perlmann, "NURR1 in Parkinson disease-from pathogenesis to therapeutic potential," Nature Reviews. Neurology, vol. 9, no. 11, pp. 629-636, 2013.

[91] M. Carloni, C. Nasuti, D. Fedeli et al., "Early life permethrin exposure induces long-term brain changes in Nurr1, NF-kB and Nrf-2," Brain Research, vol. 1515, pp. 19-28, 2013.

[92] D. Fedeli, M. Montani, M. Carloni, C. Nasuti, A. Amici, and R. Gabbianelli, "Leukocyte Nurr1 as peripheral biomarker of early-life environmental exposure to permethrin insecticide," Biomarkers, vol. 17, no. 7, pp. 604-609, 2012.

[93] M. E. Reyland, "Protein kinase C isoforms: Multi-functional regulators of cell life and death," Frontiers in Bioscience (Landmark Edition), vol. 14, pp. 2386-2399, 2009.

[94] H. Mellor and P. J. Parker, "The extended protein kinase C superfamily," The Biochemical Journal, vol. 332, Part 2, pp. 281-292, 1998.

[95] P. E. Rosenfeld and L. G. H. Feng, "11 - Pesticides," in Risks of Hazardous Wastes, P. E. Rosenfeld and L. G. H. Feng, Eds., pp. 127-154, William Andrew Publishing, Boston, 2011.

[96] B. Ritz and F. Yu, "Parkinson's disease mortality and pesticide exposure in California 1984-1994," International Journal of Epidemiology, vol. 29, no. 2, pp. 323-329, 2000.

[97] Z. Jia and H. P. Misra, "Exposure to mixtures of endosulfan and zineb induces apoptotic and necrotic cell death in SHSY5Y neuroblastoma cells, in vitro," Journal of Applied Toxicology, vol. 27, no. 5, pp. 434-446, 2007.
[98] D. R. Green and J. C. Reed, "Mitochondria and apoptosis," Science, vol. 281, no. 5381, pp. 1309-1312, 1998.

[99] A. Ashkenazi and V. M. Dixit, "Death receptors: signaling and modulation," Science, vol. 281, no. 5381, pp. 13051308, 1998.

[100] G. P. Das, A. P. Shaik, and K. Jamil, "Estimation of apoptosis and necrosis caused by pesticides in vitro on human lymphocytes using DNA diffusion assay," Drug and Chemical Toxicology, vol. 29, no. 2, pp. 147-156, 2006.

[101] G. Raszewski, M. K. Lemieszek, K. Łukawski, M. Juszczak, and W. Rzeski, "Chlorpyrifos and cypermethrin induce apoptosis in human neuroblastoma cell line SH-SY5Y," Basic \& Clinical Pharmacology \& Toxicology, vol. 116, no. 2, pp. 158-167, 2015.

[102] R. Venkatesan, Y. U. Park, E. Ji, E. J. Yeo, and S. Y. Kim, "Malathion increases apoptotic cell death by inducing lysosomal membrane permeabilization in N2a neuroblastoma cells: a model for neurodegeneration in Alzheimer's disease," Cell death discover, vol. 3, no. 1, p. 17007, 2017.

[103] C. Yang, W. Lim, and G. Song, "Mediation of oxidative stress toxicity induced by pyrethroid pesticides in fish," Comparative Biochemistry and Physiology, Part C: Toxicology \& Pharmacology, vol. 234, article 108758, 2020.

[104] M. T. Islam, "Oxidative stress and mitochondrial dysfunction-linked neurodegenerative disorders," Neurological Research, vol. 39, no. 1, pp. 73-82, 2017.

[105] T. B. Sherer, J. R. Richardson, C. M. Testa et al., "Mechanism of toxicity of pesticides acting at complex I: relevance to environmental etiologies of Parkinson's disease," Journal of Neurochemistry, vol. 100, no. 6, 2007.

[106] A. H. Bhat, K. B. Dar, S. Anees et al., "Oxidative stress, mitochondrial dysfunction and neurodegenerative diseases; a mechanistic insight," Biomedicine \& Pharmacotherapy, vol. 74, pp. 101-110, 2015.

[107] J. D. Malhotra and R. J. Kaufman, "ER stress and its functional link to mitochondria: role in cell survival and death," Cold Spring Harbor Perspectives in Biology, vol. 3, no. 9, article a004424, 2011.

[108] H.-M. Chen, Y.-H. Lee, and Y.-J. Wang, "ROS-triggered signaling pathways involved in the cytotoxicity and tumor promotion effects of pentachlorophenol and tetrachlorohydroquinone," Chemical Research in Toxicology, vol. 28, no. 3, pp. 339-350, 2015.

[109] C. Pellacani and L. G. Costa, "Role of autophagy in environmental neurotoxicity," Environmental Pollution, vol. 235, pp. 791-805, 2018.

[110] C. Rodolfo, S. Di Bartolomeo, and F. Cecconi, "Autophagy in stem and progenitor cells," Cellular and Molecular Life Sciences, vol. 73, no. 3, pp. 475-496, 2016.

[111] J. H. Park, J. E. Lee, I. C. Shin, and H. C. Koh, "Autophagy regulates chlorpyrifos-induced apoptosis in SH-SY5Y cells," Toxicology and Applied Pharmacology, vol. 268, no. 1, pp. 55-67, 2013.

[112] H. Dai, Y. Deng, J. Zhang et al., "PINK1/Parkin-mediated mitophagy alleviates chlorpyrifos-induced apoptosis in $\mathrm{SH}$ SY5Y cells," Toxicology, vol. 334, pp. 72-80, 2015.

[113] J. H. Park, J. E. Lee, S. J. Lee et al., "Potential autophagy enhancers protect against fipronil-induced apoptosis in $\mathrm{SH}$ SY5Y cells," Toxicology Letters, vol. 223, no. 1, pp. 25-34, 2013.

[114] S. Wang, X. Zhu, L. Xiong, Y. Zhang, and J. Ren, “Toll-like receptor 4 knockout alleviates paraquat-induced 
cardiomyocyte contractile dysfunction through an autophagy-dependent mechanism," Toxicology Letters, vol. 257, pp. 11-22, 2016.

[115] Q. Zhou, H. Zhang, Q. Wu, J. Shi, and S. Zhou, "Pharmacological manipulations of autophagy modulate paraquatinduced cytotoxicity in PC12 cells," International Journal of Biochemistry and Molecular Biology, vol. 8, no. 2, pp. 13-22, 2017.

[116] Y. Jie, R. Wenkai, W. Xiaosong et al., "Oxidative stressmediated signaling pathways: A Review," Journal of Food, Agriculture \& Environment, vol. 11, no. 2, pp. 132-139, 2013.

[117] M. Cargnello and P. P. Roux, "Activation and function of the MAPKs and their substrates, the MAPK-activated protein kinases," Microbiology and Molecular Biology Reviews: $M M B R$, vol. 75, no. 1, pp. 50-83, 2011.

[118] U.S. Environmental Protection Agency, "Reregistration eligibility decision for pentachlorophenol," in Prevention, Pesticides and Toxic Substances, U.S. Environmental Protection Agency, Washington, DC, 2008.

[119] J. J. Morrell, "Chapter 17 - Protection of Wood-Based Materials," in Handbook of Environmental Degradation of Materials (Third Edition), M. Kutz, Ed., pp. 343-368, William Andrew Publishing, 2018.

[120] N. Maheshwari and R. Mahmood, "Protective effect of catechin on pentachlorophenol-induced cytotoxicity and genotoxicity in isolated human blood cells," Environmental Science and Pollution Research, vol. 27, no. 12, pp. 1382613843, 2020.

[121] "NTP toxicology and carcinogenesis studies of two pentachlorophenol technical-grade mixtures (CAS no. 87-86-5) in B6C3F1 mice (feed studies)," National Toxicology Program Technical Report Series, vol. 349, pp. 1-265, 1989.

[122] P. G. Jorens and P. J. C. Schepens, "Human pentachlorophenol poisoning," Human \& Experimental Toxicology, vol. 12, no. 6, pp. 479-495, 1993.

[123] B. Wispriyono, M. Matsuoka, and H. Igisu, "Effects of pentachlorophenol and tetrachlorohydroquinone on mitogen-activated protein kinase pathways in Jurkat $\mathrm{T}$ cells," Environmental Health Perspectives, vol. 110, no. 2, pp. 139-143, 2002.

[124] C. Ventura, A. Venturino, N. Miret et al., "Chlorpyrifos inhibits cell proliferation through ERK1/2 phosphorylation in breast cancer cell lines," Chemosphere, vol. 120, pp. 343350, 2015.

[125] S. Shiizaki, I. Naguro, and H. Ichijo, "Activation mechanisms of ASK1 in response to various stresses and its significance in intracellular signaling," Advances in Biological Regulation, vol. 53, no. 1, pp. 135-144, 2013.

[126] D. N. Meijles, J. J. Cull, T. Markou et al., "Redox regulation of cardiac ASK1 (apoptosis signal-regulating kinase 1) controls p38-MAPK (mitogen-activated protein kinase) and orchestrates cardiac remodeling to hypertension," Hypertension, vol. 76, no. 4, pp. 1208-1218, 2020.

[127] M. Niso-Santano, J. M. Bravo-San Pedro, R. Gómez-Sánchez et al., "ASK1 overexpression accelerates paraquat-induced autophagy via endoplasmic reticulum stress," Toxicological Sciences, vol. 119, no. 1, pp. 156-168, 2011.

[128] E. Kansanen, S. M. Kuosmanen, H. Leinonen, and A. L. Levonen, "The Keap1-Nrf2 pathway: Mechanisms of activation and dysregulation in cancer," Redox Biology, vol. 1, no. 1, pp. $45-49,2013$.
[129] F. Zheng, F. M. Gonçalves, Y. Abiko, H. Li, Y. Kumagai, and M. Aschner, "Redox toxicology of environmental chemicals causing oxidative stress," Redox Biology, vol. 34, article 101475,2020

[130] S. E. Purdom-Dickinson, E. V. Sheveleva, H. Sun, and Q. M. Chen, "Translational control of nrf2 protein in activation of antioxidant response by oxidants," Molecular Pharmacology, vol. 72, no. 4, pp. 1074-1081, 2007.

[131] K. Chan, X.-D. Han, and Y. W. Kan, “An important function of Nrf2 in combating oxidative stress: Detoxification of acetaminophen," Proceedings of the National Academy of Sciences, vol. 98, no. 8, pp. 4611-4616, 2001.

[132] M. Ramos-Gomez, M. K. Kwak, P. M. Dolan et al., "Sensitivity to carcinogenesis is increased and chemoprotective efficacy of enzyme inducers is lost in nrf2 transcription factor-deficient mice," Proceedings of the National Academy of Sciences of the United States of America, vol. 98, no. 6, pp. 3410-3415, 2001.

[133] X. Yuan, C. Xu, Z. Pan et al., "Butylated hydroxyanisole regulates ARE-mediated gene expression via Nrf2 coupled with ERK and JNK signaling pathway in HepG2 cells," Molecular Carcinogenesis, vol. 45, no. 11, pp. 841-850, 2006.

[134] M. S. Dhivya Vadhana, S. Siva Arumugam, M. Carloni, C. Nasuti, and R. Gabbianelli, "Early life permethrin treatment leads to long-term cardiotoxicity," Chemosphere, vol. 93, no. 6, pp. 1029-1034, 2013.

[135] T. Dou, M. Yan, X. Wang et al., "Nrf2/ARE pathway involved in oxidative stress induced by paraquat in human neural progenitor cells," Oxidative Medicine and Cellular Longevity, vol. 2016, Article ID 8923860, 8 pages, 2016.

[136] H. Y. Li, S. Y. Wu, Q. Ma, and N. Shi, “The pesticide deltamethrin increases free radical production and promotes nuclear translocation of the stress response transcription factor Nrf2 in rat brain," Toxicology and Industrial Health, vol. 27, no. 7, pp. 579-590, 2011.

[137] W. T. Thomson, "Agricultural Chemicals," in Book I, Thomson Publications, Fresno, CA, 1992.

[138] Organization, WH, World Malaria Report 2015, World Health Organization, 2016.

[139] A. G. Kanthasamy, M. Kitazawa, A. Kanthasamy, and V. Anantharam, "Dieldrin-Induced Neurotoxicity: Relevance to Parkinson's Disease Pathogenesis," Neurotoxicology, vol. 26, no. 4, pp. 701-719, 2005.

[140] B. Çiğ and M. Nazıroğlu, "Investigation of the effects of distance from sources on apoptosis, oxidative stress and cytosolic calcium accumulation via TRPV1 channels induced by mobile phones and Wi-Fi in breast cancer cells," Biochimica et Biophysica Acta (BBA)-Biomembranes, vol. 1848, no. 10 Part B, pp. 2756-2765, 2015.

[141] R. H. Westerink, "Modulation of cell viability, oxidative stress, calcium homeostasis, and voltage- and ligand-gated ion channels as common mechanisms of action of (mixtures of) non-dioxin-like polychlorinated biphenyls and polybrominated diphenyl ethers," Environmental Science and Pollution Research International, vol. 21, no. 10, pp. 6373-6383, 2014.

[142] A. Saad-Hussein, K. S. Ibrahim, M. S. Abdalla, H. A. el-Mezayen, and N. F. A. Osman, "Effects of zinc supplementation on oxidant/antioxidant and lipids status of pesticides sprayers," Journal of Complementary and Integrative Medicine, vol. 17, no. 1, 2019. 
[143] N. S. el-Shenawy, F. el-Salmy, R. A. al-Eisa, and B. el-Ahmary, "Amelioratory effect of vitamin E on organophosphorus insecticide diazinon- induced oxidative stress in mice liver," Pesticide Biochemistry and Physiology, vol. 96, no. 2, pp. 101-107, 2010.

[144] I. Ben Amara, N. Soudani, A. Troudi, H. Bouaziz, T. Boudawara, and N. Zeghal, "Antioxidant effect of vitamin $\mathrm{E}$ and selenium on hepatotoxicity induced by dimethoate in female adult rats," Ecotoxicology and Environmental Safety, vol. 74, no. 4, pp. 811-819, 2011.

[145] S. M. Abou-Zeid, "Ameliorating effects of green tea on ethephon-induced immunotoxicity and oxidative stress in mice," International Journal of Pharma Sciences and Scientific Research, vol. 4, no. 1, pp. 1-9, 2018.

[146] S. John, M. Kale, N. Rathore, and D. Bhatnagar, "Protective effect of vitamin $\mathrm{E}$ in dimethoate and malathion induced oxidative stress in rat erythrocytes," The Journal of Nutritional Biochemistry, vol. 12, no. 9, pp. 500-504, 2001.

[147] K. S. el-Gendy, N. M. Aly, F. H. Mahmoud, A. Kenawy, and A. K. H. el-Sebae, "The role of vitamin C as antioxidant in protection of oxidative stress induced by imidacloprid," Food and Chemical Toxicology, vol. 48, no. 1, pp. 215-221, 2010.

[148] D. K. Rai, P. K. Rai, S. I. Rizvi, G. Watal, and B. Sharma, "Carbofuran-induced toxicity in rats: protective role of vitamin C," Experimental and Toxicologic Pathology, vol. 61, no. 6, pp. 531-535, 2009.

[149] S. K. Jaiswal, N. J. Siddiqi, and B. Sharma, "Carbofuran induced oxidative stress in rat heart: ameliorative effect of vitamin C," ISRN Oxidative Medicine, vol. 2013, Article ID 824102, 10 pages, 2013.

[150] N. Aly, K. el-Gendy, F. Mahmoud, and A. K. el-Sebae, "Protective effect of vitamin $C$ against chlorpyrifos oxidative stress in male mice," Pesticide Biochemistry and Physiology, vol. 97, no. 1, pp. 7-12, 2010.

[151] C. Otuechere, S. O. Abarikwu, M. A. Rufai, A. E. Ohiozoje, E. Martins, and E. O. Farombi, "Protective effects of vitamin C against propanil-induced hepatotoxicity in Wistar rats," Asian Pacific Journal of Tropical Disease, vol. 2, pp. S212S217, 2012.

[152] T. Yavuz, N. Delibas, B. Yildirim et al., "Vascular wall damage in rats induced by methidathion and ameliorating effect of vitamins E and C," Archives of Toxicology, vol. 78, no. 11, pp. 655-659, 2004.

[153] M. I. Yousef, T. I. Awad, and E. H. Mohamed, "Deltamethrininduced oxidative damage and biochemical alterations in rat and its attenuation by vitamin E," Toxicology, vol. 227, no. 3, pp. 240-247, 2006.

[154] M. Singh, R. Sandhir, and R. Kiran, "Effects on antioxidant status of liver following atrazine exposure and its attenuation by vitamin E," Experimental and Toxicologic Pathology, vol. 63, no. 3, pp. 269-276, 2011.

[155] M. Singh, R. Sandhir, and R. Kiran, "Oxidative stress induced by atrazine in rat erythrocytes: Mitigating effect of vitamin E," Toxicology Mechanisms and Methods, vol. 20, no. 3, pp. 119-126, 2010.

[156] S. A. Mansour and A.-T. H. Mossa, "Lipid peroxidation and oxidative stress in rat erythrocytes induced by chlorpyrifos and the protective effect of zinc," Pesticide Biochemistry and Physiology, vol. 93, no. 1, pp. 34-39, 2009.

[157] S. A. Mansour and A.-T. H. Mossa, "Oxidative damage, biochemical and histopathological alterations in rats exposed to chlorpyrifos and the antioxidant role of zinc," Pesticide Biochemistry and Physiology, vol. 96, no. 1, pp. 14-23, 2010.

[158] A. Goel, V. Dani, and D. K. Dhawan, "Protective effects of zinc on lipid peroxidation, antioxidant enzymes and hepatic histoarchitecture in chlorpyrifos-induced toxicity," Chemico-Biological Interactions, vol. 156, no. 2, pp. 131-140, 2005.

[159] V. Mokhtari, P. Afsharian, M. Shahhoseini, S. M. Kalantar, and A. Moini, "A review on various uses of $\mathrm{N}$-acetyl cysteine," Cell Journal, vol. 19, no. 1, pp. 11-17, 2017.

[160] J.-D. Yang, S. H. Liu, M. H. Liao, R. M. Chen, P. Y. Liu, and T. H. Ueng, "Effects of tebuconazole on cytochrome P450 enzymes, oxidative stress, and endocrine disruption in male rats," Environmental Toxicology, vol. 33, no. 8, pp. 899-907, 2018.

[161] Y. Ben Othmène, K. Monceaux, A. Karoui et al., “Tebuconazole induces ROS-dependent cardiac cell toxicity by activating DNA damage and mitochondrial apoptotic pathway," Ecotoxicology and Environmental Safety, vol. 204, article 111040, 2020.

[162] J. Dorval and A. Hontela, "Role of glutathione redox cycle and catalase in defense against oxidative stress induced by endosulfan in adrenocortical cells of rainbow trout (Oncorhynchus mykiss)," Toxicology and Applied Pharmacology, vol. 192, no. 2, pp. 191-200, 2003.

[163] I. Cankayali, K. Demirag, O. Eris, B. Ersoz, and A. R. Moral, "The effects ofN-acetylcysteine on oxidative stress in organophosphate poisoning model," Advances in Therapy, vol. 22, no. 2, pp. 107-116, 2005.

[164] M.-J. R. Howes, "Chapter 28 - Phytochemicals as Antiinflammatory Nutraceuticals and Phytopharmaceuticals," in Immunity and Inflammation in Health and Disease, S. Chatterjee, W. Jungraithmayr, and D. Bagchi, Eds., pp. 363-388, Academic Press, 2018.

[165] J. P. E. Spencer, H. Schroeter, G. Kuhnle et al., "Epicatechin and its in vivo metabolite, $3^{\prime}$-O-methyl epicatechin, protect human fibroblasts from oxidative-stress-induced cell death involving caspase-3 activation," The Biochemical Journal, vol. 354, no. 3, pp. 493-500, 2001.

[166] L. A. Abdulkhaleq, M. A. Assi, M. H. M. Noor, R. Abdullah, M. Z. Saad, and Y. H. Taufiq-Yap, "Therapeutic uses of epicatechin in diabetes and cancer," Veterinary World, vol. 10, no. 8, pp. 869-872, 2017.

[167] A. L. Al-Malki and S. S. Moselhy, "Protective effect of vitamin $\mathrm{E}$ and epicatechin against nicotine-induced oxidative stress in rats," Toxicology and Industrial Health, vol. 29, no. 2, pp. 202-208, 2013.

[168] M. Lefaki, N. Papaevgeniou, and N. Chondrogianni, "Redox regulation of proteasome function," Redox Biology, vol. 13, pp. 452-458, 2017.

[169] J. Zhang, X. Wang, V. Vikash et al., "ROS and ROS-mediated cellular signaling," Oxidative Medicine and Cellular Longevity, vol. 2016, Article ID 4350965, 2016.

[170] H. Tian, B. F. Zhang, J. H. di et al., "Keap1: one stone kills three birds Nrf2, IKK $\beta$ and Bcl-2/Bcl-xL," Cancer Letters, vol. 325, no. 1, pp. 26-34, 2012.

[171] K. K. S. Nordgren and K. B. Wallace, "Keap1 redoxdependent regulation of doxorubicin-induced oxidative stress response in cardiac myoblasts," Toxicology and Applied Pharmacology, vol. 274, no. 1, pp. 107-116, 2014.

[172] H. Kanzaki, F. Shinohara, M. Kajiya, and T. Kodama, "The Keap1/Nrf2 protein axis plays a role in osteoclast 
differentiation by regulating intracellular reactive oxygen species signaling," Journal of Biological Chemistry, vol. 288, no. 32, pp. 23009-23020, 2013.

[173] T. Frankič, T. Pajk, V. Rezar, A. Levart, and J. Salobir, “The role of dietary nucleotides in reduction of DNA damage induced by T-2 toxin and deoxynivalenol in chicken leukocytes," Food and Chemical Toxicology, vol. 44, no. 11, pp. 1838-1844, 2006.

[174] X. Liu, P. Guo, A. Liu et al., "Nitric oxide (NO)-mediated mitochondrial damage plays a critical role in T-2 toxininduced apoptosis and growth hormone deficiency in rat anterior pituitary GH3 cells," Food and Chemical Toxicology: An International Journal Published for the British Industrial Biological Research Association, vol. 102, pp. 11-23, 2017.

[175] T. J. Martin, S. Gabure, J. Q. Maise, S. Snipes, M. Peete, and M. M. Whalen, "The organochlorine pesticides pentachlorophenol and dichlorodiphenyltrichloroethane increase secretion and production of interleukin 6 by human immune cells," Environmental Toxicology and Pharmacology, vol. 72, article 103263, 2019.

[176] A. Kartin, H. W. Subagio, S. Hadisaputro, M. I. Kartasurya, S. Suhartono, and B. Budiyono, "Pesticide exposure and stunting among children in agricultural areas," The International Journal of Occupational and Environmental Medicine, vol. 10, no. 1, pp. 17-29, 2019.

[177] M. Pajares, N. Jiménez-Moreno, I. H. K. Dias et al., "Redox control of protein degradation," Redox Biology, vol. 6, pp. 409-420, 2015.

[178] J. George and Y. Shukla, "Emptying of intracellular calcium pool and oxidative stress imbalance are associated with the glyphosate-induced proliferation in human skin keratinocytes HaCaT cells," ISRN Dermatology, vol. 2013, 825180 pages, 2013.

[179] V. Kašuba, M. Milić, R. Rozgaj et al., "Effects of low doses of glyphosate on DNA damage, cell proliferation and oxidative stress in the HepG2 cell line," Environmental Science and Pollution Research, vol. 24, no. 23, pp. 19267-19281, 2017.

[180] Y.-H. Kim, J. R. Hong, H. W. Gil, H. Y. Song, and S. Y. Hong, "Mixtures of glyphosate and surfactant TN20 accelerate cell death via mitochondrial damage-induced apoptosis and necrosis," Toxicology In Vitro, vol. 27, no. 1, pp. 191-197, 2013.

[181] N. S. El-Shenawy, "Oxidative stress responses of rats exposed to roundup and its active ingredient glyphosate," Environmental Toxicology and Pharmacology, vol. 28, no. 3, pp. 379-385, 2009.

[182] D. C. Bailey, C. E. Todt, S. L. Burchfield et al., "Chronic exposure to a glyphosate-containing pesticide leads to mitochondrial dysfunction and increased reactive oxygen species production in _Caenorhabditis elegans_, Environmental Toxicology and Pharmacology, vol. 57, pp. 46-52, 2018.

[183] D. M. Romero, M. C. Ríos de Molina, and Á. B. Juárez, “Oxidative stress induced by a commercial glyphosate formulation in a tolerant strain of Chlorella kessleri," Ecotoxicology and Environmental Safety, vol. 74, no. 4, pp. 741-747, 2011.

[184] S. Gao, Z. Wang, C. Zhang, L. Jia, and Y. Zhang, "Oral exposure to atrazine induces oxidative stress and calcium homeostasis disruption in spleen of mice," Oxidative Medicine and Cellular Longevity, vol. 2016, Article ID 7978219, 9 pages, 2016.

[185] N. El-Shenawy, "Mitigating effect of ginger against oxidative stress induced by atrazine herbicides in mice liver and kid- ney," Journal of Biofertilizers \& Biopesticides, vol. 2, no. 1, p. 107, 2011.

[186] S. O. Abarikwu, A. C. Adesiyan, T. O. Oyeloja, M. O. Oyeyemi, and E. O. Farombi, "Changes in sperm characteristics and induction of oxidative stress in the testis and epididymis of experimental rats by a herbicide, atrazine," Archives of Environmental Contamination and Toxicology, vol. 58, no. 3, pp. 874-882, 2010.

[187] O. Adedosu, A. Badmus, G. Adeleke, and R. Raji, “_Telfairia occidentalis_seed extract protects against oxidative stress, inflammation and some haematological disorders associated with atrazine- induced prostate cancer in rats," European Journal of Cancer, vol. 72, p. S94, 2017.

[188] M. A. Abass, S. A. Elkhateeb, S. A. Abd el-Baset, A. A. Kattaia, E. M. Mohamed, and H. H. Atteia, "Lycopene ameliorates atrazine-induced oxidative damage in adrenal cortex of male rats by activation of the Nrf2/HO-1 pathway," Environmental Science and Pollution Research International, vol. 23, no. 15, pp. 15262-15274, 2016.

[189] W. Liu, Y. Du, J. Liu et al., "Effects of atrazine on the oxidative damage of kidney in Wister rats," International Journal of Clinical and Experimental Medicine, vol. 7, no. 10, pp. 3235-3243, 2014.

[190] K. Ma, H. Y. Wu, B. Zhang, X. He, and B. X. Li, "Neurotoxicity effects of atrazine-induced SH-SY5Y human dopaminergic neuroblastoma cells via microglial activation," Molecular BioSystems, vol. 11, no. 11, pp. 2915-2924, 2015.

[191] W. A. Keshk, N. A. Soliman, M. M. Abo el-Noor, A. A. Wahdan, and M. M. Shareef, "Modulatory effects of curcumin on redox status, mitochondrial function, and caspace3 expression during atrazin-induced toxicity," Journal of Biochemical and Molecular Toxicology, vol. 28, no. 8, pp. 378-385, 2014.

[192] H. Liu, Y. L. Xia, W. Cai, Y. Zhang, X. Zhang, and S. du, "Enantioselective oxidative stress and oxidative damage caused by _Rac-_ and _S_ -metolachlor to _Scenedesmus obliquus_," Chemosphere, vol. 173, pp. 22-30, 2017.

[193] D. Špoljarić Maronić, I. Štolfa Čamagajevac, J. Horvatić et al., "S-metolachlor promotes oxidative stress in green microalga _Parachlorella kessleri_ I- A potential environmental and health risk for higher organisms," Science of the Total Environment, vol. 637-638, pp. 41-49, 2018.

[194] Q. Qu, M. Ke, Y. Ye et al., "Enantioselective Oxidative Stress Induced by S- and Rac-metolachlor in Wheat (Triticum aestivum L.) Seedlings," Bulletin of Environmental Contamination and Toxicology, vol. 102, no. 3, pp. 439-445, 2019.

[195] P. Bernat, J. Nykiel-Szymańska, P. Stolarek, M. Słaba, R. Szewczyk, and S. Różalska, "2,4-Dichlorophenoxyacetic acid-induced oxidative stress: metabolome and membrane modifications in Umbelopsis isabellina, a herbicide degrader," PLoS One, vol. 13, no. 6, article e0199677, 2018.

[196] M. C. Romero-Puertas, I. Mccarthy, M. Gomez et al., "Reactive oxygen species-mediated enzymatic systems involved in the oxidative action of 2,4-dichlorophenoxyacetic acid," Plant, Cell \& Environment, vol. 27, no. 9, pp. 1135-1148, 2004.

[197] F. P. Peixoto, J. Gomes-Laranjo, J. A. Vicente, and V. M. C. Madeira, "Comparative effects of the herbicides dicamba, 2,4-D and paraquat on non-green potato tuber calli," Journal of Plant Physiology, vol. 165, no. 11, pp. 1125-1133, 2008.

[198] D. Zhang, Y. Wu, Y. Yuan et al., "Exposure to 2,4-dichlorophenoxyacetic acid induces oxidative stress and apoptosis in 
mouse testis," Pesticide Biochemistry and Physiology, vol. 141, pp. 18-22, 2017.

[199] T. M. Atamaniuk, O. I. Kubrak, K. B. Storey, and V. I. Lushchak, "Oxidative stress as a mechanism for toxicity of 2,4-dichlorophenoxyacetic acid (2,4-D): studies with goldfish gills," Ecotoxicology, vol. 22, no. 10, pp. 14981508, 2013.

[200] N. A. Ossana, J. M. Pérez-Iglesias, S. Soloneski, and M. L. Larramendy, "Auxinic herbicides induce oxidative stress on Cnesterodon decemmaculatus (Pisces: Poeciliidae)," Environmental Science and Pollution Research, vol. 26, no. 20, pp. 20485-20498, 2019.

[201] Z. Liu, P. Li, X. Sun et al., "Fluazifop-P-butyl induced ROS generation with IAA (indole-3-acetic acid) oxidation in _Acanthospermum hispidum_ D.C.," Pesticide Biochemistry and Physiology, vol. 143, pp. 312-318, 2017.

[202] B. Bongiovanni, P. de Lorenzi, A. Ferri et al., "Melatonin decreases the oxidative stress produced by 2,4-dichlorophenoxyacetic acid in rat cerebellar granule cells," Neurotoxicity Research, vol. 11, no. 2, pp. 93-99, 2007.

[203] A. Troudi, I. Ben Amara, A. M. Samet, and N. Zeghal, "Oxidative stress induced by 2,4-phenoxyacetic acid in liver of female rats and their progeny: biochemical and histopathological studies," Environmental Toxicology, vol. 27, no. 3, pp. 137-145, 2012.

[204] L. Tichati, F. Trea, and K. Ouali, "Potential role of selenium against hepatotoxicity induced by 2,4-dichlorophenoxyacetic acid in albino Wistar rats," Biological Trace Element Research, vol. 194, no. 1, pp. 228-236, 2020.

[205] W. Tayeb, A. Nakbi, I. Cheraief, A. Miled, and M. Hammami, "Alteration of lipid status and lipid metabolism, induction of oxidative stress and lipid peroxidation by 2,4-dichlorophenoxyacetic herbicide in rat liver," Toxicology Mechanisms and Methods, vol. 23, no. 6, pp. 449-458, 2013.

[206] W. Tayeb, A. Nakbi, M. Trabelsi, A. Miled, and M. Hammami, "Biochemical and histological evaluation of kidney damage after sub-acute exposure to 2,4-dichlorophenoxyacetic herbicide in rats: involvement of oxidative stress," Toxicology Mechanisms and Methods, vol. 22, no. 9, pp. 696704, 2012.

[207] W. Tayeb, A. Nakbi, M. Trabelsi, N. Attia, A. Miled, and M. Hammami, "Hepatotoxicity induced by sub-acute exposure of rats to 2,4-Dichlorophenoxyacetic acid based herbicide "Desormone lourd"," Journal of Hazardous Materials, vol. 180, no. 1-3, pp. 225-233, 2010.

[208] S. B. Pruett, B. Cheng, R. Fan, W. Tan, and T. Sebastian, "Oxidative stress and sodium methyldithiocarbamate-induced modulation of the macrophage response to lipopolysaccharide in vivo," Toxicological Sciences : An Official Journal of the Society of Toxicology, vol. 109, no. 2, pp. 237-246, 2009.

[209] P. F. Martins, G. Carvalho, P. L. Gratão et al., "Effects of the herbicides acetochlor and metolachlor on antioxidant enzymes in soil bacteria," Process Biochemistry, vol. 46, no. 5, pp. 1186-1195, 2011.

[210] Y. Liu, Y. Zhang, J. Liu, and D. Huang, “The role of reactive oxygen species in the herbicide acetochlor-induced DNA damage on _Bufo raddei_tadpole liver," Aquatic Toxicology, vol. 78, no. 1, pp. 21-26, 2006.

[211] Y. Zhang, W. Xue, R. Long, H. Yang, and W. Wei, “Acetochlor affects zebrafish ovarian development by producing estrogen effects and inducing oxidative stress," Environmen- tal Science and Pollution Research, vol. 27, no. 22, pp. 27688-27696, 2020.

[212] X. Song, F. Zhang, D. Chen et al., "Study on systemic and reproductive toxicity of acetochlor in male mice," Toxicology Research, vol. 8, no. 1, pp. 77-89, 2019.

[213] T. Huang, Y. Huang, Y. Huang, Y. Yang, Y. Zhao, and C. J. Martyniuk, "Toxicity assessment of the herbicide acetochlor in the human liver carcinoma (HepG2) cell line," Chemosphere, vol. 243, article 125345, 2020.

[214] J. Jiang, S. Wu, X. Liu et al., "Effect of acetochlor on transcription of genes associated with oxidative stress, apoptosis, immunotoxicity and endocrine disruption in the early life stage of zebrafish," Environmental Toxicology and Pharmacology, vol. 40, no. 2, pp. 516-523, 2015.

[215] D. G. Goswami, R. Kant, D. A. Ammar et al., "Toxic consequences and oxidative protein carbonylation from chloropicrin exposure in human corneal epithelial cells," Toxicology Letters, vol. 322, pp. 1-11, 2020.

[216] M. Pesonen, M. Pasanen, J. Loikkanen et al., "Chloropicrin induces endoplasmic reticulum stress in human retinal pigment epithelial cells," Toxicology Letters, vol. 211, no. 3, pp. 239-245, 2012.

[217] M. Pesonen, M. Häkkinen, K. Rilla et al., "Chloropicrininduced toxic responses in human lung epithelial cells," Toxicology Letters, vol. 226, no. 2, pp. 236-244, 2014.

[218] M. N. Haque, H. J. Eom, S. E. Nam, Y. K. Shin, and J. S. Rhee, "Chlorothalonil induces oxidative stress and reduces enzymatic activities of $\mathrm{Na}+/ \mathrm{K}+$-ATPase and acetylcholinesterase in gill tissues of marine bivalves," PLoS One, vol. 14, no. 4, article e0214236, 2019.

[219] J. da Silva Barreto, F. de Melo Tarouco, F. G. A. de Godoi et al., "Induction of oxidative stress by chlorothalonil in the estuarine polychaete _Laeonereis acuta_" Aquatic Toxicology, vol. 196, pp. 1-8, 2018.

[220] J. da Silva Barreto, F. de Melo Tarouco, and C. E. da Rosa, "Chlorothalonil causes redox state change leading to oxidative stress generation in Danio rerio," Aquatic Toxicology, vol. 225, article 105527, 2020.

[221] T. Suzuki, H. Nojiri, H. Isono, and T. Ochi, "Oxidative damages in isolated rat hepatocytes treated with the organochlorine fungicides captan, dichlofluanid and chlorothalonil," Toxicology, vol. 204, no. 2-3, pp. 97-107, 2004.

[222] F. Cima, M. Bragadin, and L. Ballarin, "Toxic effects of new antifouling compounds on tunicate haemocytes: I. Sea-Nine $211^{\mathrm{TM}}$ and chlorothalonil," Aquatic Toxicology, vol. 86, no. 2, pp. 299-312, 2008.

[223] M. Lodovici, C. Casalini, C. Briani, and P. Dolara, "Oxidative liver DNA damage in rats treated with pesticide mixtures," Toxicology, vol. 117, no. 1, pp. 55-60, 1997.

[224] I. Ahmad and M. Ahmad, "Fresh water fish, Channa punctatus, as a model for pendimethalin genotoxicity testing: a new approach toward aquatic environmental contaminants," Environmental Toxicology, vol. 31, no. 11, pp. 1520-1529, 2016.

[225] M. I. Ahmad, M. F. Zafeer, M. Javed, and M. Ahmad, "Pendimethalin-induced oxidative stress, DNA damage and activation of anti- inflammatory and apoptotic markers in male rats," Scientific Reports, vol. 8, no. 1, p. 17139, 2018.

[226] S. M. Ansari, Q. Saquib, S. M. Attia et al., "Pendimethalin induces oxidative stress, DNA damage, and mitochondrial dysfunction to trigger apoptosis in human lymphocytes and 
rat bone-marrow cells," Histochemistry and Cell Biology, vol. 149, no. 2, pp. 127-141, 2018.

[227] P. Gupta and S. K. Verma, "Evaluation of genotoxicity induced by herbicide pendimethalin in fresh water fish Clarias batrachus (linn.) and possible role of oxidative stress in induced DNA damage," Drug and Chemical Toxicology, vol. 43, pp. 1-10, 2020.

[228] H. Tabassum, M. A. Afjal, J. Khan, S. Raisuddin, and S. Parvez, "Neurotoxicological assessment of pendimethalin in freshwater fish_Channa punctata_Bloch," Ecological Indicators, vol. 58, pp. 411-417, 2015.

[229] H. Tabassum, M. Ashafaq, J. Khan, M. Z. Shah, S. Raisuddin, and S. Parvez, "Short term exposure of pendimethalin induces biochemical and histological perturbations in liver, kidney and gill of freshwater fish," Ecological Indicators, vol. 63, pp. 29-36, 2016.

[230] Z. Sarı̈öl Kılıç, S. Aydın, Ü. Ündeğer Bucurgat, and N. Başaran, "In vitro genotoxicity assessment of dinitroaniline herbicides pendimethalin and trifluralin," Food and Chemical Toxicology, vol. 113, pp. 90-98, 2018.

[231] M. Hodjat, M. Baeeri, M. A. Rezvanfar, M. Rahimifard, M. Gholami, and M. Abdollahi, "On the mechanism of genotoxicity of ethephon on embryonic fibroblast cells," Toxicology Mechanisms and Methods, vol. 27, no. 3, pp. 173-180, 2017.

[232] L. Öztürk and Y. Demir, "Effects of putrescine and ethephon on some oxidative stress enzyme activities and proline content in salt stressed spinach leaves," Plant Growth Regulation, vol. 40, no. 1, pp. 89-95, 2003.

[233] Z.-Y. Sun, T. J. Zhang, J. Q. Su et al., "A novel role of ethephon in controlling the noxious weed _Ipomoea cairica (Linn.) Sweet," Scientific Reports, vol. 5, no. 1, p. 11372, 2015.

[234] O. I. Kubrak, T. M. Atamaniuk, V. V. Husak et al., "Oxidative stress responses in blood and gills of _Carassius auratus_ exposed to the mancozeb-containing carbamate fungicide Tattoo," Ecotoxicology and Environmental Safety, vol. 85, pp. 37-43, 2012.

[235] T. M. Atamaniuk, O. I. Kubrak, V. V. Husak, K. B. Storey, and V. I. Lushchak, "The mancozeb-containing carbamate fungicide tattoo induces mild oxidative stress in goldfish brain, liver, and kidney," Environmental Toxicology, vol. 29, no. 11, pp. 1227-1235, 2014.

[236] U. Majid, Mahmooduzzafar, T. O. Siddiqi, and M. Iqbal, "Antioxidant response of Cassia angustifolia Vahl. to oxidative stress caused by Mancozeb, a pyrethroid fungicide," Acta Physiologiae Plantarum, vol. 36, no. 2, pp. 307-314, 2014.

[237] D. C. Bailey, C. E. Todt, S. E. Orfield et al., “_Caenorhabditis elegans_ chronically exposed to a $\mathrm{Mn} / \mathrm{Zn}$ ethylene-bisdithiocarbamate fungicide show mitochondrial Complex I inhibition and increased reactive oxygen species," Neurotoxicology, vol. 56, pp. 170-179, 2016.

[238] C. E. Todt, D. C. Bailey, A. S. Pressley et al., "Acute exposure to a $\mathrm{Mn} / \mathrm{Zn}$ ethylene-bis-dithiocarbamate fungicide leads to mitochondrial dysfunction and increased reactive oxygen species production in_Caenorhabditis elegans_,"Neurotoxicology, vol. 57, pp. 112-120, 2016.

[239] M. A. Saraiva, E. da Rosa Ávila, G. F. da Silva et al., "Exposure of Drosophila melanogaster to Mancozeb Induces Oxidative Damage and Modulates Nrf2 and HSP70/83," Oxidative Medicine and Cellular Longevity, vol. 2018, Article ID 5456928, 11 pages, 2018.
[240] G. Calviello, E. Piccioni, A. Boninsegna et al., "DNA damage and apoptosis induction by the pesticide Mancozeb in rat cells: Involvement of the oxidative mechanism," Toxicology and Applied Pharmacology, vol. 211, no. 2, pp. 87-96, 2006.

[241] M. Mohammadi-Sardoo, A. Mandegary, M. Nabiuni, S. N. Nematollahi-Mahani, and B. Amirheidari, "Mancozeb induces testicular dysfunction through oxidative stress and apoptosis: protective role of $\mathrm{N}$-acetylcysteine antioxidant," Toxicology and Industrial Health, vol. 34, no. 11, pp. 798811, 2018.

[242] V. Pavlovic, S. Cekic, B. Kamenov, M. Ciric, and D. Krtinic, "The effect of ascorbic acid on Mancozeb-induced toxicity in rat thymocytes," Folia biologica, vol. 61, no. 3, pp. 116123, 2015.

[243] K. Kumar, A. Sabarwal, and R. P. Singh, "Mancozeb selectively induces mitochondrial-mediated apoptosis in human gastric carcinoma cells through ROS generation," Mitochondrion, vol. 48, pp. 1-10, 2019.

[244] J. E. Lee, J. H. Park, S. J. Jang, and H. C. Koh, "Rosiglitazone inhibits chlorpyrifos-induced apoptosis via modulation of the oxidative stress and inflammatory response in SH-SY5Y cells," Toxicology and Applied Pharmacology, vol. 278, no. 2, pp. 159-171, 2014.

[245] J. E. Lee, J. H. Park, I. C. Shin, and H. C. Koh, "Reactive oxygen species regulated mitochondria-mediated apoptosis in PC12 cells exposed to chlorpyrifos," Toxicology and Applied Pharmacology, vol. 263, no. 2, pp. 148-162, 2012.

[246] A. A. Alvarez, E. Ramírez-San Juan, and A. CanizalesRomán, "Chlorpyrifos induces oxidative stress in rats," Toxicological \& Environmental Chemistry, vol. 90, no. 5, pp. 1019-1025, 2008.

[247] T. K. Mandal and N. S. Das, "Correlation of testicular toxicity and oxidative stress induced by chlorpyrifos in rats," Human \& Experimental Toxicology, vol. 30, no. 10, pp. 1529-1539, 2011.

[248] A. Imam, N. A. Sulaiman, A. L. Oyewole et al., "Chlorpyrifosand dichlorvos-induced oxidative and neurogenic damage elicits neuro-cognitive deficits and increases anxiety-like behavior in wild-type rats," Toxics, vol. 6, no. 4, p. 71, 2018.

[249] H. BaŞ and Y. Kalender, "Chlorpyrifos induced cardiotoxicity in rats and the protective role of quercetin and catechin," Gazi University Journal of Science, vol. 24, pp. 385-395, 2011.

[250] Y. Zhao, C. Fan, A. Zhang et al., "Walnut polyphenol extract protects against malathion- and chlorpyrifos-induced immunotoxicity by modulating TLRx-NOX-ROS," Nutrients, vol. 12, no. 3, p. 616, 2020.

[251] S. P. Pereira, M. A. S. Fernandes, J. D. Martins et al., "Toxicity assessment of the herbicide metolachlor comparative effects on bacterial and mitochondrial model systems," Toxicology In Vitro, vol. 23, no. 8, pp. 1585-1590, 2009.

[252] D. Štajner, M. Popović, and M. Štajner, "Herbicide induced oxidative stress in lettuce, beans pea seeds and leaves," Biologia Plantarum, vol. 46, no. 4, pp. 575-579, 2003.

[253] C. Otuechere, O. J. Avwioroko, S. Tinuala, S. Fayemi, and B. A. Salau, "Oral supplementation of coconut oil attenuates propanil-induced oxidative stress in the testes of rats," Asian Journal of Biological Sciences, vol. 13, no. 1, pp. 7076, 2019.

[254] C. A. Otuechere, S. O. Abarikwu, V. I. Olateju, A. L. Animashaun, and O. E. Kale, "Protective effect of curcumin against the liver toxicity caused by propanil in rats," 
International Scholarly Research Notices, vol. 2014, Article ID 853697, 8 pages, 2014.

[255] M. Rehman, B. Ahmad, M. . R. Mir et al., "Propanil-induced neurotoxicity in freshwater common carp (Cyprinus carpio)," Applied Biological Research, vol. 18, no. 3, p. 312, 2016.

[256] F. Peixoto, J. A. Vicente, and V. M. Madeira, "The herbicide dicamba (2-methoxy-3,6-dichlorobenzoic acid) interacts with mitochondrial bioenergetic functions," Archives of Toxicology, vol. 77, no. 7, pp. 403-409, 2003.

[257] C. Gleason, R. C. Foley, and K. B. Singh, "Mutant analysis in Arabidopsis provides insight into the molecular mode of action of the auxinic herbicide Dicamba," PLoS One, vol. 6, no. 3, article e17245, 2011.

[258] Z. Denek, G. Erbil, S. Ozbal, S. C. Micili, and C. Ozogul, "The effects of resveratrol against trifluralin toxicity in the urinary tract of rats," Toxicology and Industrial Health, vol. 32, no. 1, pp. 106-117, 2016.

[259] M. S. Kumar, A. N. Kabra, B. Min et al., "Insecticides induced biochemical changes in freshwater microalga Chlamydomonas mexicana," Environmental Science and Pollution Research International, vol. 23, no. 2, pp. 1091-1099, 2016.

[260] P. Rajak, S. Khatun, M. Dutta, M. Mandi, and S. Roy, "Chronic exposure to acephate triggers ROS-mediated injuries at organismal and sub-organismal levels ofDrosophila melanogaster," Toxicology research, vol. 7, no. 5, pp. 874$887,2018$.

[261] S. Datta, P. Dhar, A. Mukherjee, and S. Ghosh, "Influence of polyphenolic extracts from _Enydra fluctuans_on oxidative stress induced by acephate in rats," Food and Chemical Toxicology, vol. 48, no. 10, pp. 2766-2771, 2010.

[262] A. Thapar, R. Sandhir, and R. Kiran, "Acephate induced oxidative damage in erythrocytes," Indian Journal of Experimental Biology, vol. 40, no. 8, pp. 963-966, 2002.

[263] P. Sharma, A. Sharma, N. D. Jasuja, and S. C. Joshi, "Organophosphorous compounds and oxidative stress: a review," Toxicological \& Environmental Chemistry, vol. 96, no. 5, pp. 681-698, 2014.

[264] M. A. T. Dhanushka and L. D. C. Peiris, "Cytotoxic and genotoxic effects of acephate on human sperm," Journal of Toxicology, vol. 2017, 2017.

[265] A. S. al-Sarar, A. E. Bayoumi, H. I. Hussein, and Y. Abobakr, "Cytotoxic effects of acephate, ethoprophos, and monocrotophos in CHO-K1 cells," CyTA Journal of Food, vol. 13, no. 3, pp. 427-433, 2015.

[266] V. S. Poovala, V. K. Kanji, H. Tachikawa, and A. K. Salahudeen, "Role of oxidant stress and antioxidant protection in acephate-induced renal tubular cytotoxicity," Toxicological Sciences, vol. 46, no. 2, pp. 403-409, 1998.

[267] H. Rodriguez-Rocha, A. Garcia-Garcia, C. Pickett et al., "Compartmentalized oxidative stress in dopaminergic cell death induced by pesticides and complex I inhibitors: distinct roles of superoxide anion and superoxide dismutases," Free Radical Biology and Medicine, vol. 61, pp. 370-383, 2013.

[268] H. M. Cochemé and M. P. Murphy, "Complex I is the major site of mitochondrial superoxide production by paraquat," The Journal of Biological Chemistry, vol. 283, no. 4, pp. 1786-1798, 2008.

[269] K. Shimizu, K. Matsubara, K. Ohtaki, S. Fujimaru, O. Saito, and $\mathrm{H}$. Shiono, "Paraquat induces long-lasting dopamine overflow through the excitotoxic pathway in the striatum of freely moving rats," Brain Research, vol. 976, no. 2, pp. 243252, 2003.

[270] D.-C. Wu, P. Teismann, K. Tieu et al., "NADPH oxidase mediates oxidative stress in the 1-methyl-4-phenyl-1,2,3,6tetrahydropyridine model of Parkinson's disease," Proceedings of the National Academy of Sciences of the United States of America, vol. 100, no. 10, pp. 6145-6150, 2003.

[271] X. Chang, W. Lu, T. Dou et al., "Paraquat inhibits cell viability via enhanced oxidative stress and apoptosis in human neural progenitor cells," Chemico-Biological Interactions, vol. 206, no. 2, pp. 248-255, 2013.

[272] H. K. Takano, R. Beffa, C. Preston, P. Westra, and F. E. Dayan, "A novel insight into the mode of action of glufosinate: how reactive oxygen species are formed," Photosynthesis Research, vol. 144, no. 3, pp. 361-372, 2020.

[273] H. K. Takano, R. Beffa, C. Preston, P. Westra, and F. E. Dayan, "Reactive oxygen species trigger the fast action of glufosinate," Planta, vol. 249, no. 6, pp. 1837-1849, 2019.

[274] H. Qian, W. Chen, G. D. Sheng, X. Xu, W. Liu, and Z. Fu, "Effects of glufosinate on antioxidant enzymes, subcellular structure, and gene expression in the unicellular green alga _Chlorella vulgaris_," Aquatic Toxicology, vol. 88, no. 4, pp. 301-307, 2008.

[275] A. Leomanni, T. Schettino, A. Calisi et al., "Antioxidant and oxidative stress related responses in the Mediterranean land snail _Cantareus apertus_exposed to the carbamate pesticide Carbaryl," Comparative Biochemistry and Physiology Part C: Toxicology \& Pharmacology, vol. 168, pp. 2027, 2015.

[276] K. Habib, S. Kumar, N. Manikar, S. Zutshi, and T. Fatma, "Biochemical effect of carbaryl on oxidative stress, antioxidant enzymes and osmolytes of cyanobacterium Calothrix brevissima," Bulletin of Environmental Contamination and Toxicology, vol. 87, no. 6, pp. 615-620, 2011.

[277] Y. Han, S. Song, H. Wu, J. Zhang, and E. Ma, "Antioxidant enzymes and their role in phoxim and carbaryl stress in _Caenorhabditis elegans_," Pesticide Biochemistry and Physiology, vol. 138, pp. 43-50, 2017.

[278] S. Venkatachalam, V. P. K. Muthaiah, L. Venkitasamy, F. M. Michael, and K. Chandrasekar, "Neuroprotective role of naringenin on carbaryl induced neurotoxicity in mouse neuroblastoma cells," Journal of Pharmacology and Pharmacotherapeutics, vol. 4, no. 3, pp. 192-197, 2013.

[279] M.-L. Xu, Y. Gao, X. Wang et al., "Effect of carbaryl on some biochemical changes in PC12 cells: the protective effect of soy isoflavone genistein, and daidzein, and their mixed solution," CyTA Journal of Food, vol. 14, no. 4, pp. 587-593, 2016.

[280] N. Jawad, R. Kaur, S. S. Gouri, V. K. Dumka, and S. P. Saini, "Carbamate pesticide carbaryl induces alterations in antioxidant and oxidative stress related responses of Indian buffalo (Bubalus bubalis) after sub-chronic exposure," Toxicology International (Formerly Indian Journal of Toxicology), vol. 24, p. 198, 2017.

[281] F. Hu, L. Li, C. Wang, Q. Zhang, X. Zhang, and M. Zhao, "Enantioselective induction of oxidative stress by permethrin in rat adrenal pheochromocytoma (PC12) cells," Environmental Toxicology and Chemistry, vol. 29, no. 3, pp. 683690, 2010.

[282] S. Olgun and H. P. Misra, "Pesticides induced oxidative stress in thymocytes," Molecular and Cellular Biochemistry, vol. 290 , no. 1, p. 137, 2006. 
[283] M. N. Tiwari, A. K. Singh, I. Ahmad et al., "Effects of cypermethrin on monoamine transporters, xenobiotic metabolizing enzymes and lipid peroxidation in the rat nigrostriatal system," Free Radical Research, vol. 44, no. 12, pp. 14161424, 2010.

[284] C. Bouaziz, I. Graiet, A. Salah, I. Ben Salem, and S. Abid, "Influence of bifentrin, a pyrethriod pesticide, on human colorectal HCT-116 cells attributed to alterations in oxidative stress involving mitochondrial apoptotic processes," Journal of Toxicology and Environmental Health, Part A, vol. 83, no. 9, pp. 331-340, 2020.

[285] Y. Jin, J. Wang, X. Pan, L. Wang, and Z. Fu, “_cis_-Bifenthrin enantioselectively induces hepatic oxidative stress in mice," Pesticide Biochemistry and Physiology, vol. 107, no. 1, pp. 61-67, 2013.

[286] S. Park, J. Y. Lee, H. Park, G. Song, and W. Lim, "Bifenthrin induces developmental immunotoxicity and vascular malformation during zebrafish embryogenesis," Comparative Biochemistry and Physiology, Part C: Toxicology \& Pharmacology, vol. 228, article 108671, 2020.

[287] B. Bukowska, K. Goszczyńska, and W. Duda, "Effect of 4chloro-2-methylphenoxyacetic acid and 2,4-dimethylphenol on human erythrocytes," Pesticide Biochemistry and Physiology, vol. 77, no. 3, pp. 92-98, 2003.

[288] P. Duchnowicz, M. Koter, and W. Duda, "Damage of erythrocyte by phenoxyacetic herbicides and their metabolites," Pesticide Biochemistry and Physiology, vol. 74, no. 1, pp. 17, 2002.

[289] G. Sujetovienė, K. Gasauskaitè, and J. Žaltauskaitė, “Toxicity of a phenoxy herbicide on the lichen Ramalina fraxinea," Toxicological \& Environmental Chemistry, vol. 101, no. 910, pp. 497-507, 2019.

[290] J. J. Fortunato, G. Feier, A. M. Vitali, F. C. Petronilho, F. DalPizzol, and J. Quevedo, "Malathion-induced oxidative stress in rat brain regions," Neurochemical Research, vol. 31, no. 5, pp. 671-678, 2006.

[291] S. Selmi, K. Rtibi, D. Grami, H. Sebai, and L. Marzouki, "Malathion, an organophosphate insecticide, provokes metabolic, histopathologic and molecular disorders in liver and kidney in prepubertal male mice," Toxicology Reports, vol. 5, pp. 189-195, 2018.

[292] S. Slimen and G. N. El Fazaa Saloua, "Oxidative stress and cytotoxic potential of anticholinesterase insecticide, malathion in reproductive toxicology of male adolescent mice after acute exposure," Iranian Journal of Basic Medical Sciences, vol. 17, no. 7, pp. 522-530, 2014.

[293] C. Jalili, S. Roshankhah, M. R. Salahshoor, and M. M. Mohammadi, "Resveratrol attenuates malathion induced damage in some reproductive parameters by decreasing oxidative stress and lipid peroxidation in male rats," Journal of Family \& Reproductive Health, vol. 13, no. 2, pp. 70-79, 2019.

[294] R. I. Ali and M. A. Ibrahim, "Malathion induced testicular toxicity and oxidative damage in male mice: the protective effect of curcumin," Egyptian Journal of Forensic Sciences, vol. 8, no. 1, p. 70, 2018.

[295] F. Karabag-Coban, I. Bulduk, R. Liman, S. Ince, I. Cigerci, and O. Hazman, "Oleuropein alleviates malathion-induced oxidative stress and DNA damage in rats," Toxicological \& Environmental Chemistry, vol. 98, no. 1, pp. 101-108, 2016.

[296] H. Alp, I. Aytekin, N. K. Hatipoglu, A. Alp, and M. Ogun, "Effects of sulforophane and curcumin on oxidative stress created by acute malathion toxicity in rats," European Review for Medical and Pharmacological Sciences, vol. 16, Suppl 3, pp. 144-148, 2012.

[297] P. D. Moore, C. G. Yedjou, and P. B. Tchounwou, "Malathion-induced oxidative stress, cytotoxicity, and genotoxicity in human liver carcinoma (HepG2) cells," Environmental Toxicology, vol. 25, no. 3, pp. 221-226, 2010.

[298] D. Flores, V. Souza, M. Betancourt et al., "Oxidative stress as a damage mechanism in porcine cumulus-oocyte complexes exposed to malathion during in vitro maturation," Environmental Toxicology, vol. 32, no. 6, pp. 1669-1678, 2017.

[299] E. H. B. Delgado, E. L. Streck, J. L. Quevedo, and F. DalPizzol, "Mitochondrial respiratory dysfunction and oxidative stress after chronic malathion exposure," Neurochemical Research, vol. 31, no. 8, pp. 1021-1025, 2006.

[300] S. Ullah, Z. Li, Z. Hasan, S. U. Khan, and S. Fahad, "Malathion induced oxidative stress leads to histopathological and biochemical toxicity in the liver of rohu (_Labeo rohita_, Hamilton) at acute concentration," Ecotoxicology and Environmental Safety, vol. 161, pp. 270-280, 2018.

[301] D. Durak, F. G. Uzun, S. Kalender, A. Ogutcu, M. Uzunhisarcikli, and Y. Kalender, "Malathion-induced oxidative stress in human erythrocytes and the protective effect of vitamins C and Ein vitro," Environmental Toxicology, vol. 24, no. 3, pp. 235-242, 2009.

[302] S. Abbasabad Arab, M. R. Nikravesh, M. Jalali, and A. R. Fazel, "Evaluation of oxidative stress indices after exposure to malathion and protective effects of ascorbic acid in ovarian tissue of adult female rats," Electronic Physician, vol. 10, no. 5, pp. 6789-6795, 2018.

[303] A. K. Srivastava and D. Singh, "Assessment of malathion toxicity on cytophysiological activity, DNA damage and antioxidant enzymes in root of Allium cepa model," Scientific Reports, vol. 10, no. 1, p. 886, 2020. 